San Jose State University

SJSU ScholarWorks

Master's Theses

Master's Theses and Graduate Research

Summer 2013

\title{
An Examination of American Sport for Development and Peace Interns' Program Experiences
}

Michael Sanh Dao

San Jose State University

Follow this and additional works at: https://scholarworks.sjsu.edu/etd_theses

\section{Recommended Citation}

Dao, Michael Sanh, "An Examination of American Sport for Development and Peace Interns' Program Experiences" (2013). Master's Theses. 4332.

DOI: https://doi.org/10.31979/etd.as9h-y8hn

https://scholarworks.sjsu.edu/etd_theses/4332

This Thesis is brought to you for free and open access by the Master's Theses and Graduate Research at SJSU ScholarWorks. It has been accepted for inclusion in Master's Theses by an authorized administrator of SJSU ScholarWorks. For more information, please contact scholarworks@sjsu.edu. 


\title{
AN EXAMINATION OF AMERICAN SPORT FOR DEVELOPMENT AND PEACE INTERNS’ PROGRAM EXPERIENCES
}

\author{
A Thesis \\ Presented to \\ The Faculty of the Department of Kinesiology \\ San José State University \\ In Partial Fulfillment \\ of the Requirements for the Degree \\ Master of Arts
}

by

Michael Sanh Dao

August 2013 
(C) 2013

Michael S. Dao

ALL RIGHTS RESERVED 
The Designated Thesis Committee Approve the Thesis Titled

\title{
AN EXAMINATION OF AMERICAN SPORT FOR DEVELOPMENT AND PEACE INTERNS' PROGRAM EXPERIENCES
}

\section{By}

Michael Sanh Dao

\section{APPROVED FOR THE DEPARTMENT OF KINESIOLOGY}

\author{
San José State University
}

\section{August 2013}

Dr. Jessica Chin

Dr. Jay Johnson

Dr. Sonja Lilienthal

Dr. Matthew Masucci
Department of Kinesiology

Faculty of Kinesiology, and

Recreation Management, University

of Manitoba

Department of Kinesiology

Department of Kinesiology 


\title{
ABSTRACT \\ AN EXAMINATION OF AMERICAN SPORT FOR DEVELOPMENT AND PEACE INTERNS' PROGRAM EXPERIENCES
}

\author{
By Michael S. Dao
}

Sport for Development and Peace (SDP) is an international development movement that uses sport to address international humanitarian issues, including education on preventing HIV/AIDS, peaceful resolutions in communities experiencing conflict, and establishing gender equality in male-dominated societies. The emergence of SDP as a branch of international development over the last decade has garnered much attention. National governments, non-governmental organizations, and scholars have involved themselves in the process of SDP. The attention that SDP has attracted by these parties has been both practical and theoretical. Scholarly studies by prior researchers on SDP have included suggestions on best practices, and how people working in SDP process and handle programming based on a particular world view. Therefore, this study aimed to address how American SDP interns reflected on their internship experiences. The purpose of this study was to examine qualitatively former American SDP interns' program experiences. Semi-structured interviews were conducted with eleven former American SDP interns. The findings indicated that, in their role as American SDP interns, the participants were at once complicit in and resistant to reproducing inequitable power relations, personal ideologies and Americanization processes while in their host countries.

Keywords: Sport for Development and Peace, Americanization, Interns. 


\section{ACKNOWLEDGEMENTS}

There are many people that I want to thank for making this thesis what it is. First and foremost, I would like to thank my advisor and committee chair, Dr. Jessica Chin. Dr. Chin, thank you for being so kind and patient with me throughout this entire process. Writing this thesis was a difficult, but worthwhile endeavor. Thank you for being there and walking me through this amazing thesis adventure. Without your endless support and commitment, this thesis would have never happened. I hope you were able to learn as much from this experience as I did. To the members of the thesis committee: Dr. Jay Johnson, thank you for showing me that a good heart goes a long way, and for always believing that I could do this; Dr. Sonja Lilienthal, thank you for constantly going out of your way to help me even when that call or email was not necessary; and Dr. Matthew Masucci, you are probably the funniest smart guy I know. Your encouragement and words of wisdom kept me going when I thought I could go no more. And lastly, I would like to thank a person who was not part of this thesis experience, Dr. Tamar Semerjian. Dr. Semerjian, thank you for being the inspiration I needed during a time when I was greatly lost in life. You continue to be the academic mother I am fortunate to have. For

all of you, I leave this quote, "And, when you want something, all the universe conspires in helping you to achieve it," (Paulo Coelho, The Alchemist). 
Table of Contents

1.

INTRODUCTION 1

$\begin{array}{ll}\text { Statement of Purpose } & 7\end{array}$

$\begin{array}{ll}\text { Limitations } & 7\end{array}$

$\begin{array}{ll}\text { Delimitations } & 7\end{array}$

Definition of Terms $\quad 8$

$\begin{array}{ll}\text { Americanization } & 8\end{array}$

Developed, Northern, or Western Nation 8

$\begin{array}{ll}\text { Globalization } & 9\end{array}$

Hegemony 9

Less Developed, Southern, or Third World Nation 9

$\begin{array}{ll}\text { Non-government Organizations } & 9\end{array}$

Sport for Development and Peace 9

$\begin{array}{ll}\text { United Nations } & 10\end{array}$

$\begin{array}{ll}\text { Summary } & 11\end{array}$

2. REVIEW OF LITERATURE 12

$\begin{array}{ll}\text { Sport for Development and Peace } & 13\end{array}$

$\begin{array}{ll}\text { Definition } & 13\end{array}$

History of SDP 14

The Current Work of SDP Organizations 17

HIV/AIDS $\quad 18$

Peace and Conflict Resolution $\quad 22$

Gender Equality $\quad 25$ 
Hegemony: Power from Ideologies 28

Overview of Hegemony 28

Development Hegemony 32

Americanization: American Hegemony 36

Globalization $\quad 42$

Sport Globalization $\quad 43$

Non-Governmental Organizations $\quad 45$

$\begin{array}{ll}\text { Definition } & 46\end{array}$

Power Ideologies in NGOs 49

Research on SDP Interns and Volunteers 56

$\begin{array}{lll}3 . & 67\end{array}$

$\begin{array}{ll}\text { Participant Recruitment } & 68\end{array}$

$\begin{array}{ll}\text { Participant Demographics } & 69\end{array}$

$\begin{array}{ll}\text { Participants } & 71\end{array}$

$\begin{array}{ll}\text { SDP Organizations } & 72\end{array}$

American SDP Interns $\quad 73$

$\begin{array}{ll}\text { Procedure } & 75\end{array}$

$\begin{array}{ll}\text { Data Analysis } & 76\end{array}$

$\begin{array}{ll}\text { Academic Rigor } & 79\end{array}$

$\begin{array}{ll}\text { 4. RESULTS } & 81\end{array}$

$\begin{array}{ll}\text { Cultural Expectations } & 81\end{array}$

$\begin{array}{ll}\text { Cultural Challenges } & 83\end{array}$ 
$\begin{array}{ll}\text { Negotiating Cultural Tension } & 88\end{array}$

$\begin{array}{ll}\text { Cultural Ideas } & 95\end{array}$

$\begin{array}{ll}\text { Reflexive Privilege } & 105\end{array}$

SDP Internship Privilege 106

Change at Home 111

Expanding the American SDP Internship Role 116

$\begin{array}{ll}\text { Promoting Organizational Goals } & 117\end{array}$

$\begin{array}{ll}\text { Social Relationships } & 124\end{array}$

$\begin{array}{ll}\text { Understand the Purpose } & 128\end{array}$

Doing Something Greater 133

Giving to the Community 134

$\begin{array}{ll}\text { Teaching Sustainability } & 139\end{array}$

$\begin{array}{ll}\text { Summary } & 147\end{array}$

$\begin{array}{lll}\text { 5. DISCUSSION AND CONCLUSION } & 148\end{array}$

$\begin{array}{ll}\text { Discussion } & 148\end{array}$

$\begin{array}{ll}\text { Limitations } & 152\end{array}$

Future Research Suggestions 153

$\begin{array}{ll}\text { Implications } & 154\end{array}$

$\begin{array}{ll}\text { Conclusions } & 158\end{array}$

$\begin{array}{ll}\text { References } & 160\end{array}$

$\begin{array}{ll}\text { Appendix A - Personal Epistemology } & 168\end{array}$

Appendix B - San José State University IRB Approval 169 


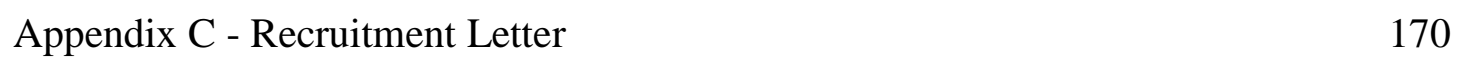

$\begin{array}{ll}\text { Appendix D - Consent Form } & 171\end{array}$

Appendix E - Semi-structured Interview Guide $\quad 172$ 


\section{Chapter 1}

\section{Introduction}

The use of sport by coaches, teachers, and parents to discuss important issues has become a regular occurrence (Arnold, 2001; Leahy; 2010; Lyras \& Hums, 2009). Issues addressed through the use of sport include a range humanitarian issues linked to broad political, social, and public health related topics. In an international development scheme, these political, social, and health problems have become pressing humanitarian concerns because of their current effect on the international community, especially in the lives of children growing up in developing nations. Some humanitarian issues of concern include child poverty in Africa, sex slavery in Southeast Asia, and religious and ethnic conflicts in the Middle East. In response to these extreme humanitarian issues vexing developing nations, a push to use sport as a vehicle for international development has emerged (Kay, 2009; Kidd, 2008; Levermore, 2008a). The increasing use of sport as a teaching mechanism over the last 15 years (Kidd, 2008) has resulted in the advancement of an internationally recognized field of research and practice known as Sport for Development and Peace (SDP) (Darnell, 2007; Darnell, 2012b; Levermore, 2008a). The logic behind using sport as a catalyst in international development is that sport often takes place in a non-formal setting, unlike that of a formal classroom or structured learning atmosphere, that attracts many people of different backgrounds (Levermore, 2008a, 2008b) and because sport is an international language (Koss \& Alexandrova, 2005) everyone can speak. Thus, sport also presents a non-verbal type of international 
communication that can be spoken by many whom are given the opportunity to participate.

The link between sport and international development is that sport, unlike many other activities, can transcend time and place, reaching all populations (Kidd, 2008; Levermore, 2008a, 2008b). Many people and organizations have recognized that sport is more than just a game (Donnelly, 2008; Kay, 2008; Kidd, 2008), and it can be used as a platform to address issues that are plaguing the world. SDP is a field in which organizations and people come together with the idea that sport is effective in educating children about humanitarian issues. Issues currently pressing the international community that SDP aims to address are violent ethnic or religious conflicts, gender inequality, HIV/AIDS awareness, and child poverty (Beutler, 2008; Levermore, 2008a). Beutler (2008) indicates that "Sport, as an international language, can build bridges between people; help overcome differences and spread an atmosphere of tolerance" ( $p$. 359). Giulianotti (2011a) noted that sport can be transformed into a socio-cultural tool to bring about a positive and effective change when dealing with international humanitarian issues. In addition, Darnell (2012) recommended using sport, physical activity, and play as tools to facilitate social improvement. In the context of SDP, sport is more than just winning or playing; instead, sport has the potential to be a vehicle for change (Donnelly, 2008; Kay, 2009; Kidd, 2008). Therefore, SDP workers go into embattled areas around the word where there are adverse situations, and use sport in an attempt to address a respective issue and to improve living conditions. 
The potential that SDP has to address humanitarian issues has caught the attention of some of the biggest non-governmental organizations (NGOs) in the international community (Jarvie, 2011; Kay, 2009). With recognition by organizations such as the United Nations (UN) and the United Nations Children Fund (UNICEF), there has been a spike of non-profit international organizations working in the field of SDP (Kay, 2009; Kidd, 2008). Some non-profit organizations, for example, include Right to Play, which uses soccer to address HIV/AIDS issues in Africa (Darnell, 2007), and Peace Players International, which uses basketball to ease tensions in war-torn areas such as the Middle East and Northern Ireland (Touhey \& Cognato, 2011). In 2001, Kofi Annan, Secretary General of the UN at the time, identified sport as a fundamental right for all human beings (Beutler, 2008), allowing that every person should be given the opportunity to participate in sport and experience the life lessons that sport can teach (Donnelly, 2008; Lyras \& Hums, 2009; Wolf \& Hums, 2006). This idea of sport as a human right led the United Nations to specifically state that SDP can be used to help achieve the Millennium Development Goals (MDGs) (Darnell \& Black 2011; Kay, 2009; United Nations, 2012), which were instituted at beginning of the new millennium on September 18, 2000, by Kofi Annan with the goal of being met by the year 2015. The MDGs as listed on the United Nations website (http://www.un.org/millenniumgoals/) are:

(1) Eradicate extreme poverty and hunger, (2) Achieve universal primary education, (3) Promote gender equality and empower women, (4) Reduce child mortality, (5) Improve maternal health, (6) Combat HIV and AIDS, malaria, and other diseases, (7) Ensure environmental sustainability, (8) Develop a global partnership for development 
Many SDP organizations have been formed using the MDGs as a foundation (Beutler, 2008; Darnell \& Black, 2011). Examples include Right to Play, which works to combat HIV/AIDS, and Fight 4 Peace, which uses boxing to educate children in disadvantaged communities like south London (Wolff, 2011).

Although SDP is an area of international development that is garnering much attention, there are scholars and government officials that criticize the field (Black, 2010; Burnett, 2009, Hartman \& Kwauk, 2011). A major criticism targets the experiences of people involved in the delivery of SDP, ranging from organizational leaders, government officers, and interns who serve in troubled areas (Coalter, 2010; Darnell, 2007; Hayhurst, 2009; Hayhurst \& Frisby, 2010; Jackson \& Haigh, 2008). In many cases, governmental and non-profit organizations working in SDP come from developed, north-western parts of the world. This may result in actors inexperienced in SDP spreading knowledge and implementing programs that are centric to their Northern or Western upbringing, rather having more a foci from the from local communities. The relevance is that a person originating from a developed country could possibly often assume an element of privilege and knowledge due to them originating from the developed world. For instance, in a country like the U.S., the HIV/AIDS epidemic pales in comparison to a countries in SubSaharan Africa because the U.S. provides adequate education on HIV/AIDS prevention (Maro et al, 2009) resulting in the severity of HIV/AIDS to not be taken as serious in the U.S and for behavior in obtaining HIV/AIDS to be more likely in those Sub-Saharan African Countries. 
Having the opportunity to grow up in the Western world provides people a socialized privilege that focuses on education, safety, health, and opportunity. Hartman and Kwauk (2011) define this as a socialized power status. Darnell (2007, 2010a, 2012a, 2012b) indicates that people working in SDP who are from developed nations carry different knowledge and experiences during their work. He found that the experiences of SDP interns lacked purpose and understanding while working in SDP related projects. Darnell, through his analysis with Canadian SDP volunteers and interns, found that racial ideologies (Darnell, 2007, 2010a, 2010b), power relationships (Darnell \& Hayhurst, 2011), and ethical challenges (Darnell, 2012a) were exhibited, and that SDP often reinforced a dominant approach, which indicated that sport reproduces and socializes power relationships and social hierarchy (Hartman \& Kwauk, 2011). Darnell (2007, 2010a, 2010b, 2012b) discusses the pre-conceived notions that SDP volunteers and interns hold, which may be due to their privileged upbringing in a developed nation. It is possible that pre-conceived knowledge on certain topics can affect the implementation of SDP programs by interns. By Western interns having their own fundamental beliefs and biases, there could be possible portrayals of ideologies through their program implementation. These portrayals of ideas and beliefs are often unintentional, but potentially have the power to shape communities. Therefore, this thesis focused on SDP interns' experiences in the field.

The purpose of this study was to explore the experiences of American SDP interns as they reflected on their program implementation in the field. Darnell (2012b) asks, "What kind of worldview is championed through SDP?" (p. i). I attempted to 
answer Darnell's question using the framework of hegemony as he used in his previous research. Similar to Darnell (2007, 2010a, 2010b, 2012b) who applied hegemony and other critical frameworks, it was my intent, through my own data analysis, to use the hegemonic theory to explain the experiences of American SDP interns in order to provide further discussion on relationship dynamics between SDP interns and those they assist in the field. Like most of Darnell's work (2010a, 2012b), I used Antonio Gramsci's theory of hegemony (Bates, 1975) to provide a critical understanding of the SDP experience. Darnell and Hayhurst (2012) suggest that it is useful to use a hegemonic framework in the continuing research of SDP because it allows for clarity in the process of organizational programs by saying, "Further, SDP research can benefit from the strong tradition of using hegemony to make sense of the very organization and interpretation of sporting practices with relations of power" (p. 115). Darnell and Hayhurst also indicate that research on SDP committed to using hegemonic theory would help in the comprehension of actors, whether it is researchers, officials, or interns who serve in the SDP field and how they work into the SDP context. The major differentiation between this thesis and Darnell's body of work is that Darnell worked primarily with Canadian SDP interns. I chose to focus on American SDP interns so that a broader discussion about those who work in the field can be developed. Most of the research involving SDP interns has come from abroad in European countries and Canada; therefore, this study is a first with an American SDP context. By focusing this thesis on American SDP interns, the breadth of literature seeking to understand the flow of power through SDP interns to program implementation, and an impact on the people of local communities will expand. 


\section{Statement of Purpose}

The purpose of this thesis was to examine qualitatively the experiences of American SDP interns through their own reflections of their program implementation in the field.

\section{Limitations}

The limitations to this thesis included the following:

1. The roles of participants while implementing an SDP program were different from one another resulting in dramatically different experiences. For example, one participant had been stationed in a managerial role working in an office during his or her tenure, while another participant was stationed as a teacher directly working with a local community.

2. The participants' inability to be thoughtful and truthful while being retrospective on their experience while working for an SDP organization.

3. The participants' unwillingness to provide further depth when probed on certain topics.

\section{Delimitations}

Criteria for participants were limited to:

1. Recent interns of an SDP organization. Recent was determined to be any time frame within the last 5 years. 
2. Interns who have worked for a Sport Plus SDP organization. Sport Plus SDP organizations are those that use sport specifically for developmental purposes.

3. Interns who have worked for a domestic American SDP organization that was created in America and is stationed in America.

4. Interns who have interned for a minimum of six months.

5. Interns who identified themselves as being American citizens.

6. Interns who have already completed their SDP internship.

\section{Definition of Terms}

Americanization - "Americanization tends to be viewed as a one-way process in which American cultural forms, products, and meanings are imposed on other cultures at the expense of the domestic culture. Evidence of Americanization of popular culture as a commodity is widespread, particularly in the fields of film, television, and popular music" (Donnelly, 1996, p. 242).

Developed, Northern or Western Nation - Although used interchangeably within SDP literature these terms have no distinct definition provided by worldwide international organizations like the United Nations. Therefore, for this thesis these terms will be used as they are used in Darnell (2007, 2010a, 2010b) and Hayhurst (2009) as being nations located in North America and Western Europe that are working in SDP. 
Globalization - A transnational theoretical trend that incorporates a process of developed nations influencing distant locations globally in a cross cultural manner. The influences include economics, politics, and social ideologies (Nixon, 2008, p. 127).

Hegemony - The power to influence dominant ideologies related to society from a superior group to an inferior group (Sage, 1990).

Less-developed, Southern or Third World Nation - Used interchangeably throughout SDP literature. The definition of these interchanged terms came from the United Nations website where they are countries lowest on the scale of development according to low income, human resource weakness and economic vulnerability criteria". (http://www.un.org/en/development/desa/policy/cdp/ldc/ldc_criteria.shtml).

Non-governmental Organizations (NGOs) - Non-profit private organizations that engage in a variety of activities. They can be oriented toward a single issue or can have a multipurpose agenda (Pease, 2011, p. 4).

Sport for Development and Peace - "Sport for Development and Peace refers to the international use of sport, physical activity and play to attain specific development and peace objectives, including most notably the Millennium Development Goals (MDGs)." (http://www.un.org/wcm/content/site/sport/home/sport). The definition of Sport for Development and Peace from the United Nations website was chosen for this thesis because of the United Nations prominent role of the United Nations in international affairs. 
United Nations - An organization created in 1945 after World War II consisting of northern and developed nations, "Its central purposes are to: (...) address economic, social, cultural and humanitarian problems; and to promote respect for universal human rights" (Pease, 2011, p. 17). 


\section{Summary}

Sport for development and peace is an emerging field that athletes, organizations, and civil society believe can make a difference in addressing social-humanitarian issues while also helping to reach the Millennium Development Goals. The positive rationale that sport can help save the lives of children in impoverished countries has influenced workers and volunteers to lend their help for the cause. It is believed that sport can be used as teaching platform that intrigues many people from around the world. With this in mind many non-governmental organizations have formed with a premise of using a sport to address certain international issues. However, many of the workers and volunteers of these non-governmental organizations come from western, democratized, and capitalist cultures leading critics to question their experiences working in a less-developed country. One persistent evaluation of SDP is that Western workers going into Eastern and Southern countries often bring with them ideologies that are attributed to Western thinking. Ideologies related to racial discourse, power distribution, and cultural differences are a few that may accompany SDP workers and volunteers. With this in mind, the intent of this study was to examine qualitatively the experiences of American SDP interns in order to understand their experiences during their time working in the field. To be clear it was not my intention to be critical in the processes of SDP, but rather to bring dialogue from another group of people who have actively participated in the field. This study was intended as an addition to previous SDP literature that also examined the role of SDP interns in the field by providing a previously unexplored outlook on the experiences of American SDP interns. 


\section{Chapter 2}

\section{Review of Literature}

This next chapter will provide literature on elements of SDP. The review of literature is organized into five sections: (1) an overview of SDP, (2) an explanation of the hegemonic theory and a discussion of two other integral aspects of SDP, (3) globalization, (4) non-governmental organizations, and (5) research on SDP volunteers and interns. The review of literature begins by providing a definition of SDP, the history of sport in international development, and examples of SDP work. The review will then proceed with a broad explanation of hegemony (Bates, 1975) and then address the specifics of globalization and non-governmental organizations as they relate to SDP. My intent of incorporating globalization and non-governmental organizations into this thesis was to provide a broader background in the attempt to understand the experiences of SDP interns. Then lastly the final section of this review will discuss the previous work of SDP scholars as it relates to SDP interns' experiences in the field.

The intent of this review of literature was to show the intersection of hegemony, NGOs, and globalization in order to establish an appropriate background of knowledge on SDP. The extensive review of literature incorporated discussion of SDP in addition to a framework that helped explain the results of the data analysis. With this review of literature encompassing many facets of SDP, one can begin to understand the depth of the SDP field. The understanding of SDP and how the field works in the international development context will provide a basis for which the study of this thesis was built upon. 


\section{Sport for Development and Peace}

In order to fully understand the purpose of this thesis it will be necessary to discuss the field of SDP. Discussion using previous literature written about SDP in this section includes a brief definition of the field, an overview of the history of SDP, and examples of current work done in SDP. By providing an overview of SDP as it the field situates itself in international development one can begin to understand the intrigue and fascination that the field has garnered, both positively and negatively.

\section{Definition}

Sport for Development and Peace (SDP) to simply put it is the use of sport to foster an education that enables people to address development issues affecting their personal lives (Kidd, 2008). Sport for Development and Peace is defined as an international movement of, "A concerted effort to remobilize sport as a vehicle for broad, sustainable social development, especially in the most disadvantaged communities in the world" (Kidd, 2008, p. 370). Giulianotti (2011a) also emphasized that within SDP, sport is transformed into a socio-cultural tool used to bring about an effective change. An important element in the definition of SDP is the usage of sport in an international context. The UN (http://www.un.org/millenniumgoals) and one of its subsidiaries, UNICEF (http://www.unicef.org/sports/index_23621.html), take into consideration that SDP complements efforts in reaching the Millennium Development Goals. Referenced by Levermore (2008a), SDP organizations include everything from non-profit, nongovernmental organizations (e.g., Right to Play, Mathare Youth Sports Association) to major international federations (e.g., Union of European Football Association, Federation 
Internationale de Football Association). All organizations working in the SDP sector have come to the conclusion that sport is an effective tool in addressing international social issues. However, there are differences that exist between SDP organizations. Levermore (2008a) identifies three types of SDP organizations: Plus Sport, Sport Plus, and Sport First. Plus sport organizations are mainstream non-governmental organizations, and only sometimes use sport to improve social issues. The second type, Sport Plus, are non-governmental organizations that focus on sport for development and highlight other social benefits. The last type, Sport First, include organizations whose primary focus is sport, and any developmental outcomes are unplanned and organic (Levermore, 2008a). These three organizational structures of SDP presented by Levermore (2008) provide the foundation on which SDP organizations are built.

In the case of SDP, sport is no longer a privilege that only a portion of the world is allowed to participate in (United Nations, 2012); instead it is a human right (Donnelly, 2008; Wolf \& Hums, 2006) that helps create a learning atmosphere in developing countries. The push behind SDP is the belief that sport can be used as a tool to teach lessons that can potentially lead to safe and healthier lives.

\section{History of SDP}

Even though SDP has made notable strides in international development, the use of sport to address social issues is not new (Levermore, 2008) and can be traced as far back as colonial times (Donnelly, 2008). Giulianotti (2011a) described three phases that sport has gone through which culminate in the sudden popular emergence of SDP: Sport, 
Colonization and Civilization; Sport, Nationalism, Post-Colonialism and Development; and Sport, Development, and Peace.

The first phase, Sport, Colonization and Civilization, occurred during the late eighteenth century and concluded around the middle of the twentieth century. During this phase, sport was introduced to many indigenous groups by people from colonizing states (e.g., soccer introduced by the British to the people of the Americas). Through this use of sport, many political and social ideologies were placed by the colonizers onto indigenous peoples, which resulted in a cultural transformation for the indigenous people. Sport was used to purposefully develop colonial ideologies and influence the people whose land was being taken.

The second phase, 'Sport, Nationalism, Post-Colonialism and Development' took place from 1940 to the beginning of the 1990s. It was during this time that sport became a contested battlefield where many nations sought to use sport to address various social issues. For instance, in South Africa, many Black South Africans used sport to battle Apartheid ideologies that controlled the country for decades. During this phase of SDP history, many nations liberated themselves and became part of sport governing bodies (e.g., FIFA). As a result, governing bodies started to fund third world nations in order for them to develop sport programs. It was at this point in time that sport was significantly starting to develop in impoverished countries. This led to the late 1990s where the third and current phase emerged: Sport, Development and Peace.

The two prior phases are still present today, but the focus has shifted to SDP where international organizations have been formed to address humanitarian issues like 
the ones presented in the MDGs. It was during this time that international organizations such as the UN and UNICEF united to support the idea of SDP. This review focuses on the third period defined by Giulianotti (2011a). It is within this period that SDP has become a world wide movement where many scholars and practitioners are trying to develop new methods to help change the world. The reason behind giving the history of SDP organizations as explained by Giulianotti (2011a) was to highlight that throughout time, sport has been used to bring about social change and address an array of pressing social and international issues.

In the last decade, there has been an increasing movement to use sport as a tool to address international humanitarian, social issues (Levermore, 2008a). The recent work of SDP emerged in the early 2000s. At a UN meeting in 2001, then UN Secretary General, Kofi Annan, emphasized the use of sport when dealing with international humanitarian issues that are addressed in the Millennium Development Goals. Sport is an international language (Levermore, 2008a) and is an exciting terrain for teaching criteria that is outside of the formal classroom realm. Beutler (2008) iterates that, "Sport, as an international language, can build bridges between people, help overcome differences and spread an atmosphere of tolerance" (p. 359). The space that sport gives is more than just physical; rather, it incorporates a space where emotions, cognitive thinking and morality are shaped (Rookwood, 2008). Sport has the ability to communicate these concepts to a wide range of people, making it a powerful tool in the realm of SDP. With international humanitarian issues like relieving conflict caused by ethnic or religious tensions, the improvement of women's rights, severe poverty, child education, and HIV/AIDS 
prevention still plaguing this world, using a new movement like sport (Kidd, 2008) can add to other methods that have been implemented in the past.

In the history of international development, many people have given much effort to alleviate humanitarian and social issues around the world. However, it is only in recent decades that sport has been used as the tool or facilitator in international development (Kidd, 2008; Levermore, 2008). In the ten years after Annan's influential statement, there has been an emergence in national governments and NGOs attempting to use sport to deal with issues that the MDGs outline. From that point, we have the field of Sport for Development and Peace, a field that is multi-disciplinary and involves many different actors (Levermore \& Beacom, 2012), so it needs to be studied from various scholarly views.

Current issues that SDP organizations specifically address are conflict resolution in war torn or ethnic torn countries (Sugden, 2008), peace education between communities (Rookwood, 2008), and HIV/AIDS preventive education (Mchombo, 2006). SDP organizations are greatly contributing to international development and are making a tremendous impact on the communities with which they are involved, but, as previously stated, there are many people that are still unsure of using sport in the context of international development relief.

\section{The Current Work of SDP Organizations}

Research done by Spaaij (2009) examined themes prevalent in SDP organizations. Spaaij's purpose (2009) was to present a new methodological and theoretical way to examine SDP organizations, to increase the academic analysis of SDP. The study 
focused its attention on essays written on SDP organizations. From the analysis, four themes emerged: (1) Sport development and social change - intended and unanticipated consequences; (2) Empowerment and personal change through sport; (3) Sport participation, social inclusion and social change; (4) the impact of sport in society: historical and comparative perspectives. From the themes formulated by Spaaij (2009) and the MDGs, three of the social issues SDP focuses on are discussed in this literature review: HIV/AIDS, peace in war-torn countries, and gender equality. These issues are common in the SDP area and related to the MDGs set up by the United Nations (Kay, 2009).

HIV/AIDS. The first major issue that many SDP organizations address is the health issues related to HIV/AIDS. Maro, Roberts, and Sorenson (2007) estimated in 2005 there were 38.6 million people in the world living with HIV/AIDS, and within that 38.6 million, 28.5 million were people living in Africa. Due to the stigmatization of HIV/AIDS in Africa, the education on preventive methods is not up to par compared to developed nations. This stigmatization is highly due to religion (Maro et al., 2007; Mchombo, 2006), and the influence that religion has on communities has impacted the way HIV/AIDS is treated in Africa. With this MDG in mind, many SDP organizations (i.e. Right to Play, Grassroot Soccer) implement programs in those affected areas (Levermore, 2008a).

Mchombo (2006), a person of Malawi (African) origin who grew up and went to university in the U.S., wrote a first hand narrative on how he was a part of a program that used soccer to help quell the spread of AIDS in Malawi. In Mchombo's (2006) story, a 
first-hand account was given on how education about HIV/AIDS was intertwined with soccer in the hopes of creating an environment that supported HIV/AIDS education. He describes that soccer has an appeal to it that is relative for many people of Malawi in that it is cheap and easily accessible even when the appropriate equipment is not obtainable. For instance, basic equipment, like a soccer ball, can be improvised by tying up water bottles. Soccer also creates an environment of cooperation and teamwork while focusing on individual traits. It is from these qualities in soccer that Mchombo (2006) started using soccer to help counter the spread of HIV/AIDS in racism.

The project that Mchombo (2006) worked on had local soccer teams of a league in Malawi use the sport as a platform to warn young children and others about the dangers of HIV/AIDS. Mchombo (2006) would use soccer contests as a classroom since large groups of people congregated, and he would have the teams and himself reiterate preventive methods in avoiding HIV/AIDS such as abstinence or the use of condoms. The descriptions given by Mchombo (2006) drew a clear picture on how sport contributed to the development of HIV/AIDS education in Malawi. Mchombo (2006) emphasized that many children for whatever reason lack the ability to go to school; therefore, most of the things they learn are through their interaction with others in the community. In this case, sport provided a metaphorical classroom for the communities of Malawi. The actual extent to which this soccer-based education program was effective was not determined by Mchombo (2006), rather his interest was centered on the interest the children took in the program. Soccer presented itself as a place where HIV/AIDS education was enjoyable to the children in Malawi. HIV/AIDS is not a topic that is 
taught in many schools throughout Malawi, even though there are high rates of infection. Soccer is able to present itself as a popular form for children to learn about HIV/AIDS prevention education.

Maro et al. (2007) investigated the effectiveness of an HIV/AIDS education program located in Tanzania. Their study investigated whether people would reduce their likelihood to engage in risky sexual behaviors if they were educated about the consequences of HIV/AIDS. They indicated that formal education had always been used to educate people about HIV/AIDS, but because HIV/AIDS is taboo in many African communities, preventive lessons are not taught in the country's education system. The organization chosen for their study was Elimu Michezo Na Mazeozi (EMIMA), a soccer based program that uses social peers as teachers and role models for youth of the community. EMIMA, whose name is in Swahili, is a community based organization that uses peer coaching and education to address HIV/AIDS issues in addition to other youth development topics.

Maro et al. (2007) looked at four different groups in their study: (1) a regular group of within EMIMA who were only exposed to regular EMIMA programming, (2) a master group within EMIMA that was highly exposed to HIV/AIDS education, (3) an inschool group who received HIV/AIDS education only through the formal school setting, and (4) an out-of-school group that received no HIV/AIDS education program. In this study, peers were trained before investigation how to instruct HIV/AIDS prevention sessions through the play of soccer to the four groups of the study. The intervention strategy used was the "Kicking AIDS Out," a soccer-based lesson plan specific to dealing 
with HIV/AIDS. By using peer coaches within a soccer coaching environment EMIMA was effective in producing knowledge about HIV/AIDS and safe sex practices (p. 137).

Through a quantitative analysis done on pre-intervention and post-intervention responses by 950 participants, Maro et al. (2007) found that participants of the program were able to receive effective instruction on safe practices regarding HIV/AIDS. The researchers found that children from four study groups learned from their peer mentors about the use of condoms, abstinence, and being in honest relationships. For every 25 students in each group, all groups had higher marks as it pertained to HIV/AIDS and safe sex. For instance the regular group had a 9.26 students have some knowledge about HIV/AIDS with EMIMA then after a second measurement the group had 12.83 students have some knowledge and the out-of-school group began with 8.42 students have correct knowledge then after a second measurement. The two other groups, master and in-school groups also gave received higher marks pertaining HIV/AIDS knowledge after participating in the EMIMA program, with the master group improving from 9.75 students to 13.33 students and the in-school group improving from 8.44 students to 11.84 students.

Important findings from Maro et al. (2007) were that the EMIMA groups expressed greater beliefs and attitudes towards safe sex and condoms, and were more likely to have knowledge on condom use and preventive measures as compared to the two school groups who either received HIV/AIDS education in the classroom or did not (p.137). This study showed that formal classroom situations are neither the only method to teach HIV/AIDS education, nor an absolutely correct way, rather there are other 
settings like sport where HIV/AIDS education can be taught. The use of peer coaches in sport, as shown by Maro et al., can effectively teach children about the dangers and prevention of HIV/AIDS. All the groups of their study showed interest when involved in soccer-based learning, and it was through this soccer-based classroom that HIV/AIDS education was taught. Maro et al. indicate that it is possible to sport-based education to teach children positive ways to approach HIV/AIDS.

The idea that sport is an alternative form of education (Kay, 2008) has made it a place where a taboo subject like HIV/AIDS can be taught. Both Mchombo (2006) and Maro et al. (2007) justify this notion through their studies of SDP organizations. The experiences and responses of the participants showed that SDP helped successfully educate people about HIV/AIDS.

Peace and Conflict Resolution. Not only has sport served as a platform to teach children about HIV/AIDS, but it has also helped foster peace in conflicted regions around the world. Beutler (2008) explains the UN's direction in obtaining a peaceful world through sport. Only until recently have scholars appreciated that sport can help in addressing conflicts and creating peaceful situations (Beutler, 2008). The concept of using sport is that it is an international language (Koss \& Alexandria, 2005; Eichberg \& Levinsen, 2009) that can be used to break down barriers between people.

Ethnic and religious tensions continue to be sources of war and unrest in many countries, like those in the Middle East (Kidd, 2008; Rookwood, 2008; Sugden, 2008). Rookwood (2008) and Sugden (2008) completed descriptive studies on Football 4 Peace, an English sports program situated in Israel using soccer to ease tensions between Jewish 
and Arab communities. Football 4 Peace's aim is to bridge the two culturally different communities and promote a peaceful existence (Sugden, 2008). To provide a brief background, Football 4 Peace primarily works in Israel and Palestine where there is a long history of tension between people from Jewish background and those from an Arab background (Sugden, 2006, 2008). The mission of the program is to bridge conflicted communities by bringing them together through the play of soccer. The thought behind using soccer as the instrument to teach children about peace, was that in soccer, there are times when players must cooperate with each other to deal with adverse situations. During these instances leaders of Football 4 peace would transform hardship moments into "teachable moments" and show the participants how to resolve conflicts in a peaceful manner (Rookwood, 2008). Depicted by Rookwood (2008), sport can organically generate scenarios into "teachable moments" where people have active dialogue with each other in order to solve a problem. When a person participates in sport, there is a co-existence that they must adhere to even if it is with people they may not admire (Sugden, 2008).

The ability to have a setting where people from divided communities can come together and cooperate with each other towards a common goal was something that formal and previous development settings did not provide (Levermore, 2008a). Sugden (2006) did a qualitative study on Football 4 Peace volunteers working in the divided region of northern Israel. Sugden's study investigated people's initiatives for volunteering for such an organization. For his research, Sugden (2008) incorporated a range of volunteers which included domestic people from the local community, from 
both Jewish and Arab backgrounds, and international volunteers from the United Kingdom. The findings of the study included different levels and reasons why people domestically and internationally wanted to volunteer towards the mission of Football 4 Peace. One Arab volunteer spoke to Sugden about how he volunteers for Football 4 Peace because he wants to set an example for young Jewish and Arab boys to come together and interact with each other. By setting this example, the hope is that this new generation of Jewish and Arab youth can overcome a history of violence. One participant of the Sugden's (2008) study spoke to how even though he experienced extreme violence in his youth, he put that behind him so he could show people that Arabs and Jews can live together. The ability to have volunteers who have experienced this kind of religious conflict all their lives provides great coaches for a program like Football 4 Peace.

People being able to look past their issues with another culture or religion and realizing that all the fighting is wrong helps create a safe space for SDP. The goal was to bring communities together that have been divided by religious conflict for a long time, and Football 4 Peace has effectively done so by incorporating volunteers from many different groups of people.

A Swedish SDP non-governmental organization, Open Fun Football, promotes peace in conflicted areas of the world as well (Eichberg \& Levinsen, 2009). Very similar to Football 4 Peace, Open Fun Football brings children from different ethnic backgrounds together by using soccer as a theoretical bridge. Described by Eichberg \& Levinsen (2009), the program's goal is to group children from different backgrounds together and have them forget about any historical conflicts. The atmosphere created by playing 
soccer together broke down barriers and allowed the children to build a new identity of "we" and disregard the idea of "them" (Eichberg \& Levinsen, 2009). Open Fun Football's success was illustrated through program leaders stating that earlier in their lives they had shot bullets at each other and now they are working together to teach children about peace and social cohesion. With many conflicts around the world, sport has been an agent in promoting resolution and peace. As a place where people are able to come to work toward a common goal, sport has allowed people to forget their differences and learn values to live peacefully.

Gender Equality. SDP organizations have also aspired to help provide rights to women in underdeveloped nations. For example, Meier and Saveedra (2009) stated that in a country like Zambia where there is much disparity in rights between men and women, sport can be a way for women to overcome these problems. Sport can provide a place for social change in regards to women's rights by empowering them in a physical manner (Lyras \& Hums, 2009). Lyras and Hums (2009) suggested that equality among genders can be achieved if both groups come together and work towards a common goal. They also suggested that there are fundamental principles that men experience but women do not, and through sport, women can experience these principles. Principles mentioned were teamwork, leadership, and empowerment, which they suggest could be taught through sport. Women in underdeveloped countries do not have the interactions to learn about these principles in their everyday lives, leading SDP organizations to address this issue by using sport. 
SDP organizations also help promote gender equality by the use of female role models. Bringing in female program leaders as role models can have an impact on female participants of an SDP program (Meier \& Saavedra, 2009). Meier and Saveedra's (2009) case study followed Esther Piri, a female Zambian boxer, and the use of her as a role model in SDP programs in Zambia. With low resources in Zambia, young girls and women do not have access to education or other social interactions where they can feel empowered. Also, in Zambia, many women wed at a young age and therefore, are forced into household chores and then eventually bearing children (Meier \& Saveedara, 2009). As a successful female boxer in a male dominated culture, Esther Piri was able to become a source of inspiration to young females in Zambia.

Kay (2009) examined the GOAL project in New Delhi, India. The GOAL project is another organization that addressed gender inequality and empowered women through net ball. Similar to the situation in Zambia, in India, women's rights are not equal to those of men. Data was collected by interviewing staff and participants of GOAL. From the data, Kay (2009) showed that participants of the program acquired beneficial knowledge and felt empowered by an increase in self-confidence. By participating in netball, the women grew more self-confident and experienced the positive impact sport had on their body such as better health and increased energy. Instead of being confined, they were allowed to communicate to each other in a more enthusiastic manner, which is against societal norms, and gave participants a sense of freedom.

The women who participated in the GOAL project were given space to be independent and freely express themselves in ways that their society did not allow. In 
this case in particular, netball created a place where women were allowed to be educated and create an image of themselves that challenged social norms. Kay (2009) stated that qualitative-based research using interviews was able to retrieve valuable information from the participants. The quotes used by Kay (2009) drew a vivid picture of how sport helped Indian women participating in the GOAL project obtain life lessons that helped them challenge a culture dominated by male ideology. Kay's (2009) use of qualitative research and interviews was a new approach in acquiring substantial information on how sport helped change the lives of women in New Delhi by creating substantial stories to how sport can effect the lives of underprivileged women.

Incorporating SDP into the efforts of addressing international humanitarian issues has had much success as suggested by the previous research. Sport has been used effectively to create a learning atmosphere in which international development can work. Sport is used to address many issues ranging from HIV/AIDS education (Maro et al., 2007; Mchombo, 2006) to easing tensions in conflicted regions of the world (Eichberg \& Levinsen, 2009; Rookwood, 2008; Sugden, 2008), and help promoting gender equality in areas where social ideologies are constructed by male dominance (Lyras \& Hums, 2009; Kay, 2009; Meier \& Saveedra, 2009). However, similar to Hayhurst (2009), the purpose of this thesis is not about SDP's effectiveness; rather, this thesis questions how SDP works. Focusing on the program implementation of American SDP interns will provide insight to how the outcomes of the previously mentioned research are experienced by SDP workers. 


\section{Hegemony: Power from Ideologies}

As previously stated, one of the most important researched areas of SDP are the experiences of workers in the field. Hegemony in the context of SDP is constructed as the hidden power ideologies that are indirectly applied within the field (Darnell, 2010a). Darnell (2012b) emphasizes the importance of studying relationships between SDP workers and the people participating in SDP programs because it allows for insight on the interaction between the people who are implementing SDP programs and the people who are learning from SDP programs. In looking at experiences of SDP interns as they reflect on their program implementations, a hegemonic framework can be used to help examine and critically discuss the experiences of American SDP interns by looking at what sort of relationships and ideologies are created. In relation to the purpose of this thesis, hegemony helped interpret power ideologies through cross cultural representations when applied to the experiences of American SDP interns. What follows is a broad discussion of the hegemonic theory that is a framework to this thesis.

\section{Overview of Hegemony}

The most common model of hegemony used in research related to power was developed by Antonio Gramsci (Bates, 1975). Antonio Gramsci was a member of the Italian Communist Party during the 1920s. Due to Gramsci's political stance, he was imprisoned by the Italian government; while in prison, he developed a theory on how governments and politics ruled in a certain way. It was during his confinement that Gramsci developed the theory of hegemony. Hegemony during the time of Gramsci strictly dealt with how national governments were controlling their people through 
systematic placement of ideologies (Bates, 1975). Even though hegemony was born through Gramsci's debate on politics and governments, an actual definition of the theory was never established by Gramsci. An exact definition of hegemony was never put forth by Gramsci because of his untimely death in prison, but Bates (1975) explains the basic premise of hegemony to be, "That man is not ruled by force alone, but also by ideas" (p. $351)$.

The ideas that Gramsci spoke of in his theory of hegemony related to societal norms and beliefs that controlled society. Gramsci believed that it was through ideologies that society was controlled by one group over another. In summarizing Gramsci's theory of hegemony, Bates (1975) states, "The concept of hegemony is a really simple one. It means political leadership based on the consent of the led, a consent which is secured by the diffusion and popularization of the world view of the ruling class" (p. 352). Powerful groups like national governments have the ability to promote and reproduce ideologies that are used to maintain their power over the rest of society. A historical example of this is Hitler's ideological rule over Germany. Therefore, hegemony is theoretical in practice based on how one group or person can influence another group through a constant reproduction of ideas.

As Sage (1990) discusses in his book on power ideology in American sport, using a hegemonic framework is one of the leading ways within the field of sport sociology to study the ongoing power troubles impacting sport. In his description of what he calls the hegemonic image, Sage emphasizes the dominance of power associated with societies incorporated in sport and how that affects social relations (p. 20). The interaction 
between groups that have power or perceive that they have power with those who do not is important in sport because of the dominance and control they are able to acquire from that power. Sage sees ideological hegemony as the process by which a group influences a larger group by reproducing their own ideologies and promoting them throughout society. These ideologies eventually permeate throughout all of society and become the social norm.

In the case of SDPs, and for this thesis, the minorities are the SDP interns, the beliefs are those that are culturally ingrained into the interns, the practices are those that are taught through SDP program implementation, and the societies affected are those being helped by SDP organizations. Sage states in his book that hegemony "literally means dominance" and that "Major societal power, control, and influence emanate from economically, politically, and culturally dominant groups, even though they are muted and filtered through the popular consent of "the people"” (p. 21).

Throughout this thesis, I stress not the physical power and domination of hegemony that is explained by Sage, but rather ideological domination. Ideological hegemony refers to how current practices and/or beliefs are developed and distributed throughout a society by social institutions until they eventually become societal norms (Sage, 1990). Ideological hegemony is important for this thesis because it will help with interpreting and examining power ideologies negotiated by American SDP interns the people of the communities in which they helped.

In general, hegemony refers to power, authority, and control that one group possesses over another. The hegemonic theory emphasizes that certain groups have 
control over others due to a power that is negotiated through consent by society (Bates, 1975). From Gramsci’s definition of hegemony as explained by Bates (1975) and the definition used in sport sociology by Sage (1990), this thesis looks at the hegemonic relationship between American SDP interns and the local communities which with they have worked.

Hegemony derives from a variety of social elements such as gender, race, or culture. In the case of SDP, hegemony has been applied by cultural ideologies that are learned. Darnell (2010a, 2012b) has found that this can lead to internal and external problems concerning of SDP since many workers in the field are unaware of their ideologies while working the field. This lack of cultural awareness (Kidd, 1991) has lead to negative attitudes and disregard for the culture of indigenous peoples. The question is then presented, "Are international humanitarian organizations really helping or are they just providing another avenue for developed states to demonstrate their global dominance?" This is an argument that is presented with all humanitarian efforts whether SDP or any other field of international development.

Having discussed the definition of hegemony, the next section explains the relevance of hegemony to the overall development scheme. Looking at how hegemony has been applied and evaluated by international development scholars will help assist in understanding ideological problems within SDP. Discussing general studies of hegemony and development is relevant because SDP addresses international development issues. The issues that have been examined in past literature are the perceived help given by international and domestic humanitarian organizations (Tilley, 2002), neo-liberalism 
in Latin America (Petras, 1997), and control of development practices by organizations in Africa (Okolie, 2002).

\section{Development Hegemony}

After discussion of the hegemonic theory and indicating how it will be used for this thesis in the case of SDP, one must look at how hegemony has been applied overall in international development. Tilley's (2002) study centered on the perceived help that was given by organizations like the European Union (EU) and United Nations Social, Economic and Social Organization (UNESCO) in their efforts to improve the economy and political support for the indigenous people of El Salvador. The importance of Tilley's (2002) study centered on the actions of organizations that were attempting to help build an economy and then the results that actually occurred from the organizations' help.

In El Salvador, the indigenous populations are not acknowledged much by the general population or the El Salvadorian government, which results in the welfare of the indigenous population not being taken into consideration when decisions on development are made. The EU and UNESCO found this to be a problem and implemented their own programs to promote indigenous rights. The presence of the EU and UNESCO, however, resulted in both organizations taking control over what they believed to be important for the indigenous population. Although the intent of the EU was to improve conditions of the indigenous people, they took the objectives and activism of indigenous groups and transformed them into what they thought was more proper. 
A major point that Tilley (2002) makes is the "contradictory effects through a focus on indigenous ethnopolitics" (p. 528), indicating that the help that is provided is at times not the help that is needed by the indigenous population. This conflict between the organization and the indigenous population on how help is provided is important to understand because it strongly exhibits how one group of people attempt to control another by way of providing assistance that is based on what the actors believe is right and not what the indigenous population of El Salvador believed they needed. Tilley showed that the ideas of help were controlled by the NGOs and not by the indigenous populations. The NGOs ignoring the social concepts of the indigenous populations resulted in a power disposition of who knows what is best. In the case of Tilley, the developed actors believed they knew best.

Petras (1997) examined the assistance of NGOs in Latin America and the costly and negative effects that resulted from the movement. He explains that NGOs and corporations justify their involvement in aiding underdeveloped countries in Latin America by stating that their presence allows for growth through social improvements. However, he determined that NGOs were strategically placed and funded by bigger corporations to facilitate the intentions of the bigger corporations. He sums it up by saying, "In reality, however, the World Bank, the neoliberal regimes, and western foundations co-opted and encouraged the NGOs to undermine the national welfare state by providing social services to compensate the victims of multinational corporations (MNCs)" (p. 11). 
NGOs in the case of Petras' study were the ruling groups that held the power to implement the programs in ways they wanted to. An example given by Petras, of how NGOs functioned in ways that they wanted to, was in Bolivia. In Bolivia, NGOs only acted on issues in which their supporters wanted them to. For instance, when public school teachers went on strike, NGOs ignored it, and when there was a health scare, NGOs did nothing. As Petras notes in his study, NGOs were not taking into consideration the desires of respected communities because of their interaction with private corporations. This suggests that NGOs are at the bidding of the people and MNCs that fund their projects abroad. There is not only a power problem between developed actors and the people of less-developed communities, but there is also a power struggle between two developed actors. The NGO is one developed actor and the MNC is another developed actor. If both NGOs and MNCs do not cooperate, there can potentially be a problem in program implementation, because MNCs may feel they are in control because of their monetary donations. As one can see, hegemonic stability is an all-inclusive dilemma that affects every player. The predicament as we look at NGOs in the development context is that not all NGOs take into consideration the ideas and beliefs of the people they are trying to help.

Okolie (2002) argues that the international development efforts from development agencies to some parts of Africa are more about the control of the development policies than the actual help provided. Okolie states many international development agencies fight for the control of development practices in Africa so that they can implement their own programs. Many African countries lack monetary resources that will help establish 
themselves in the burgeoning world economy; therefore, African governments seek external help from the international community.

International organizations like the International Monetary Fund (IMF) and the World Bank have loaned funds to growing African nations, but only to a limited extent. The amount of money loaned is based on where and how governments spend the money (Okolie, 2002). For instance, some African nations are rich in agriculture and may use loans from the IMF or World Bank to invest in improving their agricultural system, but that may not be the area that the IMF or World Bank wants the money to go to. The assistance of the IMF and World Bank allows for the development of nations, but whose development, the IMF or the country itself, is brought into question. Historically, African nations have been heavily influenced by European and American ideologies which exclude “... local peoples' knowledge, worldviews, and lived experiences...” (p. 431). The local people in this context are people of African nations.

Okolie (2002) shows how Western powers tend to believe that they know what is best for the lives of others, especially in the case of Africa, where the thinking is about what Africa needs and not about what it has or wants. As Okolie has shown through his interpretation of development in Africa, powerful groups who do not take into consideration the ideas of local communities display a sense of ideological control because their idea overrules the local community. If organizations continue to put their ideologies over the needs of others, those ruling by hegemonic ideological control will continue to be present. Hegemony, in the context of international development, is shown 
by powerful groups such as NGOs or MNCs placing their ideas over the needs of local communities.

In more relevant cases of hegemony, there is clear presence of powerful entities imposing their ideologies on other groups, similar to how Western nations are influencing the Middle East. Since religious struggle has taken hold of the Middle East, now a centuries old issue, there has been a clear presence of Western forces in countries such as Iraq, Afghanistan and Israel. In international development, the control of developed nations over nations they are intending to help is evident. Western organizations exclusively provide the help that they perceive is valuable and not necessarily what will improve the lives of the native people. Organizations believe they have the right idea on how to fix the troubles in less-developed nations and often times implement their own procedures and policies without taking into consideration the needs of indigenous populations (Tilley, 2002). These NGOs provide assistance according to their own agenda (Petras, 1997), and only help in international funding depending on the cause (Okolie, 2002).

The theory of hegemony and how it works within the international development context is important to this thesis because it incorporates how social relationships are built through ideologies and meanings of society. The next section will discuss hegemony in a manner that is more specific to this thesis.

\section{Americanization: American Hegemony}

Sage (1990) references America as a nation where hegemony is prevalent because America has virtues and ideas that, indeed, form powerful social relationships. General 
examples of how hegemony can be seen as a force of ideological domination are the expansion of McDonald's restaurants across the globe, the showing of Hollywood movies in other countries, or the American government's attempt to spread democracy (Kroes, 1999). The global reach of American companies, politics, and, most significantly, ideals, represents, as Gramsci described, a national government controlling people by imposing their ideologies on them. America in this case, is the national government and the ideology is American culture being exported to other countries. America has the power to promote its ideologies through international society. A term closely associated to American hegemony is Americanization (Donnelly, 1996; Kidd, 1991). The process of Americanization is how America influences other cultures and societies (Kidd, 1991; Kroes, 1999). Americanization has been much discussed as a form of hegemony which entails much of the western, capitalist views of America (Donnelly, 1996). Donnelly (1996) explains that "Americanization tends to be viewed as a one-way process in which American cultural forms, products, and meanings are imposed on other cultures at the expense of the domestic culture" (p. 242). Much of this can be seen in the business, popular culture, and media that are spread all over the international community. The driving force behind this global Americanization act is the capitalist belief controlling Western economies. The exponential growth of a company like McDonald's, especially in developing parts of the world, illustrates the power corporate America (Houlihan, 1994) has on the world. People are led to believe that this expansion of the Western world is a good thing because of the economic opportunity that is provided (Houlihan, 
1994). However, there are unconsidered consequences that populations and communities are faced as a result of these everlasting Americanization processes.

Americanization can be viewed as a hegemonic process because there are ideologies of a powerful group (the United States) being negotiated to other groups (lessdeveloped nations). Kroes (1999) states that Americanization is regarded as "the semantic transformations that attend the dissemination of American cultural messages across the world" (p. 463). America is a country with much power in the world which results in many other nations and cultures being highly influenced by American ideas and culture (Kroes, 1999). Kroes further explains that Americanization allows for American ideas and products to be delivered to all parts of the world while in the United States, non-American practices are ignored (p. 465). What happens in the process of Americanization is that America exports its ideologies to other countries while not allowing any other countries' ideologies into America.

As discussed previously, Americanization is the process by which American ideas, culture, and products are distributed throughout the world resulting in social changes abroad (Kroes, 1999). Therefore, with hegemony being described as being ruled through ideas, and Americanization being the process of how America influences other cultures, American hegemony can be interpreted by forms of Americanization. Americanization has the ability to make a meaningful impact on domestic sporting culture (Donnelly, 1996). Donnelly (1996) and Nixon (2008) both discuss how an act of stealing or taking away from the culture of the indigenous people is perpetrated when Americanization occurs. What these scholars are depicting is that the lives of the people 
affected by Americanization are not included in process of economic development or expansion; rather they are forced to assimilate to the changes that occur. There is a shift in ideologies and meanings to the point that a cultural change occurs (Maguire, 1994). People from less-developed areas of the world may be seeking assistance; however, the changes needed to occur for assistance to happen may dramatically change their way of life.

To frame American hegemony in a sporting context for this thesis, I will encompass Kidd's (1991) discussion of Americanization. In his commentary on Americanization, Kidd notes that the push behind Americanization in sport is a capitalistic market in which hegemony is portrayed. Historically, American innovations in sport have been adopted by other nations due to the high success of American sports which is defined by the expansion and economic growth of American sport. The influence of American sporting ways, whether through sport business practices or style of play, has had an impact of sporting cultures abroad. Seeing American sporting ideologies taking control of the sporting landscape, Kidd asked, "How can sports foster socially responsible personal growth and community when outsiders determine the dominant meanings and forms of activities?" (p. 179). America's dominant rule of sporting ideologies creates a conundrum on how sporting ideas are created by other cultures. Placing American meanings and values in other sporting cultures hinders the possibility for other cultures to establish their own ideas about sport.

Kidd (1991) uses the culture of Canadian sports as an example of how Americanization causes concern to national sporting meanings. Kidd states that 
Americanization hinders the development of ideas and meanings in Canadian sport because Americanization incorporates ideas that are taken and used throughout Canadian sports. Examples given by Kidd on Americanization consist of the National Football League's control of the inclusive football market where American football is seen as better than Canadian football, as well as the National Hockey League's importation of foreign players. America's rule of these sports lies within Americanization and the process of how American meanings are influencing other nations. The hegemonic implementation of American sports into Canadian sports is problematic to the extent to which American ideas control how Canadian sport meanings are created and negotiated. Americanization can be greatly seen in the expansion of American sport abroad. An example of Americanization in international sport is Major League Baseball in the Caribbean (Klein, 1991). A common belief about the exportation of baseball to Caribbean countries is that Major League Baseball (MLB) teams are helping local players by giving them an opportunity to improve their lives. However, what is not being presented is the way Americanization works in these countries. Klein (1991) depicts how Major League Baseball teams establish training academies in Caribbean nations where native players hope to attend in order to be selected to play with a MLB affiliated organization. It is in these academies that controlling ideologies are displayed. The academies took native players and taught them an American system of playing baseball while incorporating their talents in different ways (Klein, 1991). What the native players thought was the right way to play baseball was displaced by American ideologies. An example of American ideologies influencing Caribbean players is teaching the players 
how to behave on the field and in the clubhouse of a baseball team. Also, with the potential monetary gains that these academies provided, many players would rather be in an academy instead of a low paying domestic team. These academies provide greater opportunities to make money because of the increased chance of being selected by a Major League team. Americanization in this instance has resulted in Caribbean baseball culture being displaced by American meanings.

Galily and Sheard (2002) looked at the impact of Americanization on Israeli basketball. Historically, American basketball players have been allowed to play in Israel with ease due to the relationship between the two countries. However, with a growing group of American players in Israel, the Israeli league is changing. Galily and Sheard explained that American players were awarded higher salaries compared to the Israeliborn players; this then meant that only Israeli teams with high payrolls would be able to afford American players. As a result, a hierarchy of Israeli teams was created based on teams' monetary funds. The American ideology displayed here is capitalism where wealth is valued. Americanization is impacting Israeli basketball leagues where American economic ideologies are controlling the sporting ideas in Israel.

In regards to SDP, sport is culturally changed into a teaching mechanism.

Therefore, it is crucial to understand how Americanization may be happening in the field of SDP. There could potentially be organizations that are constructing ideologies and meanings in their teachings that are not ideal for people they are attempting to help. SDP as a social global movement (Kidd, 2008) involves actors from many different countries who may or may implement programs in different ways. The purpose of discussing the 
hegemonic theory was to elaborate on how ideas can control groups of people.

Discussion of the hegemonic theory, as it related to American ideas, and Americanization was done in this literature review to provide a more specific meaning of hegemony. Analysis of the data attempted to apply the hegemonic theory to see if any ideologies arise from American SDP interns. The following sections of this literature review will elaborate two important elements of SDP. The first is globalization, and the second is non-governmental organizations.

\section{Globalization}

As history has shown (Donnelly, 2008; Giulianotti \& Robertson, 2007), sport has had a major impact on global society. The impact of sport all over the world can be debated as negative or positive. Globalization of sport has long been associated with monetary aspects like sponsorship, commercialization, and expansion into different markets, as well as social-political aspects like nationalism and racism (Nixon, 2008). Nixon (2008) refers to this global impact of sport as the Golden Triangle. The Golden Triangle incorporates many elements of sport, which includes products, private companies, and agents that have monetary goals in mind. Political means associated with globalizing sport refer to the use of sport on the international level as tool of communication, something that is very relevant to SDP. Sport's grip on the world intertwines cultural, economic, and political concepts together (Nixon, 2008). Sport globalization having this mixture of culture, economy, and politics creates an empirical dilemma of sport on the global level. This section of the literature review will focus on 
the globalization of sport and how it connects to the previous section in terms of the widespread of ideas throughout sporting culture. I will extend on globalization to build on the literature that is being used to provide a sufficient background for this thesis. SDP being an international movement (Kidd, 2008) allows for discussion on the globalization of sport.

\section{Sport Globalization}

It is important to understand the general study of globalization when looking at SDP because SDP is a global movement. Globalization has occurred in other cultural areas such as entertainment, private industries, and music (Donnelly, 1996). Sport has become a global phenomenon where people from many different countries tune into their television sets to watch events such as the Olympics and FIFA World Cup. At one moment in time, two people on opposite ends of the world may be watching the same live sporting event. With that in mind, one can begin to see the influence sport has in the world. Thibault (2009) identified sport as an international dimension that has grown greatly in recent decades. This optimistic view of sport's inclusivity is not without its dissention as many have commented on the injustice of sport globalization. The increased expansion of sporting culture can be vividly seen. In the U.S., the National Basketball Association (NBA) has marketed their product to China extensively while the English Premier League of England has a presence in Africa (Thibault, 2009).

Thibault (2009) poses that globalizing sport can result in many problems such as "the use of performance enhancing drugs, migration of athletes and coaches, the use of developing countries' workforce for the production of sportswear and sport equipment, 
and the general commodification and commercialization of sports in society" (p. 2). In addition to the outcomes mentioned by Thibault, sport has also allowed for international communities with tension-filled histories to come together. One example is the unity between Japan and South Korea as they co-hosted the 2002 World Cup together after many years of conflict and war. Hence, sport on the global level has an impact in the construction of lasting social relationships.

Donnelly (1996), a prominent figure in sport sociology, reviewed this trend in sport globalization, and indicated that sport globalization is connected to hegemony. In relation to globalization, Donnelly, as referenced in the previous section, introduces Americanization as "cultural hegemony," which is an act of American products and ideologies being established in other nations in a dominant manner. From Donnelly's discussion on sport globalization, there is indeed a platform of American hegemony, otherwise known as Americanization. There are many reasons why sport has been expanded to all parts of the world, including monetary incentives that accompany a sport's expansion to a new market, a greater recruiting base from which to find talented athletes, and to show and develop their product in the international community. According to Houlihan (1994) the underlying concept of motives for globalizing sports is power. If we look at America's domestic leagues, such as the NBA, as an example, we see attempts of the league expanding into markets abroad by drafting highly talented international players (e.g., Yao Ming from China, Ricky Rubio from Spain) and also selling their products such as jerseys and airing rights into these markets. Nixon 
(2008) posits that many corporations, whether sport-oriented or not, may have their own interests in play when they attempt to grow their product in different markets (p. 127).

The purpose of sport globalization, on the part of teams, companies, and executives is to enter other countries with the goal of placing their sporting values and culture onto others. This has come to be known as a new type of colonialism often referred to as cultural imperialism (Donnelly, 1996; Nixon, 2008). Cultural imperialism in the sporting realm is the act of direct influence by an outside culture into an indigenous culture (Donnelly, 1996). Cultural imperialism in the sense of sport is how sporting cultures and ideologies are transformed by an outside source (Donnelly, 1996). Driven by a capitalist imperative (Nixon, 2008), globalization usually originates from established countries and expands to other established countries or, more commonly, into developing countries of the Eastern and Southern part of the world. The problem often associated with developed countries going into struggling countries is the displacement of power and culture.

Donnelly’s (1996) description of cultural imperialism in sport shows through a hegemonic discourse the Americanization that occurs in other cultures through sport. Donnelly argues that sport has been more Americanized than areas like music and film due to the many forms sport presents itself in, such as "products, services, and ideas" (p. 246). Houlihan (1994) argues that the problem with Americanization occurs when companies (in these case sport teams/organizations) influence other cultures in assimilating to what they are introducing to outside populations. In relation to this thesis, cultural imperialism relates to the placement of a dominant sporting culture onto another 
sporting culture. For instance, the thought that sport can develop character, discipline, and responsibility in individuals may be relevant in one sporting culture, but not in another culture. The purpose of discussing the process of globalization for this thesis was to show SDP as a global movement that is quickly growing throughout the world. Therefore, the influence of another's sporting culture is a crucial critique of sport globalization.

\section{Non-Governmental Organizations}

When discussing the field of SDP, it is necessary to understand that most, if not all, organizations working in SDP are non-governmental organizations (NGOs). Though there are major international NGOs such as the United Nations supporting the call for sport in international development, it is still important to examine general power

problems plaguing NGOs, so that we can see if any of these general NGO problems are present in SDP. Now that the hegemonic framework and globalization has been laid in the previous sections I will now situate NGOs within this thesis and how NGOs deal with the general idea of power through ideas. The emphasis on NGOs in this literature was done to provide a broad discussion overall NGO realm, so that one could see the potential conflicts an SDP NGO may face.

\section{Definition}

Non-governmental organizations did not exist until after World War II (Martens, 2002) when there was a call for international support in the development and reconstruction of the world due to the aftermath of the war. In response to this call, the 
United Nations was formed. The purpose was to form a coalition of nations in order to address social issues that had resulted as an outcome of World War II. In the beginning, the United Nations consisted of the countries that survived World War II physically, socially, and economically (Martens, 2002).

Throughout the $20^{\text {th }}$ century, smaller NGOs were created privately by groups of individuals and did not involve national governments. In essence, NGOs are independent organizations that aim to address a variety of issues all the way from domestic issues like animal rights to grander international issues like child poverty (Martens, 2002). Willets's (2006) description and focus of NGOs are transnational organizations addressing international development issues. Defined by Willets, "The term, 'non-governmental organization' or NGO came into currency in 1945 because of the need for the UN to differentiate in its Charter between participation rights for intergovernmental specialized agencies and those for international private organizations" (p. 1). They are independent from governments with primary focuses on human rights and non-profit making. They are also transnational actors that work across national boundaries seeking to help as many nations that will accept them. Clarke (1998) added that, "NGOs are private, non-profit, professional organization with a distinctive legal character, concerned with public welfare goals" (p. 36). Also, NGOs must be non-violent, non-profit, and cannot be aligned with a political party (Willets, 2006), which is contradictory to government supported NGOs.

In correlation to this thesis, the definition of NGOs will focus primarily on those organizations that are addressing international development issues since that is the main 
concern of SDP. In the case of SDP, we see many organizations working in countries located in the Middle East, Latin America, Africa, and Southeast Asia. Unassociated with for-profit organizations, SDP organizations intend to provide services that will help make the world a safer and healthier place to live in through sport. The missions of NGOs, in general, cover a variety of issues: they aim to provide healthcare to areas lacking in adequate medical services, build homes in countries affected by natural disasters, and create clean water systems in countries going through drought. In SDP NGOs, sport is used as the focal point in addressing certain issues. Certain issues that some SDP NGOs help address are HIV/AIDS education (e.g., Grassroot Soccer), conflict in areas that are rife with ethnic or religious tension (e.g., Peace Players International), and gender equality (e.g., Soccer Without Borders).

In connection to the discussion of NGOs, all SDP NGOs share the same qualities. SDP NGOs are private organizations, not aligned with any particular party, but supported by national governments as seen in Canada and England, financially supported from private donors, and assist in addressing international welfare goals (Wright, 2012). SDP organizations being NGOs allows for interpretation of overall problems within NGOs to be applied in SDP.

There are many difficulties that arise for NGOs. Some issues NGOs face that relate to SDP are the interaction between financial providers and workers, motivation of NGO workers, and how NGO workers separate ideologies between them and the population they are working with. However, as stated in the section discussing hegemony in this review of literature, this thesis will focus on how hegemony is situated 
within SDP, as shown through the experiences of American interns. Understanding the nature of NGOs is important to this study because it allows for insight into how NGOs work and what problems arise in them. By looking at the common problems that NGOs encounter, we can examine how they transfer into SDP organizations. For the purpose of this thesis, the problems within NGOs will focus on power and ideologies. The reason for this is to outline what struggles NGOs have in dealing with power relationships.

\section{Power Ideologies in NGOs}

A main argument that is pitted against NGOs is how they go about assisting communities in underdeveloped countries. People may find it commendable that others are volunteering their time in a community that needs assistance, but there are critiques about how and why people are helping others. Certain difficulties mentioned before include accountability (Brown \& Moore, 2001; Hilhorst, 2002), political socialization (Warleigh, 2001), trust (Osswaarde et al., 2008), and ethics (Frangonikopoulos, 2005). It is important to first note that coming from a developed nation like the U.S. gives an NGO privilege of power and knowledge (Wright, 2012). Wright (2012) describes that coming from an established country allows for a learned ideology to be present in NGOs, where NGOs tend to believe they know the correct ideas on how to approach problems that local communities encounter. Western NGOs have this privileged knowledge because they originate in a developed country (Wright, 2012). Having this learned knowledge can lead to a discourse by communities being helped because the communities may believe whatever the NGOs are giving and teaching them is best for them, even though it may harm their indigenous culture. 
A general example of ideological power can be the effect of religious groups going into less-developed communities to spread their religious beliefs (Manji \& O’Coill, 2002). The religious groups may feel that they are assisting communities by teaching them about religion, but these communities may not want religion, instead they would have rather help with economic growth (Manji \& O'Coill, 2002). Looking at the notion of power by learned consent (Bates, 1975) is important in examining the relationship between NGOs and their benefactors because it allows for insight into the relationship of those helping and those being helped.

Fowler (1991) brings attention to the notion that NGOs challenge local governments' and organizations' power while also instilling their own ideologies. In his early look at NGOs in Eastern and Southern Africa, he found that NGOs would adopt political agendas, challenging local governments, so the organizations could work freely without interference from local authorities. By imposing on local governments, the NGOs would put forth their own political agenda from their own nation. For instance, in communities that lack a structured government, NGOs from democratic nations would instill democratic principles into the local communities (Mohan, 2002). Not only were local politics attacked, but local NGOs addressing the same issues felt discomfort by the presence of the international NGO. In some cases, there are already local NGOs addressing a certain issue. To then have an international NGO address this issue may cause difficulties to arise (Lewis, 1998).

Multiple NGOs in the same area working on the same issue could lead to a bitter competition between the organizations, resulting in one of them, usually the local NGO 
due to its lack of resources and power, being displaced (Obiyan, 2005). Lewis and Sobhan (1999) suggest that instead of building a partnership, outside NGOs become the leaders and incorporate the local NGO in their programs and teach them their methods of conducting business. As outside NGOs work with local NGOs, the outside NGOs become the dominant organization while the role of the local NGO is redefined into a more subordinate position (Lewis \& Sobhan, 1999). When there are already local organizations on site addressing an issue of a local community, an NGO from the outside coming in and providing assistance on the same issue in a different manner creates a level of hierarchy where one NGO may be seen as better than the other.

In this hierarchical system, the organizations with the most power are the ones that are well-funded and visible, usually the international NGOs. Fowler's (1991) argument demonstrates hegemonic actions of NGOs. He noted that NGOs go into communities in which they are trying to help, but in order to achieve their objectives, they will undermine local agencies and governments. The hegemonic theoretical framework is relevant here because there is an indirect power disposition by certain NGOs. NGOs may believe the work they are doing is well intended, but there are instances shown by Fowler (1991) and Obiyan (2005) where NGOs use their power to give themselves an advantage rather than giving priority to the needs and values of the local people.

The challenge to local governments and organizations by NGOs is a hegemonic change in ideologies (Wright, 2012). NGOs that are actors from outside a country may possibly arrive with their own ideas of how to change the social setting for the better. 
NGOs that have this attitude do not take into consideration the cultural practices of the locals and how that might differ from the NGOs teachings. As referenced in Wright (2012), Bratton (1989) discusses that NGOs working in underdeveloped countries tend to encourage ideologies like democracy because democracy is what controls civil society; even though NGOs may not intend to do so, nor may their primary purpose be in promoting democracy, it is latently done. NGOs that are closely related to Western democratic governments have a tendency to sway their teachings in promoting Western ideologies. An example of this could be the United State's presence in the Middle East where democratic based NGOs are stationed in order to help victims of a cultural tradition (e.g., treatment of Muslim women). The contradiction here is that NGOs are intended to be apart from their national governments, but what we see through hegemonic discourse is the difficulty that NGOs have in concealing their Western governmental ideologies.

Another dilemma circulating within NGOs is the critical situation pertaining to the accountability and legitimacy of their actions. Frangonikolopoulos (2005) brings light to this problem in NGOs by challenging current NGO workers to be more responsible for their actions. Frangonikolopoulos states that due to the increased pressure from private donors and powerful governments, NGOs have lost touch of their core values; instead, they are controlled by these groups and are willing to follow their objectives.

It is important to note that in relation to the power that governments have over NGOs, many NGOs working with national governments are from developed nations, and 
they do control most of the international policy. For instance, the United States of America's push to spread democracy around the world initiated its efforts to support NGOs, which started at \$162.2 million in 1991 and increased \$637.1 million in 1999. Other nations that support their own national NGOs include Denmark, Great Britain, and France. Governments have given up to $\$ 5.9$ billion dollars to humanitarian efforts as of 2000 (Frangonikolopoulos, 2005).

The alliance that NGOs have with private financial donors and governments creates tension between the NGOs and the less-developed communities they are trying to help. The tension is created because issues that the local people find important are avoided by the NGOs. The agenda is set by the private donors and not by the NGOs or the local communities. Also, if an NGO is not working with a high-profile donor, then the organization may not be seen as legitimate as others (Wright, 2012).

The cooperation between NGOs, their national governments, and private donors illustrates the predicament of who is in power when it comes to NGO programs, missions, and values. When there are many people invested in an organization, there are multiple views on how programs should be implemented. The NGO may have a developed lesson plan that addresses a certain issue, but it may not meet the cultural understandings of the local community. Also, the influence that private donors have on SDP NGOs through large monetary donations may lead the donor to believe they can tell the NGO where to work. It is important to understand the relationships between all actors in the SDP movement because they all portray some sort of hierarchical power relationship. 
In relation to the prior dilemmas concerning the authority of NGOs is the socialization of indigenous populations (Warleigh, 2001). Socialization occurs when people are systematically taught norms and ideologies that eventually become the status quo (Donnelly, 1996). Usually, the issues that arise when discussing the topic of socialization deal with politics and public policy (Warleigh, 2001). NGOs that focus on international development issues, like the MDGs, work in environments where local culture may not mesh well with the NGOs intentions; this in turn creates a situation where NGOs unknowingly carry out teachings that teach the local communities a different way of living.

This sequence of events can be seen historically by religious expansion in lessdeveloped countries and, currently, is visible through the capitalist investments in the developing world (Manji \& O’Coill, 2002). With much of the Western world culturally influencing less-developed countries, there are lasting impacts on matters such as economics, government, and religion. What comes to pass is the disregard for native improvement through native customs. NGOs are more inclined to impose their own ways on how to improve life within the local communities.

In referencing back to the definition of hegemony by Sage (1990), it is defined as dominant ideologies and meanings that shape the way communities build social groups and interact. Applying Sage (1990) to Warleigh (2012) and Manji and O’Coill (2002), there are NGOs acting in a hegemonic manner due to the expansion of ideologies that influence meanings of how local communities live. The authority of an NGO creates a space where their teachings are culturally accepted without question. 
Power ideology is an issue of concern to NGOs in general (Wright, 2012). The concept of NGOs was to provide assistance in international development without the aid of governments. But as Wright (2012) illustrates, without government assistance, NGOs had to seek out other avenues for monetary funds in order to supplement their programs. By doing so, private donors, whether they were individual philanthropists or transnational corporations, were incorporated into the NGO paradigm in order to provide financial support.

Capitalist beliefs have a strong control on the workings of NGOs from developed nations (Wright, 2012) because it is learned through the success of coming from a developed country like Canada or the United States. The power that circulates within NGOs is controlled by actors with the believed authority that they can make changes. Problematic power ideologies that are discussed focus more on the actions of NGOs. The problems associated with NGOs are accountability, relationships with local organizations and governments, socialization into different cultures, and overall ethics. Actors included into the realm of NGOs are private donors, governments, and organizational leaders who hold fundamental capitalist ideologies.

As I have interpreted throughout this section, there are constant ideological struggles that affect the role of NGOs. NGOs have the power to teach ideologies that differ from local cultures; they can have skewed values when it comes to whose goals and missions are being met; and they can socialize local communities into a different way of living. Darnell (2007, 2010a, 2010b, 2012b) denoted hegemonic ideologies present in SDP, as shown through his work with Canadian NGOs. Some hegemonic ideologies 
found through his research with interns from SDP NGOs include racial differences (Darnell, 2007; 2010), cultural ideologies about sport (Darnell, 2010b), and ethical challenges (Darnell, 2012a).

The United States bases its international image on democratic and liberal principles providing a prime example of how a country can control other societies (Sage, 1990) because of its ideological influence in other countries. In relation to SDP, there could be culturally hegemonic ideologies that are present within American SDP NGOs. Not much research has been done focusing on primarily American SDP NGOs. By examining American SDP NGOs, we can begin to add to the literature of SDP done by scholars abroad by including an American point of view of the subject. Therefore, the discussion on NGOs allows for this thesis to expand on American SDP NGOs' interns to examine if there are any different hegemonic ideologies portrayed by American SDP interns as compared to Canadian SDP interns.

\section{Research on SDP Interns and Volunteers}

There has been much research done previously on the experiences of SDP interns and volunteers. The previous research has used different frameworks and approaches, including hegemony. Before discussion on previous research on SDP interns and volunteers, I will first discuss the intersection of hegemony within the SDP field.

Hegemony as it relates to power and controlling ideologies is a discerning critique in SDP. SDP is a place where sport can be utilized to improve the lives of people who need it. Darnell's (2007, 2010a, 2010b 2011, 2012b), Fusco's (2005), Giulianotti's 
(2011b), and Hayhurst and Frisby's ( 2010) research is based on the fact that many times sociological concepts, such as western power ideologies, hegemony, and racial discourse hold substantial influence on SDP workers in the field, which, in turn, indirectly yields counter-effective teachings. Power relationships can possibly harm SDP and could make the field ineffective.

Overall ambiguity in SDP draws out hegemony (Coalter, 2009; Hayhurst, 2009; Hayhurst et al., 2010; Black, 2010). Between academic circles and NGOs working in SDP, different terms are used to identify SDP (Hayhurst, 2009) which results in an unclear definition of the field. This ambiguity gives way to who is in charge and who has the power to define SDP, and the goals, values, and policies that go along with SDP (Darnell \& Hayhurst, 2012). Hayhurst (2009) points out that all the actors within SDP are not homogenous and to categorize them as so (Darnell \& Hayhurst, 2012) creates a "who's who" power conundrum. SDP actors may differ in where and how they work, but this does not give one or another relative power basis. Nicholls, Giles, and Sethna (2010) challenged the lack of research and evidence discourse presented by scholars. They argued that academic hegemony is displacing and undermining the work of SDP organizations by placing an emphasis on only solid rationale and solid facts that are entrenched in a positivist paradigm. Therefore the importance of this study is that it provides a look at SDP through a different lens.

Before I introduce literature discussing SDP interns or volunteers, I will first touch on the experiences of other SDP workers, specifically in the form of SDP organization officials. In relation to the section of the literature review that discusses 
NGOs, Hayhurst and Frisby (2010) found relationships between two SDP NGOs and two elite level national sport organizations were strained due to a structural power imbalance. The power imbalance in Hayhurst and Frisby's research represented how some groups have more power and control than others. In Hayhurst and Frisby, the hegemonic theory is present because of the power the elite level national sport organizations had over the SDP organizations. In their study, they found many complications in the relationship between SDP organizations and elite level sport organizations. The elite level national sport organizations were given a sense of empowerment due to their prestige in the sporting scene. With this power, the high level national sport organizations believed they had the appropriate methodology to how SDP should work. The findings of their study showed a difference in sporting values between the two areas, problems in gaining legitimacy, and an issue on resource dependency.

The competing sport values revealed that the national elite sport organizations focused more on high level sport than sport participation, and that the talented participants of the program should be recommended to the professional ranks. SDP organizations saw themselves as being part of the elite organizations program and, as a result, did not implement their own programs. In gaining legitimacy, the SDP organizations had a difficult time competing with an already established national sport organization. The elite level sport organizations were already established and had no trouble getting local communities to buy into the programs. SDP organizations expressed the difficulty they had in building themselves in local communities and relied heavily on the elite sport organizations for assistance. The SDP organizations expressed a constant 
struggle they faced in having to always get approval by the elite level organization in order for their programs to be accepted in local communities.

The finding of resource dependency indicated that there was an atmosphere where the SDP organizations continually had to show their worth to the elite level sport organization in order to receive adequate monetary assistance. Elite level national sport organizations' assistance to the SDP organizations created a feeling within the SDP organizations that if they continue to ask for help, they would be looked at as more bothersome than cooperative. The research conducted by Hayhurst and Frisby (2010) provides insight to power relationships in SDP on an organizational level. Their findings showed that unequal power distribution resulted in one group having priority and control over another.

Another examination of SDP officials was done by Giulianotti (2011b) who examined the reflective discourses of SDP project officials using a global civil society and transnational framework. From his study, four major themes emerged that dealt with ethics, anthropolitics of practice, social roles, and relationships with global civil society. Giulianotti found that participants in his study faced ethical issues and used sport to teach ethics during their time in the field. Some of the ethical issues mentioned were how the SDP workers had to deal with emphasizing development through sport rather than sport development, how they used sport to bridge divided communities, and how they practiced ethics in sports such as fair play and harmony.

Giulianotti saw that sport, when used as a tool for development rather than just competitive entertainment or skill building, can really bring people together and teach 
people respectful ethos. In relation to the theme of anthropoltics of practice, Giulianotti found from his participants that politics and culture between different groups was important to the SDP experience. The participants in Giulianotti's study critically reflected on their feelings and emotions when it came to capacity building and empowerment of user groups, but felt it difficult because some programs were not sustainable.

Due to social and political reasons, Giulianotti emphasized that SDP officials had experienced trouble in implementing sustainable programs such as co-gender education in a male dominated society. They also faced criticism internally when questioned about their motives for conducting SDP work. One participant Giulianotti referenced in his study discussed how her efforts towards peace building in the Middle East were seen as imperialistic and she felt offended by that. She acknowledged that bringing peace to a region where peace was not wanted was hard and seen as imperialistic because it was a concept that was being brought to the country.

Giulianotti found social relationships as another strong theme that emerged from his interviews with SDP officials. Social relationships referred to the co-existence and working space that the SDP officials had with family and parents, local communities, and local political authorities. By working together with these groups of people Giulianotti expressed that the goals of an SDP organization can be met, but not without difficulty. For instance, if local communities or political authorities do not buy into the SDP program, major conflicts may occur between the SDP organization and the people they are working with. Therefore, it is important to incorporate many people in the SDP 
process, such as asking parents for their opinions and input on how to implement programs (Giulianotti, 2011b).

The last theme that came out of Giulianotti's study was relationships within global civil society, which refers to how SDP officials worked with other organizations from the overall international development realm. Similar to Hayhurst and Frisby (2010), this theme discussed how SDP organizations interacted with other development actors, such as donors or other financial providers, and the complexities that come with this relationship. Since many SDP organizations are non-profit, they rely heavily on monetary assistance from outside sources. These monetary sources may have other goals or methods they want in program implementation that are different from the SDP organization. This can result in a conflict for the SDP organization because they may need the financial backing, but do not want to change their organizational mission. Within this theme of global civil society, Giulianotti also found that SDP organizations had issues within the field where there was a level of division between SDP organizations working in the same region. Differences between SDP organizations included methods, values, missions, and philosophy, which ultimately resulted in a rift among organizations. Shifting towards to SDP interns in the field, this thesis will primarily focus on the work done by Simon Darnell (2007, 2010a, 2011, 2012b) as an example. Darnell has done substantial research dealing with SDP interns as it relates to internship experiences coinciding with underlying theoretical frameworks. Darnell's (2012b) book incorporated much of his previous work on SDP discourse of Canadian interns when working in countries afflicted by an international humanitarian issue. In his book, Darnell highlights 
three concepts as they relate to the arching hegemonic theory in SDP. They are as follows: (1) sport and the hegemony of capitalist development; (2) race, gender and biopolitics; (3) the emotional experiences of the SDP subject. From his interviews with interns, Darnell was able to get an in depth analysis on how relationships were described through the experiences of the participants in his study.

The first theme given by Darnell is how Western ideologies act as a pivotal driving force in hegemonic ideology. With that being said, SDP organizations are most of the time, NGOs that come from the West. Darnell (2010a) first looked at hegemony in SDP through the experiences of interns by applying Gramscian hegemonic theory. He found that many of the interns felt that sport provided values that coincided with hegemonic beliefs and attitudes about sport. The finding from Darnell was that most, if not all, of the interns worked in an administrative or managerial position. The interns' administrative or managerial position gave them a leadership role which Darnell expressed to be a form of hegemony because the interns were given their roles based on education and experiences in sport.

Secondly, Darnell (2010a) found that many interns believed inequalities could be broken down through sport which meant that the interns did not realize that sport itself is a structure of inequality. Darnell then found that the interns saw sport as a place where character building can be taught to individuals. Character building through sport is a culturally implicit idea that many of the interns believed to hold true due to their sporting experience in Canada. 
Lastly, Darnell (2010) found that interns saw sport as a way to help facilitate social mobility. The discussion on social mobility is that sport can help a person learn qualities that would help them gain employment and other social statuses; however, as Darnell explained, social mobility is still hindered by the control of the market and those in power. Sports providing positive experiences are an example of a culturally hegemonic belief (Darnell, 2011). Having their own positive experiences through sport led interns to believe that their sporting experiences could be the same for all people. Participant interns expressed that sport has the ability to teach people organization, responsibility, leadership, overcoming social inequality, and gives them an avenue to pursue upward social mobility (Darnell 2010a). However, this thinking is culturally learned through sporting experiences by the interns and therefore cannot be translated to different cultures.

The belief that sport can communicate these traits is founded in Western hegemonic ideologies. As these sporting values are ingrained into Western sport, Darnell (2010a) found that these values are believed by the interns. An interesting theme is a sense of First World guilt (Darnell, 2011) where First World guilt was experienced by the interns through their privileged ability to volunteer in an underdeveloped community. First world guilt, as explained by Darnell, is the emotions associated with social privilege and the realization of social inequality. Many of the interns in Darnell's study realized their privilege was due to them coming from an affluent Canadian background, providing them with the opportunity to travel abroad to volunteer their services. 
Darnell expresses that being a person who is attracted to "volunteer work results in also being a person who will feel guilt in relation to privilege" (p. 982) because volunteer works not only allows one to see their privilege, but confirms that they are in fact privileged. This guilt portrayed by the interns translates into a problem because it creates a subjective worker who may be more concerned with his or her emotions rather than those of the helped community. Also, shown by Darnell (2011), guilt can lead interns having a sense of responsibility to make an effective change, which can be problematic for some because change is not always possible. As Darnell proposes, First World guilt is noticed and can be absolved due to a person's involvement in work in SDP.

Darnell $(2007,2010 b)$ also evaluated the idea of race and racism in SDP organizations. It was in these studies that Darnell applied a hegemonic theory as it related to relationships dealing with race and culture. In his earlier 2007 study, Darnell used Whiteness as the background to his theoretical research. The thought was that racial ideologies played a role in the teachings and execution of SDP programs. Darnell investigated a momentous leader in the SDP movement, Right to Play. Applying the framework of Whiteness to the study, Darnell found that race did play an important role in the shaping of ideologies between SDP volunteers and the developing communities they were working with.

Regarding this early study, Darnell, found three major themes from the working interns while they were implementing programs in a global South country. First, he conceptualizes that volunteers were unaware of their attitudes because they felt they were 
providing something better than what the communities had. The power of giving tangible objects like soccer balls and soccer nets created a hegemonic atmosphere. The appreciation displayed by the members of the disadvantaged communities affirmed the work of the volunteers. This sentiment is visible in a response by a volunteer, stating their experience working for Right to Play gave them the opportunity to use the degree they are trained in and "share that with appreciative refugees" (p. 571). The volunteers working in the communities illustrated by this quote from Darnell presents the idea that they are doing good and are unaware of the hegemony they possess being from Canada.

Second, Darnell questions the range of emotions volunteers encountered "over there." Volunteers coming from a developed nation like Canada probably never experienced the sort of atrocities that regularly occur in the global South, so it is expected that many emotions will run through an individual. However, the experience of working in SDP, as Darnell asserts, is not about the volunteers.

Lastly, the mere racial interaction presented hegemonic discourse because through their interactions within their placement communities, volunteers expressed the effect of sport in terms of their experience and not of the people of the communities. The volunteers felt more changed by the experience due to their interaction with people from a different race. For many volunteers and interns, their interaction with people being helped through SDP immediately creates a "here" and "other" scenario. The "here" and "other" scenario marginalizes the volunteers and the people of the community because the volunteers understand that they will only be helping for a time, while the people have to live in those communities forever. It is in this scenario where a real separation 
between that "helper" and the "helped" is present, and this is where there is an inevitable power relationship.

As one can see, the hegemonic theory as it relates to being influenced by ideologies creates a sense of power and control that is present in the world of SDP. It does not mean that SDP NGOs are not effective in helping with international humanitarian issues, but rather, it is a problem on the SDP movement. Interns may not believe that they are expressing hegemonic ideologies, but as Darnell has shown in his research, many do. The world is so immersed with power relationships that hegemonic theory is crucial to the understanding of how SDP works. The closer SDP actors are working within their placement communities, the more they need to be aware of what their role as interns can do. It is my attempt in this thesis to add on to the literature written by Darnell (2007, 2010a, 2011, 2012b) so that there can be more knowledge on the people working directly in field of SDP. SDP is a field within international development that is trying to help make the world a place where everyone can live in peace, have good health and have an education (Kidd, 2008; Levermore, 2008a). As shown, ideologies can be an issue for SDP interns, and I consider it a pivotal problem to address. 


\section{Chapter 3}

\section{Method}

The purpose of this thesis was to examine qualitatively the experiences of American SDP interns' program implementations using a hegemonic framework, and was influenced by previous research and future research suggestions made by Darnell (2007, 2010a, 2010b, 2011, 2012), Darnell and Hayhurst (2012), Hayhurst and Frisby (2010), and Hayhurst, Wilson, and Frisby (2010). The current thesis will add to the research of the mentioned scholars by examining the experiences of SDP interns. Before discussion of how the research for this thesis was conducted, I will briefly discuss research methodologies within the field of international development. The purpose of discussing international development research is to provide background information about this academic field. This chapter will then describe how participants were selected, data collection procedures, SDP organizations, participants, procedures for data analysis, and how academic rigor was established.

There are many challenges when doing research within the field of international development (Donnelly, 2007). General international development researchers are very cautious in the way they handle methodologies because of the many stakeholders involved throughout the process (Donnelly, 2007). Stakeholders include people from the local communities, NGOs, private donors, national governments and scholarly researchers (Donnelly, 2008). For example, local communities may want to expand different research objectives compared to scholars, and private donors may want to focus on positive findings that will support their organizations. 
In this thesis, the people involved in the research process were the participants, who were SDP interns, and myself, since the purpose of this thesis was solely scholarly based. I situated myself as a neutral academic researcher that answered a call made by other scholars (Darnell \& Hayhurst, 2012) to examine SDP by using hegemony to help explain the relationships within the SDP field. My neutral standpoint was significant in this thesis because I do not intend to change SDP organizational boundaries or take any political or ethical action as a result of this thesis. I am not associated with any sort of government or SDP organization. I am merely an outsider examining an issue that has been mentioned by previous researchers (Darnell, 2012b; Hayhurst, 2010; Levermore, 2008a). I acknowledge that it may be difficult to be completely neutral, but an attempt was made to rid myself of major and most biases.

In order to create the atmosphere of neutrality needed as a researcher, I participated in a bracketing interview (Dale, 2000). The bracketing interview was used to "minimize researcher bias by creating more awareness of preconceived notions regarding the subject" (Dale, 2000, p.21). I also kept a reflective journal during the data collection process. The reflective journal was used after each interview was conducted, so that I could write about my feelings as each interview concluded.

\section{Participant Recruitment}

The participants for this thesis were found by snowball sampling as done in previous research on SDP (Darnell, 2007, 2010a, 2010b, 2011; Giulianotti, 2011b; Hayhurst, Wilson \& Frisby, 2010). Participants were recruited through the SDP 
organizations for which they worked. I identified 10 American-based SDP organizations as potential sources of participants. The SDP organizations were determined by a search on the website www.sportanddev.org. An initial email was sent to all 10 SDP organization intern coordinators or executive officials stating the purpose of the thesis, and inquiring about their organization's interest in participating in the research. A follow-up email was then sent to each organization's intern program coordinator that included an explanation of the proposed thesis and a request for each program coordinator to email a recruitment letter, along with the contact information, to each individual former intern. In order to ensure that responses to the initial email were timely, a follow-up email was sent if there was no response within a week. After allowing time for program coordinators to forward the recruitment letters, I then asked for program coordinators' permission to inquire on potential participants' interest in participating in the research via interview methodology. I asked for organizational officials to ask for potential participants either to contact me directly or to have contact information of potential participants so that I could send a personal message. All individuals participated in the research on a strictly voluntary basis.

\section{Participant Demographics}

Because participants for this thesis were former SDP interns, it will first be important to discuss the manner in which a person becomes an SDP intern. Through looking at the application process for four American SDP organizations, I found that the requirements for becoming an SDP intern include a formal written application, official university transcripts, letters of recommendation, an interview, and evidence or ability to 
show that one can financially support themselves during their time abroad. After all of these application materials are evaluated, applicants are then selected to be SDP interns by organizations. The ability to financially support their internships is an important criterion for SPD candidates because it shapes who can socio-economically be an SDP intern. For example, some SDP organizations suggest that interns be able to support themselves by having an estimated $\$ 10,000$ dollars to live off of.

Participants had to meet certain criteria in order to stay within the delimitations of the thesis. Following Darnell's (2007, 2010a, 2010b, 2011, 2012b) selection criteria of participants, in this study participants had to have been interns for an SDP NGO at one time in their lives. The type of SDP organizations that were the focus for this thesis were Sport Plus organizations (Levermore, 2008a). I purposefully chose Sport Plus organizations because the description of Sport Plus falls in line with SDP, which are organizations that use sport predominantly for change and other humanitarian benefits. Sport Plus organizations are those that use sport specifically for developmental purposes (Levermore, 2008a).

The most important difference between this study and those of Darnell's was that he only focused on Canadian interns from Canadian-based SDP NGOs. I exclusively centered my thesis on American interns from American-based SDP NGOs. I recognized that even though the two countries are neighbors and have similarities within the Western democratic paradigm, it is possible that American interns experienced SDP differently than their Canadian counterparts. Determining if a participant is American was done by asking if they are an American citizen. Other than the participants being American, the 
SDP NGO needed to be based stateside as well. Participants for this study also needed to meet the following criteria: (1) have no restricted age limit, (2) been an SDP intern for a minimum of 6 months, (3) have already completed their SDP internship. I, however, left out a third factor from Darnell: having a significant sports background. I found that having a significant sports background was not necessary for this thesis because there could be potential participants who were more intrigued by international development and found that SDP was more of an avenue to work in international development. Alternatively I believe that incorporating a range of sports backgrounds provided greater feedback on how much sport really means to the overall development context.

\section{Participants}

After receiving approval from the San José State University Human Subjects Institutional Review Board (IRB), potential organizations identified as sources of interns were contacted for their interest and assistance in providing contact information of former interns for me to interview. Out of ten initial emails sent to American SDP organizations, participants came from the two American based SDP organizations that responded to my initial email inquiring for assistance on my thesis. A member of the executive staff from each organization contacted me expressing their interest in helping with the thesis. One organization's respected official reached out to former interns and shared the purpose of the thesis along with the recruitment letter, consent forms, and my contact information. From this point, former interns from this organization contacted me, expressing their willingness to do an interview. The second organization gave contact information of potential participants she felt would be able to help with the research. Upon receiving the 
contact information of potential participants from the second organization's executive official, I contacted the former interns to inquire about their interest in doing an interview.

SDP Organizations. In order to keep the names of the organizations confidential, this thesis will refer to the two American SDP organizations that acted as sources for participants as AES and YDS. The pseudonyms for the two American SDP organizations were created by myself taking identifiable markers of the organization that only resonate with me and creating the appropriate acronyms. The two American SDP organizations serve in developing countries around the world. AES primarily works in countries located in Africa, while YDS works in developing countries located in Africa and Latin America. Both organizations are well established in the field of SDP and have been acknowledged by major media outlets; however, by looking at date of inception, AES has been established and has served longer in the field of SDP compared to YDS. Both organizations use soccer as the vehicle to bring about an educational setting. The international humanitarian issue AES primarily aims to address is number six under the MDG's which is HIV/AIDS education in African countries. YDS focuses on MDG number two which calls for fostering youth development in populations that are underserved in Africa. In their Latin America site, YDS addresses the issue of gender equality for females - which is MDG number three. Through the use of soccer, AES and YDS create a setting where people of all ages, but especially children can come and learn about issues affecting their community and grow as positive people. It was from these two American based SDP organizations that participants for this research were recruited. 
American SDP Interns. A total of 11 former American SDP interns participated in the research. The number of participants used in this study was based on previous research on SDP consisting of interviews (Darnell, 2007, 2010a, 2010b, 2011, 2012b; Hayhurst \& Frisby 2010; Kay, 2009). Even though the numbers of participants in previous research differs, for this thesis I referenced the work of Hayhurst, Wilson, and Frisby (2010) for the minimum number of participants, who had eight participants in their study, while a maximum of twenty-seven participants was determined based on Darnell (2010a). All of the participants were asked to sign a consent form indicating that no information would be used in the thesis that could potentially lead back to them, that there was no compensation for their participation, and that they would be free to not participate in any part of the interviews if they did not feel comfortable. To ensure confidentiality of the participants in this study, I did not use any real names in analysis of the study and instead chose pseudonyms for the participants. The participants had no involvement in their chosen pseudonyms, and I chose them based on identifiers that were only relevant to me. I kept all consent forms and all of the participants' personal information in a folder at my home where I was the only one who had access to the documents.

Out of the 11 interns who were interviewed, five were female and six were male. I attempted to obtain an even female to male ratio; however, due to scheduling conflicts and time constraints, I was unable to interview a sufficient number of former female American SDP interns. All participants of the research characterized themselves as White-American. The goal was not to have all participants be White-American, but the 
former SDP interns that either contacted me or that I contacted, coincidentally all happened to be White-Americans.

The participants all graduated from a four-year university with one participant having an advanced degree. Four of the participants had worked professionally prior to their internship, whereas the other seven had gone into their internships the summer they graduated from a four-year university. Going back to the need for SDP interns to be able to support themselves financially, the participants that were interviewed in this thesis portrayed demographics that exhibited the socio-economic image of an SDP intern. People who are capable of becoming SDP interns, at least shown by this thesis, are White, university educated, and financially stable.

The time the participants interned abroad in the field of SDP ranged from 8 months to 14 months. The year that the interns finished up their tenure in the field of SDP dates as far back as 2008 and most recently 2012. The ages of the participants ranged from 24 years old to 32 years old. The interest that was common among all the participants was that each participant grew up playing soccer or grew up highly interested in the sport and continued to be greatly involved in soccer; among the eleven participants, eight played soccer on their respective university teams, while the other three participants played recreationally. I would like to also note that out of all 11 participants, 10 did not know about the field of SDP before their internship experience. This missing knowledge did not yield any substantial results, but I would like point out that almost all of the participants were more interested in international development work and found their internships in an impromptu manner. 


\section{Procedure}

The methodological procedure used in obtaining the data was a semi-structured interview (Berg, 2004). Semi-structured interviews were adequate because questions were developed in a "Systematic and consistent order, but the interviewers are allowed freedom to digress...to probe far beyond the answers to their prepared standardized questions" (Berg, 2004, p. 81). The ability in a semi-structured interview to ask formal questions in addition to the freedom to branch out if a major theme arises greatly benefited the study. Darnell (2007, 2010a, 2010b) and Giulianotti (2011b) also used semi-structured interviews for their research. Darnell was able to gain valuable insight and data from this methodology because interviews allowed for reflexive thoughts on the part of the interviewees, so I believe it was suitable that I also used it.

Kay (2009) also expressed that qualitative methodology allows for participants of SDP to freely communicate their experiences in the programs and allows for researchers to capture beneficial outcomes of SDP. I constructed the interview guide (Berg, 2004) and then members of the thesis committee who have experience creating interview guides and conducting interviews reviewed it. The guide was specific towards the ideologies and experiences of working as an American SDP intern. In order to conduct these semistructured interviews, I first emailed possible participants to gauge their willingness to be interviewed or was contacted by possibly participants whom were willing to be interviewed for this thesis.

After a total of 14 participants responded to email correspondences, I followed up with the semi-structured interviews. Semi-structured interviews were carried out in 
different ways depending on certain logistics. I was only able to conduct interviews with 11 of the 14 people who responded to my emails because of difficulty scheduling. Inperson interviews were done if a participant lived within an hour of driving distance of me. For the most part, due to time, distance, and monetary constraints (Darnell, 2010a), I conducted interviews over the telephone or via Skype ${ }^{\circledR}$, a video conferencing application. With advances in communication technology, Skype® offers a great opportunity to do interview based research. Berg (2004) refers to a program like Skype ${ }^{\circledR}$ as computer assisted interviewing. Skype ${ }^{\circledR}$ allows for a face-to-face interview without having to physically be in the same place as the subject.

All of the participants were interviewed individually based on times and location that were most convenient for each of them. I considered every participant's feelings regarding how they wanted to do the interview, where they wanted to the interview, and when they wanted to do the interview. Based on location, time, and technology, the interviews were conducted in three different fashions consisting of in-person interviews, via Skype, or over the telephone. Of the 11 interviews that were conducted, two were done in-person, five were done via Skype, and four were done over the telephone.

In attempting to stay within the predetermined timeframe of a one hour interview that was relayed by me to each participant in their recruitment letter, the length of the interviews ranged from a minimum of 48 minutes to a maximum of 64 minutes. One interview was conducted with each participant. All of the interviews were recorded using a Sony IC Digital Recorder. Each interview ended when I asked all of the questions on the interview guide or when I believed data saturation was achieved. I followed the semi- 
structured interview guide in a manner that flowed best with each respected interview and added probes when I felt that a topic being discussed needed more insight. After an interview was completed, I uploaded the interview onto my HP Pavilion dv9000 personal laptop for transcription. All of the interviews were transcribed using the program Express Scribe Pro Version 5.55 and assisted by using a VEC Infinity IN-USB-1 Step Pedal. As interviews were transcribed, I coded (Cote et al., 1993) each interview into relevant themes.

After all interviews were completed, verbatim transcriptions were sent to each interviewee to data check for any discrepancies. The act of allowing participants to review their interviews is known as member checking (Lincoln \& Guba, 1985). Member checking allowed for participants to become more involved in the research in a manner other than their dialogue in the interviews. The act of member checking allowed participants to review their interviews and either elaborate or clarify what they said. I asked for the participants to review their interview transcripts, to either add any information, clarify information, or to request omissions. The participants' active involvement in the research by their dialogue in the interviews and through member checking created a sense of viable data. Upon completion of all the semi-structured interviews, coding (Gratton \& Jones, 2004) and data analysis of the interviews into themes was done.

\section{Data Analysis}

The data analysis process started with transcribing each interview verbatim using a transcription software program, Express Scribe Pro V 5.5. Transcription of the 
interviews was done by me and one other colleague. After all interviews were transcribed, I then coded the data into relevant themes common to all the interviews. Gratton and Jones (2004) define the act of coding data to be "the organization of raw data into conceptual categories" (p. 219). The approach I took in coding the interviews into themed data was based on Cote, Salmela, Baria, and Russell (1993). The steps described by Cote et al. include a coding system that systematically brings out themes from the data by, "creating tags aims to produce a set of concepts which adequately represent the information included in the interview transcripts" (p. 130).

Incorporating steps outlined by Gratton and Jones to Cote et al., I coded the data in a step-by-step process as follows: (1) carefully read the data thoroughly; (2) assign statements relevant to the research question a code; (3) add on other relevant statements to each respected code; (4) look for patterns of relevance in; (5) read through raw data that help detail the coded themes (p. 220-221).

I followed these steps for the data analysis of this thesis. The first thing I did was read all the transcriptions multiple times so I became familiar with each participant's answers. I then highlighted quotes and answers that were relevant to the American SDP internship experience using four different colors. From the highlighted quotes, relevant themes emerged from all of the interviews. Throughout the coding process, I tagged quotes that were common topics of discussion among the interviews, eventually constructing a formation of minor themes. As I highlighted the interviews, I grouped certain quotes into major themed categories with relevant minor themes within each 
major theme. I continued to add quotes from the participants to each theme until I found that there was no more relevant data to add to any of the themes.

\section{Academic Rigor}

The academic rigor of the study is essential in making sure this study contributes to the scholarly literature. Support from colleagues and researchers were gleamed to ensure themes found from the interviews were substantial and consistent throughout all of the interviews. The assistance of colleagues and members of the thesis committee helped ensure the credibility (Lincoln \& Guba, 1985) of the data. Lincoln and Guba (1985) described credibility in research as the concern with the confidence and trustworthiness of the data. In order to establish credibility of data, there were a few approaches that were taken.

The approaches to ensure credibility for this thesis were done through triangulation (Maxwell, 2005) by way of member checking (Lincoln \& Guba, 1985) and peer-debriefing (Lincoln \& Guba, 1985). Triangulation is the act of using many different sources to provide more comprehensive data (Maxwell, 2005) and is done to ensure that there are rich and thick data established in a meaningful manner (Lincoln \& Guba, 1985). Triangulation began with member checking. Member checking assisted in establishing credibility by making sure the data was accurate in the eyes of the participants. After member checking was finished, I involved myself in a session of peer debriefing (Lincoln \& Guba, 1985).

Lincoln and Guba (1985) define peer debriefing as a process where a researcher works with a peer who is established in research and is disinterested in the present study. 
The primary purpose of peer debriefing is to keep the researcher honest and unbiased when it comes to assumptions of analysis on the data (p. 308). I was involved in peer debriefing with a colleague where I was the researcher and they were the debriefer. Peer debriefing, in addition to keeping a reflective journal, provided clear judgment when it came to analysis of the data. The purpose of keeping a reflective journal was to be aware of any potential biases that I may have had and to properly situate myself as a researcher. After each interview was conducted, I reflected on the respective interview, thinking about any biases that arose, and I analyzed how the interview went. As I recalled the interviews, I wrote down any emotions I felt during the interview to acknowledge any biases, as well as any specific topics that came out of each interview and any on the spot analyses.

The capabilities to have more people assist in the data analysis process added to the potency of any major themes derived. This also added to the credibility (Lincoln \& Guba, 2012) of the data. Thorough checking of credibility was performed by Lincoln and Guba's (1985) suggestions of retrieving rich data from the interviews by way of member checking and eliminating researcher biases by peer debriefing and keeping a reflective journal, therefore, establishing credibility to produce academic rigor. 


\section{Chapter 4}

\section{Results}

This thesis provided insight into the experiences of American Sport for Development and Peace interns' program experiences. This chapter will present and discuss the thematic findings from semi-structured interviews with 11 former American SDP interns. I took an inductive approach to code participant interviews into thematically-based categories (Cote et al., 1993), so that the themes indentified throughout the data analysis connected to the premise of this thesis which was an examination of American SDP experiences in the field. Even though the experiences of the participants differed greatly, upon transcription and coding of data, four major themes emerged and within each major theme, subsequent minor themes were found. The major themes found from analysis of the data were cultural expectations, reflective privilege, expansion of the American SDP internship role, and doing something greater. Critical analysis of the interviews showed that within each participant interview, some form of hegemonic processes was portrayed through their SDP internship experiences. This chapter will provide further details of each theme as well as their accompanying minor themes using quotes and examples from participant interviews.

\section{Cultural Expectations}

The most common theme that emerged from the interviews was that of cultural expectations. I acknowledge that culture is a highly likely topic of conversation for people who intern in a foreign country, but included it in my analysis because it was a theme that shaped the experience of all the interns. In the discussion of culture, many 
different elements of the theme were brought up, forming three minor themes related to cultural expectations. Many of the participants acknowledged that they did not know much about the countries in which they were going to intern, leading to difficult situations when implementing programs. They also explained that the overall cultural differences between their host countries and American culture resulted in difficulties dealing with problems that came regarding how programs were taught. The manner in which the participants dealt with their cultural expectations in terms of their initial reactions toward the local culture drew out a two-sided cultural exchange. The cultural exchange pitted American culture against the local culture when it came to program implementation. From discussion of this intersection of American culture into the local culture, hegemony helped explain this overall theme.

The first minor theme in relation to cultural expectations was that of cultural challenges, where many of the participants faced problematic situations, and the progress of their program was slowed as a result. The second minor theme was that of negotiating cultural tensions, which the interns cited as problematic to their program implementation and in the understanding of the culture of the local community. The third minor theme that came about was that of cultural ideas, where participants conversed about how their own personal American ideas as opposed to the ideas of the local community were dealt with in the SDP process. Between the minor themes of culture challenges, negotiating cultural tensions, and cultural ideas, the theme of cultural expectations emerged in a very significant manner from the data analysis. 
Cultural Challenges. The first minor theme that came out of the bigger discussion of culture was that the interns all faced challenges presented by the differences in culture when attempting to implement programs. Challenges due to culture were not unexpected for interns working in a different country; however, it was pertinent to discussion because challenges played an important role in the implementation of SDP programs. Problems arose because the interns not only wanted to bring in new ideas on how to handle certain issues, but also had to respect the local culture. There were many instances where the interns were not given the freedom to implement their SDP programs because the local community was not open to this type of change. Daniel spoke very vividly about his experience of dealing with this cultural challenge, commenting on the difficulty during the beginning stages of his internship in trying to implement a youth center in a culture that was not used to having kids in a place other than school or at home:

It was difficult because we would try to you know respect the cultural differences as much as possible, but to an extent it's almost that the cultural differences were the reasons for, you know, we trying to break the cultural differences. So, trying to you know go up against the idea that kids should be at home doing work all the time. Which, I mean obviously they need it, the culture within the family, they need it there, but we were trying to give the idea that kids were more than just work hands and should be able to go to you know, an after school program, which is a concept that nobody has any idea. The whole idea of a youth center and being somewhere after school as opposed to going straight home and doing work right away, like that concept, just did not make sense to a lot of the locals. (Daniel)

The community in which Daniel interned had never heard of the concept of a youth center before his arrival. A program mission of Daniel's internship was to engage the youth of the local community by giving them an outlet for growth and creativity. Daniel 
believed that establishing a youth center, an American concept, would allow a space for children to be active and creative. However, the idea of having children go to a place after school instead of going home seemed absurd to the local community and was challenged by them, which, as a result, made it hard for Daniel to bring the idea of a youth center to the community. He saw that establishing a youth center, which is an American concept, was the proper way to create a space for youth development. But due to a different view based on an American idea of how children should be living their lives, Daniel experienced pushback from the adults of the community.

The example of Daniel trying to implement a culturally different idea provides insight into how SDP can potentially produce ideological control over a group of people. The youth center was challenged by the local community because it did not fit into the culture. Daniel goes deeper in his experience and the challenge of trying to establish an American idea of a youth center in the community that he was in:

We understand that it's different from your culture, but that this is why were here. We're not here to teach in your school, we're here to have youth center and if the concept of a youth center doesn't exist, we would like to make it exist, you know. It was something that we would always have to kind of say, yeah we get it and you don't do it this way, but in the U.S., we do it this way. Not saying its better, but it's been working for us. (Daniel)

The challenge that Daniel faced during his internship was that the culture did not allow children, when they are not in school, to be at a place other than home. Daniel attempted to build this youth center, but due to the local culture not being receptive to the idea, he had much difficulty in attracting the local youth. The American idea of a youth center as an outlet for children of the local community was very complicated to instill during 
Daniel's tenure abroad. Trying to implement a concept in a community that has never had such a place like a youth center created a high level of difficulty for Daniel's implementation of programs that centered on youth development. Fowler (1991) discussed how NGOs at times challenge local communities by instilling their own ideologies, and, in this case, Daniel challenged the way children lived in his host community. Daniel's attempt at starting a youth center was built on the concept that an American idea would work, but the local community had trouble buying into the idea. The idea of a youth center that Daniel wanted to reproduce in another culture was a process of ideological control (Sage, 1990) that he thought would work within his host community. A process of Americanization (Donnelly, 1996) was initiated by Daniel in his implementation of a youth center because even though the local community was very resistant to the notion, he continued to try to make the youth center work. The local community did resist the youth center, but there was still an unequal balance of ideas between Daniel and the local community. Eventually, it became clear to Daniel that this youth center was not an idea the local community did not accept, therefore, he did not fully reproduce his positive idea of a youth center.

Other participants found that, although cultural differences created a challenging atmosphere that did not allow ease for program implementation, they were undeterred from trying to understand the culture and implement their program. Instead, some participants worked within the cultural boundaries to get their programming started. Ryan had a similar case where culture challenged his attempt to implement an SDP program. In his interview, Ryan shared how he started a soccer training program for 
young girls in a community where the role of young women was very domesticated, and they were not given much freedom to express themselves. Ryan who had experience coaching young girls in the United States was asked by his SDP organization to take initiative and start a girls' soccer program. When Ryan initially started his program, he was faced with much pushback from the local community. Ryan reflected on his experience of trying to start a girl's soccer program in a country where women's rights were not always appreciated:

So, starting a girl's soccer program in a country or in a community that that has a very, very different view of what the women should be doing, with their lives. It was pretty difficult. So, like, getting girls to come to training, and the parents might not want them to go because they think they should be doing housework, and so, like, we might have to go down and talk to a parent to try to explain like, 'Hey' here's what we're doing and it's only like an hour a day, you know it's ok if you can't come every day, we just really want to make sure you know we're a bunch of coaches, we're good people, we're here to help. (Ryan)

Ryan understood that women are treated differently depending on culture and worked his way around this cultural difference to try and get local girls playing soccer. Ryan made sure to be respectful to the cultural outlook of women where he was interning by introducing himself and informing the adults of what he was there to do. He worked around the cultural perception of women in a respectful manner, so that he could implement a girls' soccer program. Rather than letting this cultural gender challenge dictate the implementation of his program, Ryan wanted to show parents that the girls' soccer training program was a positive activity in which they should be allowed to participate. 
The challenge that culture presents in the context of the American SDP internship experience in this study was that many of the interns felt the differences greatly hindered their program implementation. Rachel was an intern who was very aware of the differences and culture and tried to be mindful of the fact. Although Rachel was thoughtful in the cultural challenges presented during her internship, she acknowledged her attempt to do things in the manner that the SDP program wanted. Below is a response given by Rachel when asked about the pushback she received from the local community when trying to bring in certain cultural ideologies not common with the local culture:

There were definitely times in meetings with our coaches when we were trying to figure out how to go about things and they'd be like, no, we don't do it like that here, that's not the way we do it. And so we would have to kind of be like, well, what if we just tried it or think about it and be like maybe this isn't going to work here right now. Or this, there was definitely a lot of trial and error. There was a lot of conversation, communication, and a lot of times we had to try it differently or not try it all and, so yeah it was definitely challenging to balance. (Rachel)

In Rachel's experience as an SDP intern, she would bring in certain ideas that she felt would work in implementing a program; however, the local coaches would comment that those ideas did not coincide with how things worked in the local community. The challenge that Rachel encountered was that her thoughts on how to implement a program were not considered pertinent by the local coaches. Rachel would try to incorporate a new way of going about programming when she and the coaches were meeting, but it never seemed to go in her favor. The notion that Rachel wanted to bring in a different way of programming indicates a degree of ideological or cultural influence between 
American culture and local culture. The recommendations that Rachel would try to make to the local coaches represent the concept of ideological influence that Fowler (1991) and Kidd (1991) discuss in their theoretical implications of Americanization.

Negotiating Cultural Tension. In relation to the overall theme of cultural expectations, the manner in which the participants of this study negotiated the cultural tensions they experienced during their internships was a commonly occurring theme among all interviews. Although the cultural differences created a sense of difficulty, they did not discourage any of the participants; instead, what is important is how the participants dealt with the cultural differences. The difference in culture played a huge role in the overall experience of many of the participants in this study. Many of the participants saw the difference in culture as difficult and a hindrance in the implementation of their programs. The only contrast among the participants' negotiation of cultural tension was in the internal or external expression of their feelings towards the culture of the communities each respectively interned in. The main reason there was a difference in how the participants negotiated cultural tensions was gender. It became apparent throughout the interviews that between the five female participants and the six male participants, the female participants had a harder time negotiating the cultural tensions. Due to their gender, the female participants were treated differently than the male participants, causing them to handle cultural situations differently. Also, some of the female participants expressed that the local culture's perception on gender became very pressing throughout their program implementation. Therefore, within their SDP 
internship experience, the female participants were conflicted on how to approach the differences in culture.

Elizabeth had a troublesome time implementing the SDP program she was working on due to the cultural differences that the local community brought into her programming. She was very vocal regarding her experience of dealing with the culture of the community she was in. Elizabeth spoke of her negotiation of cultural tensions by stating that she was there to help bring a change, but to also wanted to remain respectful to the culture of the local community:

But it's a different culture and I think that was our biggest thing that we got a lot of times, like, you guys don't know how it goes here. Which we didn't and we were trying to learn, of course, but also to find out how to be respectful and let them know that we were here for change. (Elizabeth)

Due to the differences in cultural ideals, between what she and her co-interns thought was right and what the local community thought was right, Elizabeth found it difficult to implement her organizational programs without being disrespectful to the local culture. She was aware of the cultural differences and tried to be respectful when taking into consideration the way local people live their lives. Elizabeth wanted to understand the culture, but then the attempt to understand the culture created a problem within itself. What we see in Elizabeth's case is how she had difficulty in negotiating her conflict with the culture because she did not want to change it, but saw it as a factor that made implementing an SDP program difficult. Elizabeth believed that she was there to implement a program that would bring about positive change by creating space for youth development while also being respectful to the culture. Interns who are coming to a lessdeveloped country affected by poverty, disease, and other humanitarian issues want to 
make a change, but the culture does not allow for that change to occur easily; therefore, they have to attempt to make this change while portraying a level of appreciation for the culture. One can see the difficulty for an SDP intern to be able to both implement their own programs and take into consideration the local culture.

Throughout all of the interviews, negotiating cultural tensions was done in different manners. Some interns were respectful and tried to comprehend the local culture during their internship. On the other hand, there were interns who felt very strongly that cultural differences and practices in the local community were wrong and spoke out when needed. The manner in which the participants dealt with cultural tensions began with how they wanted their own personal cultural ideologies to be portrayed to the culture of the local community. It became apparent throughout the interviews that there was a constant struggle of whose voice needed to be heard when the conversation of dealing with culture came about. Where consideration of the local culture did occur, it still occurred as an afterthought of American culture.

Some of the cultural differences did not make it easy for some of the participants in this research, especially the female interns, who were in very misogynistic societies. As stated previously, the female participants struggled when it came to handling situations that were influenced by the local culture. Just being a female in a culture that had different gender relations greatly impacted the SDP internship experience for five of the participants. Rachel reflected on her treatment as a woman, feelings about the feminist culture in her host country, and how she had to take a step back re-evaluate her feelings in order to implement a girls' soccer program. 
So, I definitely had to sacrifice, like, 'Why, wait, I could do it,' you know, why wouldn't he listen to me to be like, okay it's not about that, it's about this culture. Your agenda is not about you promoting your rights as women, it's about you giving space to these girls to play soccer, so it was kind of like re-categorizing my, you know, my personal beliefs and how I should be treated or how, you know, my other fellow female interns should be treated and just kind of really focus on the mission on hand. (Rachel)

Even though Rachel was treated differently because she was female, she understood that the culture was the way it was, and it was not her place to question the culture; rather, it was more important for her to implement a girls' soccer program that will alleviate gender inequality. Rachel's descriptive insight into her thought process when experiencing subjective treatment based on her gender gives hope that SDP interns can negotiate this cultural tension. The experience Rachel elaborated on caused her to initially put her cultural beliefs first. Similar to the experience Elizabeth shared, Rachel was conflicted about which culture she wanted to put first: her American culture on gender equality or the gender disparity in the community she was interning in. Instead of applying her own cultural idea of gender equality, Rachel instead put the focus on helping the culture battle this gender inequality discourse.

Amanda was another female participant that dealt with culturally gendered ideas. However, unlike Rachel, Amanda negotiated the cultural tensions in a less calm manner. When discussing her experience dealing with the culture and way of life in her host country, Amanda, was understanding of the culture, but was still conflicted in what she experienced, as the culture of the local community was so different from her American lifestyle. As a result, Amanda was shocked by the sort of gendered behavior that she saw during her internship experience. 
But I mean it's also completely cultural, you know what I mean? Like a lot the stuff we preach is based off of American values that were trying to adapt because they are in my opinion correct. Like you shouldn't be with someone who is still in high school if you're a grown up. Right. Like we know that. And that's so common there that at first I was like what do you mean you're dating a 16 year old? You're 25! But I got very desensitized after a while, because that's, I mean, that's what happens. (Amanda)

Amanda went on to further describe a situation where she had to reprimand a local staff member that she had become close with because he was abusive towards his girlfriend and felt no remorse for his actions due to the prevalence of domestic violence in the country. The scenario of the event that occurred as depicted by Amanda was:

I was helping him and giving him advice like any friend would give anyone advice and one time he told me, 'I got so mad at her I kicked her'. And I was like Are you fucking kidding me? You did what? And he was like 'what's the problem, what do you mean? I was frustrated she tried to take my baby away from me, so I kicked her.' And I freaked out screamed at him, caught him completely off guard, because he assumed that since we had been talking about this I'd be totally fine, kind of, with him telling me the rest of the story. (Amanda)

Amanda had expressed that the issue of domestic violence was common in her host country. Hearing that a local colleague she worked with hit his partner forced Amanda to speak up about how she felt about domestic violence and to scold him. The culture in relation to gender is very different, but Amanda did not want to recognize that difference; instead, she felt that even though it is a different culture, it is still not right to hit a woman. Rather than really trying to understand how domestic violence works in her host country and why it is looked at as unproblematic, Amanda instead lashed out on the 
concept of domestic violence. Amanda felt that it was important to break down cultural differences on issues that she felt very passionate about, such as domestic violence.

Like hitting a woman. And I made sure people knew how I felt about that kind of stuff. And they would say it's cultural. And I would say that shit is not cultural. That is wrong. You don't hit women. You know what I mean? (Amanda)

Cultural differences between the interns and the people from the communities where they were stationed created a huge dilemma. Unlike Elizabeth and Rachel, Amanda was very outspoken about how she dealt with the culture of her local community. Instead of trying to understand how and why domestic violence was apparent in the culture, Amanda immediately expressed her disapproval of domestic violence. Amanda was very adamant that there is no culture or circumstance where domestic violence should be allowed. The way that Amanda negotiated this very tensionfilled cultural situation was by articulating what she believed to be right without any consideration to how the local culture deals with domestic violence. Amanda's livid condemnation of domestic violence and ideas about gender equality were more important in this situation, and she felt it needed to be expressed.

All of the interns expressed the difficulties they experienced because of the differences in culture; however, it seemed as though that did not deter them from attempting to address an international humanitarian issue, whether it was gender equality, HIV/AIDS prevention, or youth development. One participant expressed that, rather than looking at cultural differences as an inhibiting factor of program implementation, it is better to use those differences to complement each other in the SDP process. As Natalie 
stated, her experience in dealing with the difference in culture was more about bringing cultural differences together and working to use both cultures in programming:

I think that one thing I think that at the best of the peace building in sport for development interns is that local staff and international staff bring different things to the table sometimes and that's not always true. But I feel that you can't replace the local knowledge; you can't replace the language...I don't think you can replace so much of what local staff brings in terms of context knowledge, relationships, and things like that, but what I see is kind of the best of - I mean normally American interns that I encountered is that they can learn from that local knowledge and kind of hopefully use the knowledge to transfer themselves. (Natalie)

By bringing two sets of ideas and cultures together, Natalie believed that the program she was helping to implement would improve. The way that Natalie handled cultural differences was by infusing both cultures together in an attempt to produce the best way to implement programs. What is interesting to take from Natalie's negotiation of culture was that instead of fully immersing herself and her program implementation through the culture of the local community, she believed it would be best practice to include another set of knowledge. This is interesting because there is still focus on bringing in another set of ideas to help bring positive change. From the interviews in this study, it is apparent that the local culture and ideas needed to change, and that change was brought in by the ideas and culture of the American SDP interns.

There was one participant, however, who expressed that SDP interns need to be aware of the cultural differences and be considerate in the way of life. Eric relayed that, how no matter what, when working in an international context, there will always be cultural differences. However, he feels it is not right for an intern to try to change the culture, rather they should embrace it and adapt to it, so the program can become better. 
The point that Eric conveyed during his interview was that SDP interns need to put away their own cultural biases before they commit themselves to work in an international development context:

You have to be open. You have to learn how to adapt to the culture. You have to, you know? It's not - things are going to be different. Your life is going to be different. Even outside of the programs and you shouldn't just say it's better in the US..... They have a different culture. It's not better, it's not worse. It's just different....You go there and you can share your culture, that's fine, but you're supposed to adapt to their culture. (Eric)

Eric was one of the few participants to acknowledge that he negotiated cultural tensions in a way that local culture comes first. As Eric was explaining his thought process, he noted that it is not the job of SDP interns to change the culture; rather, they should help the local community address a certain issue that is affecting their culture. In terms of Eric's experience with handling the cultural tensions between himself and the local community, he understood the importance of putting the local culture first. Eric's experience as an SDP intern was very much focused on putting the local culture first and bringing in his own culture when it was appropriate.

Cultural Ideas. Many of the participants spoke about how American cultural ideas of living conflicted greatly with the local community in which they worked. American ideas became problematic, especially as the participants tried to intertwine their American ideologies into their programming, or in their SDP experience in general. This minor theme relates to Wright (2012), who said that people who come from a developed nation like America are automatically given a sense of power and knowledge that is reflected. The participants saw that American ideas were not applicable or made it 
difficult when implementing programs that would benefit the community. It was commonly expressed throughout the interviews that interns felt that American ideas of youth development or HIV/AIDS education could work if allowed by the local community; however, the culture of the community did not always allow for that to happen. Analysis of the interviews within this minor theme of cultural ideas provided instances of hegemonic discourse (Bates, 1975; Sage, 1990) with the SDP internship context. The American ideas displayed by the participants through their experiences exhibited a source of ideological hegemony. By the participants bringing out and interweaving their American ideas on certain topics, they unintentionally put their own ideas before those of the local cultures.

Natalie brought up how American perspectives on certain issues were difficult to disregard because it was so common for her to hear that HIV/AIDS is an issue and that it is important to try and prevent it, but it was not necessarily the same in the local perspective. In her case, Natalie spoke about how even though there is a common American idea, such as HIV/AIDS prevention, it does not mean that it is the same case around the world. Natalie's example of how HIV/AIDS education is in her host country shows that not every country in the world has cultural ease in discussing the issue. Below, Natalie explained how Americans can be blinded by certain issues, like HIV/AIDS, plaguing a less-developed country because it is not as an extreme a pressing issue in America:

I think coming from an American perspective it's very easy to be like, 'I don't understand why you wouldn't avoid HIV. Like, I wouldn't understand why it would be that hard for you to avoid HIV?' Whereas I 
think that local implementers see every day the pressures that the people have on them and can identify. (Natalie)

It is a common American-taught lesson to try and avoid HIV/AIDS since there is an established health education system on the topic; however, in the country where Natalie was interning, the ideas about HIV/AIDS differed from her American upbringing. Interns bringing in their own pre-conceived ideas about an issue will possibly face a dilemma in programming. Natalie understanding that HIV/AIDS is an issue and needs to be prevented was very common, but that is due to her American cultural ideas about the issue. She had never experienced HIV/AIDS in a different culture and did not know how her host country approached the issue. Therefore, in Natalie's experience, she eventually realized that difference in the American approach towards HIV/AIDS. The integration of American ideas into SDP program implementation can create ideological biases in the form of SDP interns not understanding why a certain culture does not approach an issue in the same manner. As Natalie stated in her interview, having an American perspective can cause someone to question the local culture.

Rachel also acknowledged that American ideas differed from those where she interned. Rachel's program in her host country was centered on providing a space for young female empowerment by playing soccer. When Rachel first started to implement a girls' soccer program, it became very apparent the way she learned to value soccer was not applicable in her host community because the resources she had in America as a female soccer player were not present for the young girls of the host country. What Rachel learned to value from her American upbringing playing soccer was not transferrable to the young girls she was working with in her program implementation. In 
Rachel's interview, she spoke of how an American idea, of hard work in order to reach high levels of sport, was not the same in her host country:

I guess the culture of working hard in America and that striving because you have the opportunity to play in college, to play professional. You have these avenues. There, you don't have those outlets, so it's hard to push girls the same way that you were pushed knowing that that final goal or that goal to strive for anyway doesn't exactly exist in terms of logistics and, you know, availability. (Rachel)

Rachel's experience playing soccer in America throughout her entire life taught her that if she worked hard, she could play collegiate soccer and had those avenues provided to her through soccer. In relation to Darnell (2012b), Rachel's experience of hard work in sport reproduced an ideology that she learned in America, but was an idea that could not be reproduced in her local culture. Instead, the girls of the local community should be given the opportunity to develop their own idea of what hard work is through sport and where hard work in sport can lead them. Hard work in soccer could also be seen as an idea of meritocracy (Darnell, 2010a) because of how Rachel suggests that hard work can potentially lead a person to upward mobility. This idea of hard work and being able to play collegiate soccer that Rachel tried to push on her girls did not resonate with them.

The teachings that Rachel experienced were not transferrable in her program implementation because young girls playing college soccer in her host country was unheard of. For Rachel to apply the American idea of hard work in sport to her programs created a sense of Americanization (Donnelly, 1996; Houlihan, 1994) because it would mean she would be attempting to change the locals' ideas about sport. "Working hard" and "That goal to strive for" that Rachel spoke of is an American idea that she learned. For her to bring those ideas into program implementation created 
ideological hegemony (Sage, 1990) by way of American influence by defining sport as a place of mobility. Rachel's experiences as a young girl playing soccer in America afforded her many avenues, but for her to teach the young girls in her host country using that mindset indicates a level of Americanization (Kidd, 1991) where the young girls should be allowed to create their own ideas and meaning of soccer. In relation to the prior minor theme, Rachel was able to negotiate and recognize this tension between her sporting experiences and how she wanted to coach the young girls of the community, which resulted in Rachel having to try different ways to engage young girls in her programming.

Throughout the interviews, many of the participants expressed how their American way of doing things never seemed to fit in with their program implementation or local community. Amanda expressed that a fast-paced and efficient way of American work ethic was not necessarily appropriate for the program work that she was in; instead, Amanda revealed that it might be more helpful to take a step back and go with the flow:

A lot of issues come when, like, were really - like, Americans are like super efficient and work really hard, especially unpaid interns that want to do the best, but sometimes kind of like going with the flow and taking a back seat and can be more helpful than rewriting the entire system and I'm speaking - I'm being very vague, but I think that's a huge problem that a lot of interns have they're trying to do too much instead of just being there to help. (Amanda)

Amanda felt that an American work ethic at times was not appropriate for the setting she was in. Her outlook on how some American SDP interns approach their internship with a strong American work ethic provides insight to how interns can get lost in the work 
resulting in a lack of acknowledgement of their progress. Amanda saw some other interns doing their best, but their best could have been a huge problem.

The idea of hard work and pushing one's self that is represented in American culture as expressed by Rachel and Amanda is not evident in other cultures. The host countries that Rachel and Amanda were placed in possibly have different meanings for the concept of hard work that is applicable specifically to their local culture. Therefore, to bring in American ideas of hard work that is specific to American sport into another culture there was much contrast on the idea. To apply that sort of work ethic and mindset in a culture that does not appreciate that sort of idea brings into discussion how one set of cultural ideas are not easily reproducible in other cultures.

Pre-conceived American ideas were brought into their internships by the participants of this study. Whether it was American perception of HIV/AIDS or an American idea of working hard, these ideas came out of the analysis of the interviews and gives way to discussion of Americanization. It may have not been the intention of the participants to do so, but their ignorance of their personal ideas allows for an Americanization discourse.

As a discussion of American ideologies came up across multiple interviews, I decided to ask a participant how he felt American ideas intertwined with SDP. Aaron responded by saying that just because organizations push ideologies that are "scientifically backed," it does not mean that those ideas are right and should be placed onto a different culture. Aaron's answer supported this notion:

I think that there are many organizations that try to push their ideologies and even if those ideologies are scientifically backed, like, for example, 
condom use. That just pushing ideologies on people is not going to solve any of the problems. (Aaron)

Aaron's opinion on how ideologies are brought into the field of SDP indicate that just because a person has an idea of how things work, it does not give them the right to try and push those ideas onto a community that does things differently. During Aaron's interview, he articulated that he does not think that organizations should come and try to implement programs based on their own ideologies. From Aaron's experience, he shared that SDP interns should go and do the work in itself without bringing their own ideologies. SDP organizations or SDP interns who come with their own ideologies that they want to place on the local community are prime examples of portrayals of hegemonic control (Bates, 1975).

An interesting example of a cultural idea that was represented by a participant's SDP experience was conveyed by Elizabeth. Elizabeth saw from one of her co-interns that a Western capitalistic mindset was not transferrable when working in the field of SDP. As stated in the literature review, the process of Americanization is supported by a hegemonic capitalistic market (Kidd, 1991). The idea of Americanization surfaced when Elizabeth spoke about how the idea of people in America working for what they have is not relevant in the culture that she was in, and programs could not be implemented by interns who have that mind frame. Below is the detailed elaboration given by Elizabeth on her feelings towards those who work in SDP with a capitalistic mind frame where people work for what they get socially and economically:

I saw one of the other girls has sort of a business mind, that you work for what you get which for me doesn't really translate into this sort of setting That is a very White, or a very Western idea, concept that you work for 
what you get and so I'm sure I felt that White guilt and sort of had a difficulty separating myself from that in that I know that I don't have much but in comparison, it's just huge differences and so you do what you, can but just try to, try to establish that like, this isn't the norm. (Elizabeth)

The United States has influenced many other nations to follow the same economic capitalistic model that it has established (Donnelly, 1996). Despite the fact, as illustrated by Elizabeth, that capitalism has yet to reach all regions of the world, especially those in which SDP works. Elizabeth recognized, by watching her fellow intern, that the Western idea of capitalism did not translate into her SDP environment. Elizabeth's co-intern bringing a capitalistic mindset into their SDP internship experience implies a process of Americanization in which the theory of hegemony is clear because she unknowingly wove capitalism into the SDP experience. The application of capitalism within the SDP context gives way to a broader socio-political implication (Darnell, 2012b). For Elizabeth to imply a capitalistic work ethic gives room to a reproduction of a Northern and Western idea of economics. As Darnell (2012b) suggests in his book, it is this capitalistic model that undermines local cultures while promoting Western ideas.

SDP interns who bring in capitalistic ideologies can possibly be promoting and reproducing a political and economic structure within local communities. It is more than likely that Elizabeth's co-intern was unaware of the capitalistic ideology that she was portraying, but in the description of hegemony provided by Bates (1975), she was also controlled by capitalistic ideologies which resulted in her portraying capitalistic ideologies while she was an SDP intern. A very important finding from Elizabeth's example of cultural ideas is that American SDP interns are unlikely to be aware of their 
hegemonic dominance, which can possibly lead to problematic situations as interns implement programs.

One other interesting point from Elizabeth's experience dealing with cultural ideas that is associated with the hegemonic theory is her reference to a "White guilt" that she felt during her SDP internship. This "White guilt" that Elizabeth talked about represents her acknowledgement that she was wealthier, both materially and in opportunity than the people of the local community. Similar to Darnell (2011), Elizabeth's recognition of her own guilt created a space for Elizabeth to recognize the privilege of what she had compared to the people of the local community. Elizabeth recognized her privilege manifested from her acknowledgement of how an American economic idea of capitalism did not resonate in her host country.

To further support this point, Elizabeth provided her experience of how an American idea of making money is not always seen in the same manner in other countries:

I mean the experience really spoke to the human condition that people are so resilient and do what they need to do to get to a goal. So in America, it's blown up to an extreme. Right? I got to make the most money and do what I got to do, however. Whereas in the countries, or the countries we were, in (Country), it's you know, maybe the goal is to make money to have dinner for that night which a lot of times wasn't achievable so it's the most humbling experience to look back on. (Elizabeth)

When referring back to the hegemonic theory (Bates, 1975), the participants coming into their internship with their own preconceived ideas established a sense of bias because they intended to use those American ideas in their SDP program implementation. The ideas that these American SDP interns came in with were very different to what local 
communities were used to, and as a result, some of the participants had trouble implementing programs or getting their point across to the population they were serving. The participants of this study thought that implementing American ideas would help alleviate issues; however, in most cases, bringing in American ideas was unsuccessful. The attempt of some of the interns to intertwine American ideas into their program implementation illustrated how some of the participants came into their internship with their own personal ideologies. The integration of American ideas into their SDP experience represents the hegemonic theory because of the influence their American ideas had. In terms of American ideas, control and power could be seen because of how some of the interns came in with some pre-conceived ideas from their American upbringing. Throughout the complex relationship between American culture and local culture, an emergence of which culture's ideas should be recognized in the SDP program process emerged as a critical discussion.

In all of the interviews, culture was expressed as being difficult to deal with, but all of the interns said that it was very important to consider the local culture before any decisions were made. The difference between American culture and the culture of the local communities was very evident in the interviews. Even though it was a problem for all participants to overcome, all of the participants accepted the differences in culture and effectively worked their programming in a manner that best suited the local community and the effectiveness of their programming. The point that was clear among many of the participants was that cultural challenges were present and could not be avoided, but the manner in which the participants negotiated these cultural tensions was important. 
The participants all discussed how culture plays an important role in shaping the SDP internship experience. In regards to cultural hegemony (Donnelly, 1996), there was frustration in the challenges that arose from cultural differences, but there was no direct attempt to take over local culture. Instead what was shown through the experiences of the participants was their subtle attempt to weave in their own ideas into program implementation. Culture also played a role in how American ideas were taken into consideration when programming occurred. For the former American SDP interns who participated in this research, culture was more than just a lifestyle that they encountered. Instead, culture incorporated ideas on how to address issues at hand, treatment of women and children, and an over-encompassing different way of life. For the interns not to acknowledge their experiences as they relates to cultural expectations could possibly mean that they were not cognizant of the problems that occurred during their internship. The interns indicating the influence culture had on their internship experience shows that, in the field of SDP, culture needs to be recognized by all actors.

\section{Reflexive Privilege}

Another major theme formed through analysis of the interviews was reflective privilege. This theme is similar in comparison to Darnell (2011), who found in his research that Canadian SDP volunteers experienced a level of "First World Guilt" when looking back on their SDP internship experiences. First World Guilt as discussed by Darnell (2011) represents that the opportunity for people to be SDP interns is only open to those who are socially and economically able. 
In attempting to apply the hegemonic theory in analysis of the data, this theme of reflective privilege provided substantial data regarding how the theory resonates in the American SDP internship experience. The hegemonic theory can be most applied in this theme to how the participants expressed that the ability to be an SDP intern is solely based on who is able to financially support themselves and how their lives dramatically changed from their SDP internship experience. The privilege that the participants came to recognize stemmed from their ability to be SDP interns and how being an SDP intern changed their lives.

As a result, the minor themes under reflective privilege that I formulated for this thesis were SDP internship privilege and change at home. The minor theme of SDP internship privilege details how the participants of this study had to financially support themselves during their time abroad. Change at home refers to the critical reflection the participants had on their internship when looking back on their experiences and how their lives now in the U.S. have been greatly affected. The result of reflective privilege as a theme will be discussed in the following sections at length.

SDP Internship Privilege. The participants' reflections on their SDP internship privilege elaborates on the ability that SDP interns have to acquiring the adequate funds to support themselves while they are abroad. To start off this discussion on the privilege of being an SDP, I would like to bring to attention how being an SDP intern is actually a privilege in itself. Many SDP organizations do not pay their interns any sort of compensation while they are abroad. As a result, applicants who are accepted as interns for an SDP organization must individually obtain a sufficient amount of money to 
support themselves for how ever long they intend to be an intern. Both of the organizations that were sources of participants for this thesis require their interns to support themselves abroad, which means that participants were required to either work or fundraise for their finances. In order to raise the money needed, some participants spoke of how they solicited people for help, had parents that were financially able to help, personally fundraised, and even used their own personal savings to support their internship. A broad range of answers were given when I asked about this process in achieving financial stability; some participants had ease in obtaining the financial assistance, while other participants had a more difficult time doing so. Interns having to be able to financially independent is an important element of the SDP field because it sheds light on who qualifies to be an SDP intern based on socio-economic background. Analyses of the interviews showed that participants, for the most part, came from a higher socio-economic background that allowed them to gather the financial means from different sources. The amount of money each participant devoted towards their SDP internship differed. When asked why some people cannot be interns, Taylor responded with this extensive reply that expanded on how some people are afforded a privilege to become SDP interns:

You know not a lot of people have the being fortunate enough to take time off of school. Some people don't have college debt. Others who tend to have more college debt might decide they need to pay that off sooner than later. Most are forced to do so and dedicate X period amount of time, so, you know, I think that has a huge effect on people because there isn't enough time for them to have what I could call free time as opposed to what work would offer them and benefit them, so I think the way that socioeconomically if there is a factor. (Taylor) 
All of the participants in this study were required to fund themselves throughout their internship. As Taylor expressed, one reason preventing people from becoming SDP interns is because they are not financially viable. Taylor saw that only people who are fortunate enough to be able to take time off and not have other financial obligations, like college debt, are given the opportunity to be an SDP intern. None of the participants in this study had to worry about any other financial obligations in their lives, allowing them to focus solely on raising money specifically for their SDP internship.

The privilege shown by the participants in this study indicates that only certain groups of people that come from financially stable backgrounds are able to be SDP interns. As Darnell (2011) found in his study on Canadian SDP interns, those who came from affluent backgrounds were provided with the privilege to volunteer abroad. In this study, the participants showed that they had the time and the financial support that allowed them to be SDP interns. The recognition the participants had of their social ability to be SDP interns confirms the notion that only those that are financially able can be SDP interns (Darnell, 2011). People who come from lower socio-economic backgrounds may not have the network or financial backing to be SDP interns, which in turn, decreases the selection pool of qualified candidates. What becomes evident in having only economically-dominant groups of American SDP interns serving abroad is that it allows for only one group of people to intern, while people from other economic groups are left out of the American SDP experience. It is a challenge to raise money and not everyone is given the same opportunity to have the money needed to be an SDP intern. 
The participants who reflected on their fundraising indicated different levels of success. For some of the participants, it was easier to gather a sufficient amount of funds because they had the network to do so, while other participants struggled to get enough money for their year-long internship. Eric brought up how he took his SDP internship on short notice and did not have much time to raise the funds to support himself while he was going to be abroad, so instead he invested some of his personal savings to support himself during his internship. Eric's financial self-sufficiency is another example of how being an SDP intern is a privilege. The common notion in the United States is that people work to earn money to support themselves and their family. In the field of SDP, interns are spending their own money to be able to work. The two ideas show the economic privilege required of SDP interns because they are asked to earn money in order to volunteer their time working on an international humanitarian issue.

Some of the other participants spoke about their experience with the funding component of being an SDP intern. Isabelle, for example, said that her network enabled her to easily obtain the necessary funds to be an SDP intern. Ian, on the other hand, had a more difficult time in acquiring the funds for his internship. The difference in both Isabelle's and Ian's fundraising experience can be seen below:

Luckily, I have a great network of people to reach out to who were able to donate on my behalf and I was also very used to asking people for money, because I spent the previous year canvassing for an environmental organization, so actually, hah, it actually worked out pretty easily. (Isabelle)

I mean, I spent a lot of time leading up to it trying to figure out ways to fundraise. A lot of them were not very successful, but that was - like, I was working two jobs just trying to save up some money and then, also trying to do some fundraisers on the side. (Ian) 
The different experiences of fundraising depicted by Isabelle and Ian showed how some people have the privilege to be SDP interns and others struggle. Because money plays a role in the SDP intern selection process, there are potential applicants that are forced to turn away from the opportunity. As stated before, the selection of SDP interns based on this concept of self-reliable funding provides SDP organizations a limited choice from an economically dominant group of people. There may be highly suitable candidates for SDP internship positions, but they may come from less economically viable backgrounds. This excludes a large percentage of capable applicants who can be effective SDP interns. Taylor concludes his sentiment on the privilege of being an SDP intern, saying in his interview:

I think the biggest challenge is fundraising. You know you can have provide a potential, you know, employee or intern or volunteer I should say an X period amount of your time to get that money, but some people don't have the network to get that money in that period of time and if you are, you need between 5-6 thousand dollars to live I would say comfortably in (Country). T hat's unfortunate, you know. That's not cool for someone who may want to do it, who may have a bigger heart than the ones who can afford it. (Taylor)

People who have the money or means of financial assistance are given a privilege compared to those who do not have money when it comes to being an American SDP intern. Darnell (2012b) indicates through his research that SDP interns who come to terms with their social status recognize that they are given a privilege because they are able to be SDP interns. However, there are still people who do not have the privilege and luxury to be SDP interns. As a result, there are people left out of the SDP internship experience. SDP organizations' having the criterion of interns financially supporting 
themselves implies hegemony because only certain groups of people are able to SDP interns. Money can be seen as a hegemonic privilege in the context of American SDP interns because not everyone has the opportunity to raise the money needed or have their own money to use. In terms of how time can be seen as a hegemonic privilege, there may be people who do not have the time in their life to volunteer due to the fact that they use their time to work. Once again like those with financial freedom, the people with free time control the SDP internship position. As a result, those groups that do not have the money or the free time needed to be SDP interns are essentially excluded from the overall American SDP internship process.

Change at Home. In other discussions of privilege, many of the participants discussed how their ideas and thoughts about their lives in America drastically changed after their internship experience. Due to their experiences as SDP interns in lessdeveloped countries, many of the participants came home with a different mindset about their lives in America. From their experiences, many participants were greatly changed, and made cognizant about how their lives in the U.S. differed to what they experienced in their host country. The realization that many of the participants had privileged lives at home was created through their SDP internship experience. These realizations were subjective to each participant, but indicate how SDP interns take into account their own personal change. Being able to come to terms with how good their lives are allowed the participants to distance themselves from what they saw during their internship. Eric was very emotional when discussing his newfound way of thinking about life. Eric felt that his SDP internship experience took him back to what life was really about: 
It really allowed me to, kind of, go back to reality. Okay, like, you tend to live and kind of start thinking that you need all these materials. Think things like that you need to get a bigger TV and going back there it was like, you go back there in Africa - it was (Country) so it was not as rough as like some other countries, but still it was like, you know, back down to the basics. We were staying next to (Community). (Eric)

Eric came home to a realization that, although he had a lot in America, he did not need everything he had and only needed basic things in life. Eric went on to comment that his internship experience taught him to live with only the basic necessities and how he does not need a nice car, only one that is functional, in addition to a few personal items like a laptop and a few articles of clothing. For Eric, having the experience of living in a country where poverty is extreme allowed him to realize what he really needed in his life. Eric's description of not needing materialistic commodities was also found by Darnell (2012b) who saw in his data analysis that some Canadian SDP interns portrayed a First World privilege by the change they experienced form their SDP internship experience. Darnell stated that those who experience international development and then change by recognizing their own privilege back in their home country produce First World guilt.

When Rachel returned to the United States after her internship, she was very aware of the privilege she has in America. In her mind, it is what people do with that privilege that is important. Rachel expressed that America is where she comes from and that it is not necessarily negative that she has any sort of privilege. Instead, what is crucial is how she uses her privilege to better the world. Rachel explained her feelings by saying: 
Initially when I got to back to the U.S., I was like why are we driving? We should walk. Why would I buy that? It's too expensive, you know? As anyone probably does in reverse culture shock. But then you get to see that's the privilege I have and that's where I come from. It's not necessarily bad. It's how I file it way in my perspective and my memory and what I can do to make it positive and be a responsible citizen and helpful citizen and used what I've learned and shared what I've learned. (Rachel)

Rachel understood that she has a certain level of privilege, but just because someone has privilege does not mean they are better or worse; rather, it is just something they have. Rachel's reflection on her privilege was about how to use that privilege to educate others around her. Amanda had a more a descriptive illustration of how she saw her privilege in America. Amanda's experience from her SDP internship taught her to have an attitude that things are far worse in other parts of the world, so for her to worry about any troubling situations she encounters in America would be ignorant:

There's a level in (Country), where people - everyone's living in shacks and that it changes your whole perspective on a lot of things and that for one thing and I always use that example when I tell my friends about it. If you were like trying to catch a plane and you missed it, like, when you miss it, it feels like the worse thing in the world. But what I've done post (Country) or if you drop your cell phone in the toilet or something it feels like the world ended and you don't know what to do. But post (Country) every time shit like that happens I literally say, 'what's the worse that could happen?' in this situation. (Amanda)

What Amanda was able to see and experience in her internship taught her not to worry about the worst that could happen in her life, because the worst that could happen in her life is nothing compared to the worst that could happen in her host country. This reflective privilege that Amanda depicted in her interview provides deep insight into how she looks at her life now because of her internship experience. The privilege in Amanda's case is that the struggles she encounters in her life, whether they are big or 
small, will never compare to the struggles of the people she interacted with during her internship. Amanda's experience is similar to what Darnell (2010a, 2012b) found with Canadian SDP interns in that some interns confront and intrinsically notice their First World privilege. He also saw from his participants that their First World guilt was based on realizing their ability to "have" more than compared to their host countries (Darnell, 2012b). In Amanda's quote, she explains that her life in America is far better than what she experienced abroad and she was able to be more aware of that because of her internship experience.

In relation to Amanda, Taylor saw his life change in America as it pertained to not worrying about the small things and being considerate to various aspects of his life that he previously had ignored. When discussing his thoughtful perspective on his life back home, Taylor brought up how, after his internship, he cared less about his living conditions because he saw how people lived in his host country:

You see a lot of things in your house really, you're living with other creatures in your house in (Country) and here it totally doesn't bother me, so like that's one thing that kind of bothers me. People kind of don't really know what other people's living conditions are like and it's you know, you don’t know need to shit a brick over something small. (Taylor)

Taylor came to realize that there are graver conditions in other countries, and that people should be aware of the ways others live before complaining about their own situations. This reflexive privilege indicates a concept similar to that of Darnell's (2011), whose studies show that interns who come to appreciate their own privilege indicated a level of hegemonic ideology. The participants who reflected on their lives back in America and compared them to their lives during their SDP internship implied a reflexive privilege. In 
following the analysis of previous research, the reflexive privilege indicates a level of hegemony. Hegemony is pertinent to the participants' reflexive privilege because they recognized how affluent their lives are in America, and that is why they were able to be SDP interns.

The privilege of being an SDP intern and the change at home that the participants felt create a reflection of their privilege that was present among many of the interviews. This theme of reflexive privilege was the most consistent within the hegemonic theory framework, in that it portrayed instances of ideological power. The hegemonic concepts that emerged from the participants' reflection on their own personal privilege were discussed from their ability to be an SDP intern and how the SDP internship changed them. In terms of being an American SDP intern, many of the participants spoke to how they had to financially support their time abroad because they were not getting paid. The hegemony in this case is that only certain groups that have money and the free time are allowed to be SDP interns. For people who come from economic groups that are not privileged financially or do not have the free time to volunteer their services are consequently disregarded from the American SDP experience.

The critical reflection on some of the participants' own privilege also provided deep insight into how their lives in the U.S. either changed due to their internship experience or allowed the interns to become more aware of their privileged lives in America. Due to their SDP internship experience the participants in this study became aware of the privilege they had being an intern and as an American. The participants exuded hegemonic attitudes through their reflexive privilege because of what the SDP 
internship taught them, such as the realization of their social-economic status back home in America. It became apparent through their personal reflection that the SDP internship became a learning experience for the participants even though they were there to help the local communities. The hegemonic problem that arises here is who is learning what and who is able to learn. From the data analysis of the interviews, only Americans who were financially able to be SDP interns were learning and changing. This theme was similar to Darnell's $(2011,2012 b)$ which found that Canadian SDP interns also felt an emotional privilege when reflecting about their SDP experiences.

\section{Expanding the American SDP Internship Role}

Most of the participants also recounted stories that took them beyond their internship duties, both on a professional level and personal level. Participants had stories that detailed what they did beyond the duties of their SDP internship, and, interestingly enough, the reasons why they went beyond the scope of their internship job description. When it came to their professional role as an intern, many of the participants saw that they did many things not directly involved in their role as an intern. On a personal level, participants established relationships outside of the internship realm that created a lasting impact. For the most part, many of the participants explained they expanded on their SDP internship role because they wanted to bring a significant change to their local communities. This theme describes how the participants expanded on the American SDP internship role in order to bring about a change in the communities in which they were working. In an attempt to critically analyze the American SDP internship experience, I applied the process of Americanization and the theory of hegemony to help explain this 
theme. The hegemonic theory explained this theme by allowing more insight to how and why the participants expanded on their SDP internship role. The three minor themes drawn from the major theme of expanding the American SDP internship role were: promoting organizational goals, social relationships, and understanding the purpose. Examples of the three minor themes are given in the following sections.

Promoting Organizational Goals. The minor theme of promoting organizational goals was determined after many of the participants felt that during their internships, they had to do more or were put in positions in order to promote the organizational goals of the SDP organization for which they interned. The participants felt strongly that in order to have an effective program that would reach a wide population, they had to run programs and activities that stretched further than their assigned internship duties. Participants who talked about how their SDP internship role expanded displayed various forms of hegemony in relation to ideas and power relationships. I found within most of the interviews that the participants had experiences that took them outside of their role normal role as an SDP intern for many different reasons. Ryan put it ever so eloquently that he felt the need to do more was due to the work he and his fellow interns were doing in the community, and he believed that it was necessary for him and his colleagues to do more than what they were assigned in order to better the community. He believed that in order to have a successful SDP program, interns needed to do things that went beyond their internship duties to achieve their goal of youth development:

I think that's like something you have to do be if your goal is to be moving your mission forward and trying to create something sustainable, there's 
so much work that goes into that. You can't just say I'm only here to do this, I'm only here to do that, because you're not going to get everything done that you want to get accomplished. There's a lot of stuff that I think indirectly are made big impacts, so we never anticipated going out and doing like, you know, we did remote training for different coaches like around (Country) that we had - that contacted us and said, 'Hey we saw you guys coaching in (Name of community) we heard of you, we heard of YDS, can you come out and do a clinic for us?' (Ryan)

Ryan was very passionate in detailing the need to do more in order to create an atmosphere of growth for the program. In moving YDS's mission forward, Ryan realized that he needed to expand his soccer training program into remote communities. Ryan's realization that the YDS soccer program could be provided to other populations shows how the idea of youth development was reproduced and promoted throughout other communities. In promoting the SDP organizational goal of providing a space for youth development through soccer, Ryan portrayed ideological hegemony (Sage, 1990). The idea of youth development being reproduced by Ryan venturing into remote areas and implementing soccer training complies with the hegemonic theory because of the reproduction of the idea throughout society.

It is important for SDP interns to recognize the sort of ideas they are reproducing as they implement programs. In Ryan's case, he was not aware that he was reproducing an idea of youth development and what this idea of youth development meant. Ryan did not speak to this idea, but it may have been that the remote communities saw soccer as more of a physical activity and wanted that idea more than the implementation of youth development. Therefore, how Ryan implemented extra soccer training programs across communities is important because he reproduced a general ideology that soccer training 
is beneficial to youth development, even though it may not be an overall idea that all societies consider.

Natalie also saw her role as an intern expand as a result of trying to promote one of the goals of her SDP organization. When Natalie was an SDP intern, her role was more administrative and managerial, but because she was one of few females in the community, she felt that the need to do more and have a greater presence as a female role model. As a former collegiate soccer player, Natalie, exuded a female soccer persona that she believed many of the young girls of the community could look up to. This was important because the community in which Natalie interned did not give women the same equality as it did to the men. For instance, while the local high school in the community had a boys' soccer team and a girls' soccer team, the boys' team was given all of the resources and appropriate coaching. Ultimately, Natalie offered to become a coach for the local high schools girls' soccer team. Her internship description did not entail her being a coach for the local high school girl's soccer team; however, Natalie chose to offer her assistance because of her background as a soccer player. Natalie becoming a coach for the girls' team put her in a position of power which resulted in her becoming an authoritative figure (Darnell, 2012b).

In relation to Darnell's (2012b) discussion of race, gender, and bio-politics, the coaching position Natalie took created a power relationship where she was looked at as a female role model for the young girls. The role model persona that Natalie took can be seen as hegemonic because it showed her as a White female role model. The relationship dynamic created by Natalie was between coach and players, where Natalie was placed in 
the more dominant coaching role. Therefore, as a role model, Natalie potentially could have exhibited ideas and knowledge to which she was accustomed to her girl's soccer team. The American hegemonic idea (Donnelly, 1996) of female equality and being a female role model was shown through Natalie's experience of being a soccer coach at the local high school. Natalie providing a service that was not in the context of her SDP internship role was something she felt she needed to take on based on her own idea of the importance of being a female role model.

Amanda shared a story where she displayed a sense of hegemonic power in her decision making. In order to work towards the goal of her organization, which is HIV/AIDS education, Amanda was put in a strenuous situation that involved the health of a young girl. Amanda's story involved her making an executive decision for a young girl to get tested for HIV/AIDS. Her role as an SDP intern did not require Amanda to make such a difficult decision, but because of her position of power with the young girl, Amanda took the initiative and allowed the young girl to get tested:

We had another incident where a girl, basically her mom didn't consent to her to test for HIV. In (Country) if you're 12 years old or older, you don't need consent. And she wanted to test and I made the decision to let her test and it turns out her mom didn't want her to test because her mom was HIV positive and didn't want her to know that she had passed it on to her. She didn't 100 percent know her daughter was HIV positive, but she had an idea and passed it on to her. The girl tested positive and there was this huge controversy over legally what was right and obviously, she had the permission, so it was fine. (Amanda)

In her role as an intern who is advocating education about HIV/AIDS, Amanda believed it was right of her to allow the young girl to test for the virus. However, the hegemonic implication that is apparent in Amanda's decision was that Amanda used her power as an 
SDP intern in a manner to promote HIV/AIDS prevention. What can be seen from Amanda's experience is how her position as an SDP intern gave her a position of power. Also, Amanda's decision to allow the young girl to be tested for HIV/AIDS exemplifies a power relationship between her and the girl's mother. Even though Amanda believed it was right to allow the young girl to test, she still undermined the authority and respect of the young girl's mother. Consequently, a complicated ordeal ensued between Amanda and the young girl's mother. Amanda stepping outside of her boundaries as an SDP intern who was supposed to be implementing programs on HIV/AIDS preventive education exemplifies how SDP interns create a hegemonic power relationship between themselves and the people of the local community. In Amanda's mind, she was doing the right thing by consenting for the young girl, but what Amanda thought was right and what the girl's mother thought was right were completely different, and that is where the hegemonic theory became apparent.

All of the interns felt that for most of their time in their internship abroad their duties greatly extended out of their internship description. Along the lines of Amanda's experience, Isabelle felt that in order to create an effective program and an atmosphere for young local girls to participate in a girl's soccer program, she had to create a relationship with the young girls and their families. The manner in which Isabelle used her role as an SDP intern afforded her a position of trust that allowed her to enter the homes of local families to investigate what problems could potentially deter a girl from coming to programming. Isabelle felt that she had to personally communicate with families to uncover any problems that would lead to young girls not coming to 
programming, so that she could understand how to work around these problems. Going into the homes of the young girls in the community to inquire and understand the cultural implication of gender ultimately relays back to the goals of her SDP organization.

Isabelle was able to gain knowledge regarding why girls could not come to programming; however, it became noticeable to Isabelle that her comprehension of certain problems was not adequate:

When for different variables they couldn't come anymore and upon doing a little investigation and having conversations with them and their families realizing those, the reasons that kept them from attending were so beyond my or our staff or any individuals' means. (Isabelle)

In order to promote the organizational goals, Isabelle did her own research by talking to families. To Isabelle, exploring the reasons why some girls were not able to come to her programs was something she felt she needed to do in order to understand the problem at hand, so that she could further establish the SDP program. Isabelle's relationship with the local community was essential to how effectively the SDP program worked. To draw a clearer picture of her experience and how she did not intend to go to the homes of families, Isabelle expressed her mindset of her internship when she first got to her host country and settled into her internship position:

When I first began the internship, I definitely took the approach of this is an internship that I'm doing in this community for 40 hours a week and when I'm not doing this internship, I'm living in the community, but I'm trying to detach those two identities of work self and home self. (Isabelle)

Although, Isabelle wanted to separate herself from her internship and other parts of her life abroad, she was evidently unable to. She found that to make a difference as an SDP intern she had to build a relationship with the local community. In a follow-up question 
to the above statement, I asked Isabelle what led her to become more involved in her internship than she was initially:

At some point, it clicked that at least for this case for YDS in (City) that was not a possibility. I mean to be able to do your job well and to be able to work well trivial, to work well with co-coaches, and really get to know the community and the challenges facing the girls and what the girls would need out of programming, it clicked that those worlds had to come together. (Isabelle)

Isabelle's experience exemplifies the need for interns to be well immersed in their programs and internships to increase their program's effectiveness. Isabelle situated herself as more than just an SDP intern for the sake of the program's implementation. The promotion of the organizational goals as in Isabelle's case, evidently promotes the SDP organization first. Therefore, getting to know the community and the challenges that many of the local girls faced was something that Isabelle experienced, and it helped with promoting the YDS goal of gender equality. In immersing herself in the community, hegemony can be applied because Isabelle got to know the community so the SDP program would be effective.

If the mission of an SDP organization is to reach a wide population, interns might have to implement programs in areas other than where they are designated, such as the example of Ryan. If an intern would like to see his or her program participants succeed and learn, then he or she might have to become more immersed in the local community as Isabelle did. In both cases, however, the goal of the SDP organization is supported by its interns. How the participants went about promoting organizational goals is important to the SDP experience because they are more focused on the goals of the SDP program rather than how the SDP program ultimately affects the community. 
Social Relationships. Expansion of the American SDP internship role also brought out how the participants experienced personal relationships with the local community. I saw that social relationships fell under the theme of expanding the SDP internship role because it required the participants to extend themselves from their role as an intern to create a more intimate relationship with the local coaches, community, and population. The social relationships formed by the participants during their SDP internship experience created a distinct dichotomy between the participants and the people of the local communities. These relationships between the participants and the local community were clear forms of hegemony because the participants were situated in positions of knowledge and power and were there to help the local community. Applying the hegemonic theory to the relationship dynamic, one can see how the people from the local communities could be viewed as the group that was being controlled due to the position of power that the American SDP interns had. Examples of how participants experienced personal relationships follow in the section below.

Amanda spoke to great lengths that her personal relationship with the local staff had the same importance, if not more, than her HIV/AIDS education programs that served the youth population. During her time abroad, Amanda spent much of her time with local staff helping them through their personal lives. Once again, Amanda's role as an SDP intern gave her a position of authority. Due to this position, the local staff saw her as a source and provider of help. In the quote below, Amanda emphasizes the importance of being on a personal level with the local staff:

The coaches were all locals (Country) that were my age and just needed just as much help and being there for them, whether it's working with, 
like, a family issue or were having trouble setting up their bank account so they could get paid and get food, that is like the heart of where AEG is. Everyone is, like, a team and they work together and that's what I felt was most important that I did. I think I had a greater impact on those coaches that are my age than I personally I had on the kids .... think that was the most valuable and most important, was helping change their lives and helping them as opposed to the children, which I know is crazy, like, I'm making this huge judgment. (Amanda)

Other than just implementing programs that would address a pressing international humanitarian issue, the participants saw their roles as interns as being mentors to their local peers. Amanda's interaction with the local coaches in her program caused her to realize that they needed just as much help as the children did. Amanda took on the responsibility of helping the local coaches with whatever issues came about, and, in doing so, she ultimately created a relationship that positioned her in a role of power. As a result, Amanda was able to create personal relationships with the local coaches because of the help she was able to give them.

The personal relationships Amanda established are similar to Natalie's role as a coach because she created a power dynamic between herself and the coaches (Darnell, 2012b). The help that Amanda was giving the local coaches was based on her own ideas and knowledge on a certain topic. For instance, Amanda teaching the local coaches how to set up bank accounts was through her own way of doing it. It is possible that Amanda unknowingly implemented a process of Americanization (Donnelly, 1996) through the help she gave to the local coaches. Therefore, she produced hegemonic ideas from her own teachings that she displaced onto the local coaches. Amanda felt that the personal friendships she established in her internship meant more than her program 
implementation, but the creation and meaning of that friendship is crucial in understanding the SDP experience.

As Amanda's example above showed, the SDP program implementation was not the only important experience participants had during their internship; the participants saw their roles as friends and colleagues as being important, as well. Eric was another participant who felt that his personal relationship with the local staff and coaches he worked with was beneficial for everyone's experience. In a similar manner to Amanda's experience, Eric's relationship was built on the fact that he was seen as a source of help to the local coaches. In his interview, Eric talked about the relationships that he created with the local coaches and how they confide in him. Once again, being an SDP intern forged this identity of a provider to which the local coaches looked. The helper and helped relationship created in the SDP experience as illustrated by Amanda and Eric provides a description of how SDP interns are given a position of inequitable power. People from the local community looking at SDP interns as sources of help and knowledge can potentially establish hegemonic social relationships where one group presents ideas of help and the other group is influenced by those ideas.

Ryan experienced a more sensitive case when it came to regarding a social relationship he had with a child that was part of his program. When asked to describe a positive experience that he had during his experience, Ryan shared a very deep story about how, on the day before he left, he went around to some of the homes of the children that participated in his programs. In particular, there was one boy who Ryan bonded with 
very closely who, at first, was a problem child for Ryan, but eventually became one of his

favorite kids. The story below depicts the scene Ryan retold during his interview:

So, like I never been to his house and when I went and visited him I found out that his dad was like alcoholic and was never there, his mom worked for the city, like, cleaning up the sewer in the entire streets, but sometimes they wouldn't pay her, so very, very poor. They didn't have a roof. They kind of had like a dilapidated hut thing that was like a little shanty set up right in the slum across from where the youth center was and the mom who didn't speak any English had to translate through the international coach told me, like, I asked her a couple of questions, like, 'Hey did (Name of boy), did you see a change in him recently, like have you seen him change?' and she was like 'Absolutely, he is like the man of our house now, he cleans, he goes to school now he takes care of his siblings, he is respectful to me', and all this stuff. And it was really, really emotional. (Ryan)

Ryan's detailed experience of his relationship with the young boy entails the positive work that SDP does for youth living in less-developed countries. By getting on a personal level with his program's participants, Ryan was able to see the life of a young child outside of the SDP program and how the program really affected the child's life. The emotional story that Ryan told during his interview illustrates the power that SDP interns have in building relationships with the local community. The relationship Ryan established with the young boy was a traditional teacher-student relationship, where Ryan was the one who taught the boy to be responsible and respectful. With the close interaction that SDP interns have in their host countries, it is evident that social relationships will be created between the SDP interns and the local community. What is important to acknowledge is the meaning behind the relationship that is created.

The friendships that participants created with people of the local community continue to this day. It was not only a working relationship that the interns had with 
people from the community or with the local staff, but also a personal one. Aaron and Natalie shared that, on occasion, they would have dinner with members of the local staff they worked with or they would all go out to a bar together. The social relationships that were created through the SDP internship experiences illustrates that the internship role is more than merely implementing programs on how to prevent HIV/AIDS or soccer training; rather, it is about the whole internship and how being an intern affects every element of life. The interns are just not there to be interns, but are there to be friends, role models, and colleagues. The meaning behind the social relationships and how ideologies were transferred by the participants needs to be recognized by American SDP interns.

Understand the Purpose. The minor theme of understanding the purpose arose when participants were asked what advice they would like to give to potential SDP interns. The participants who expressed that people really need to make sure they want to be SDP interns was a result of experiences they saw in other interns who were jaded by being SDP interns. From the discussion provided by the participants, many spoke to how interns can come in and, at times, not really buy into the programming that is carried out. As a result, there are SDP interns who implement programming without regard for their benefactors.

It was suggested that interns need to understand the mission, the program, the community, and other elements associated with being an SDP intern. Taylor said that, generally, people who want to become SDP interns need to "Stand firm with yourself and be sure you want to go, because sometimes it's not right for people, it's not, it doesn't 
work out." Taylor expressed that potential SDP interns should do their own research on the field to see if they fit the role of an SDP intern. As a field that is trying to help people afflicted by pressing issues living in a less-developed country, it is crucial that people who are going abroad in SDP are people who want to be there and want to help. SDP organizations that select people who do not buy into the mission could potentially be sending interns that are more concerned with their own ideas, resulting in these interns implementing hegemonic ideologies throughout their programming.

Ryan was one participant who gave a personal account about why people need to be immersed in the purpose of their SDP organization. From his experience with one of his fellow interns, Ryan experienced first-hand the negative impact of an SDP intern not understanding the purpose of the SDP organization can have. The story Ryan recounted was about a conflict he had with one of his fellow interns:

Make sure you understand what you're going there for. I had a little conflict with one of the other interns that I was with because he really wanted to teach English and it became apparent that he had been deciding between teaching English somewhere or doing YDS and so he tried to incorporate a lot of that into our program and I felt like that wasn't our mission. (Ryan)

Ryan felt that another intern he worked with was more focused on providing English lessons, while Ryan believed the mission of the program was to provide youth development in a variety of different ways. Ryan saw this as problematic because their mission was not to teach English. The attempt that Ryan's colleague made in teaching English during SDP program signifies how hegemony is present within the international development context. 
The act of teaching English in a country other than the U.S. represents the process of Americanization precisely as Donnelly (1996) describes the concept where American culture is imposed at the expense of the local culture. To teach English in a community that did not need English lessons is directly imposing on the local culture. Ryan was able to understand that the purpose of YDS was to provide youth of the local community a space for their own personal growth and to establish an atmosphere of gender equality, so teaching English was totally inappropriate. English can possibly be a supplemental lesson, but what was more important was that children were provided a place to develop and sport was the place for that happen.

Organizations that have a clear purpose have the potential to provide programs that are correlated with that mission. The focus for Ryan's SDP programming was specifically youth development and gender equality. Ryan summed up his view of being on board with the organizations purpose by saying:

Really being on board to doing what you're going there to do and not going there and thinking 'I'm just going to help like, help, (Country) kids, I'm going to help little, Southeast Asian kids,' but you're going there to help them through sport, so you need to on board with that mission. (Ryan)

Ryan's conversation about being immersed in the purpose of the SDP organization was very energetic. It was significant for him to ensure that anyone who is thinking about becoming an SDP intern really understands the mission of the organization for which they are applying to intern. The participants emphasize that understanding your purpose will ultimately affect the program. Critical to Ryan's comment of being on board with the purpose of the SDP organization, the participants of this study have shown the 
difficulty they have in trying to understand the local culture. What resonates here is that the participants want potential interns to understand the purpose of the SDP organization, but did not mention that they need to really try and understand the local culture. This was an interesting finding from this minor theme.

As Isabelle reflected on her SDP internship experience, the advice she would like to give to potential new SDP interns was to learn about the program and understand the approach that is taken by the organization for which you intend to intern. For instance, the approach that is taken in SDP is using sport as a catalyst and place for change, but if sport does not appeal to you, SDP may not be the appropriate field for you in international development. Isabelle advised potential interns about understanding the purpose of what they will be doing as interns:

I would encourage them to ask a lot about the program before they get to know what they're getting into...that it's really important for new faces in an organization to understand the initial approach and approach that is taken, so I would encourage them to really pay attention when people are talking about that and if people aren't talking about that then ask about it. (Isabelle)

Isabelle insisted that people should investigate the program before-hand because it will give them a sense of what they might experience when they are abroad. Nevertheless, the relevant discussion is for people to truly understand what they are doing and how they are going to do it.

Potential interns understanding the purpose of the SDP organization only acknowledges one group within the SDP field. The local community as the other group was not brought up in discussion of advice given by the participants. As mentioned in the literature review of this thesis, Donnelly (1996) described the process of 
Americanization as a one-way process where American ideas are imposed onto another culture. By excluding the local community from their opinions, the only understanding that SDP interns need to have is that of the organization for which they are interning. Interns being on the same page with the organizational purpose and with each other, as well as believing in what they are doing, are vital components in the success of the SDP organizational goals, but this does not mean that the success of the SDP organization will transfer into making an effective change in a community.

The last comment in relation to understanding the purpose was made by one of the last interviews that was conducted. Ian imparted one piece of advice that he felt would be most helpful for anyone thinking about becoming an intern. Near the end of the interview, Ian said, "I think really immerse yourself, in that really understand the place you're going. I think that is more helpful than any amount of coaching experience." Simply put: just understanding where you are going will be helpful throughout a person's internship experience. For Taylor, Ryan, Isabelle, and Ian, understanding the internship in all of its principles, whether it was the mission of the organization they were SDP interns for, the country in which they were lived and worked, the programs they implemented, or the approach that they took in program implementation, is what they felt will make or break the internship experience.

The expansion of the SDP internship details the actual SDP internship experience. It is not necessarily important for SDP interns to be confined to their role as an intern, but it is the way they deviate from their internship role that is important to study. This important theme emerged because it really elaborates on the total SDP internship 
experience and how interns innocently display hegemonic notions. SDP interns may be required to implement programs in different communities or make difficult decisions that they may not be used to. However, when SDP interns implement programs in different communities, they should be aware of what ideologies they are reproducing throughout local society, and they should acknowledge the power they have that comes with being an SDP intern. Therefore, it is valuable for SDP interns to understand that the internship extends beyond the actual job description. In promoting organizational goals, creating the personal relationships, and understanding the purpose of the organization through the description of the participants, one can see that how the hegemonic theory was applied to the analysis.

\section{Doing Something Greater}

The fourth major theme that emerged from analysis of the participant's interviews was doing something that was greater than themselves. Under this theme of doing something greater, the participants spoke about the different ways of how the internship was essentially not for their benefit. Many of the participants felt that their SDP internship experience granted them the opportunity to volunteer in helping address a pressing issue in a different region of the world. The participants in this study saw the SDP internship as a good way to work in the international development. Mentioned in the previous chapter, almost all the participants in this study were not familiar with the field of SDP before their internship, rather, the attraction started with the desire to work in an international development context. 
The use of sport as a tool to address international humanitarian issues in SDP was the other major factor to why the participants interned for the AES and YDS. The participants deciding to intern for an SDP organization because of the role sport played in the methodology of each organization constructs a hegemonic belief. The idea that sport can teach certain characteristics is a culturally ingrained idea (Darnell, 2012b) that the participants felt would work in a non-American culture. Similar to previous research, the participants used their own positive sporting experiences as a reference, intriguing them to work in a development context (Darnell, 2012b). However, sport may create the same positive experience as it did for the participants for this study. For participants to choose an SDP organization based on the connotation of sport reproduces a hegemonic ideology. From the interviews, two minor themes were formed regarding doing something greater. The two minor themes are giving to the community and teaching them to sustain.

Giving to the Community. Throughout their experiences, the participants reiterated that what they were doing abroad was for the community and not for personal gain. I saw this minor theme come out across many of the interviews as the participants discussed the importance of why they applied and were interested in applying to becoming an SDP intern. Frangonikolopoulos (2005) points out how NGO workers need to be responsible for their actions, as many of the participants saw their purpose for being in SDP as beneficial to the local community. The participants were all passionate about helping the community, especially the children that they interacted with. Daniel was one participant who spoke very passionately about how potential SDP interns should be interested in making a difference in the lives of the kids that they are supposed to help 
and that the experience should not be about the intern or what the intern wants to get out of it:

And that's something that I think a lot of volunteers need to realize is that, and especially if they're volunteering abroad and working with kids is that it shouldn't be you know, it shouldn't be like, 'I want to go into it because I want to go to Africa or because I want to experience.' It should be because you actually want to make a difference and that's one of the things I think you see with a lot of volunteers, especially ones that they get there and they just want to go, you know, they want to go on safari right away or they want to go do something cool right away. (Daniel)

People that volunteer their time to work in an international development setting should be concerned with trying to address a pressing issue such as youth development or HIV/AIDS. As Daniel avidly proclaimed from his experience, it is important for interns to appreciate that the internship experience is not about them, but about the people they are trying to help. They were not there to implement any non-essential programs, nor were they there for selfish reasons. If people come into development scenarios and are more interested in their own personal benefits, there could possibly be a detrimental effect on programming. Similar to Daniel, Taylor was open about how being there for kids and helping them was what drove him during this internship. When I asked about how Taylor handled dealing with the crazy scenes he witnessed, such as seeing a man set on fire, Taylor responded by saying that working with the kids took precedence whenever he encountered an adverse situation. Taylor explained this feeling of being present and accountable for the children and overcoming his emotions by saying:

Yeah, I just get really, because I love working with kids so much, I think that kind of emotion took precedence over the kind of feelings of being lost or a, just a White person there. I was just excited to be around the kids and kick the ball around with them and being able to teach them 
something that they may have never learned before in the game of soccer. (Taylor)

Taylor's awareness of his own personal feelings displayed notions of the hegemonic theory because he put his feelings first (Darnell, 2007). Even though Taylor experienced some dramatic instances, he strongly felt that his role in the community was to provide a positive role model for the kids, and, because of that mindset, he was able to suppress those things to effectively continue his work for the kids and the community. Taylor was able to put into perspective that SDP was for the local community and not for his own personal gain.

Eric also saw during his internship that what he was doing in his host country was far more for the community than it was for him. He expressed how he learned that the internship was not about people coming over to the host country and teaching in the community and then to, in his words, "Bugger off." Rather, the SDP interns were there to provide assistance to the local staff in different ways. It is better for the program and the communities that the interns are there to help, and monitor, and, as Eric said, view the staff from the community as "the leaders" because "they are the ones that the kids look up to." At the end of his internship, Eric was comfortable that his experience in SDP helped the community more than it helped himself saying, "All that really matters is the people you're with, the impact you're having on others, and I think it's a good way to do that." Eric was really involved in trying to help the community he was in, and that experience came out as he discussed his feelings about his impact on the local community. 
Aaron's experience of doing work that was focused on giving to the community was very similar to Eric's. When Aaron first began his internship, he thought he was going to be directly involved in program implementation, but he quickly realized that, instead, he was there as support for the people doing the direct service. Aaron's explanation on his confusion regarding who should be doing the direct service in the community was:

That was what I applied for and that was what I wanted to spend my year doing was this kind of direct service and I think in some ways it was partly my fault for not understanding really the direct service should be done by local staff and that is what it really ended up being. So, my experience was sort of more direct service to the people who were providing direct service. (Aaron)

Aaron's experience indicates that the SDP interns are there for the community and not there for themselves. The SDP internship experience is really about providing a service to the community. It is important for potential interns to understand this because they should not be going to a less-developed country for their own selfish reasons. Aaron admitted that, in the beginning, he thought he was going to be more involved, but was able to realize that it was more beneficial for him to support the people of the local community who are actually doing the direct service. The interns being present and doing work that is centered on the people of the community was important because, at the end of their internships, the interns will return home, leaving the local community there to continue the programs.

Amanda reflected on her feeling of giving to the community in a way that emphasized how it led her to give back to another culture and community. Amanda 
described how, during her time as an SDP intern, she developed intrinsic feelings regarding her work in the local community:

Oh it's, I mean, it's a feeling that, it sounds kind of corny, but it's just, especially with kids for me. I get - it's - you feel like you're doing something that has some sort of meaning as opposed to just going about your daily day. Like when I wasn't working; when I got back from (Country), you wake up and you do a bunch of things, you go to bed and you look back on your day like, 'What the hell did I just do?' But when you go and you go into the field, talking to kids, helping kids and then at the end of the day they all know your name and trying to speak to you in English and they say 'Thank you' for your help.' It's a different sort of feeling. You don't really care if you're making money or not. (Amanda)

Amanda's experience of giving to the community gave her a feeling of gratification as a result of her work. The emotion that Amanda was able to experience during her internship could be seen as a selfish emotion because the emotion was created by her position of being able to give back to the community. Interestingly, Amanda was aware of her selfishness, and, in a way, hegemonic actions as an SDP intern. She was able to discuss and explain her feelings of satisfaction because of what she was doing while she was an SDP intern by conveying, in her words, "Cynical" thoughts about how there is no such thing as a selfless act, and that people volunteer because they want to feel better about themselves. However, Amanda also said that even though people may volunteer for their own personal reasons, those who volunteer are still able to create a positive change. Amanda's thought was that just because someone was giving back to make herself or himself feel better, that does not mean that they are negatively impacting the community. Amanda showed that SDP interns can be aware of hegemonic discourse during their experiences in the field. This discussion of giving to the community gives 
way to the next minor theme of sustainability, where participants of this study expressed the importance of having the local community sustain SDP programs.

Teaching Sustainability. All of the participants spoke about how, while they were in the SDP field, it was important to implement programs that incorporated people from the community in order to achieve sustainability. It is important for sustainability to occur within an SDP organization for two reasons: the yearly rate at which interns cycle through and the local staff bringing in a local appreciation. SDP organizations usually send a new group of interns every year, leaving local communities to deal annually with a different group of people. As interns come and go, the local staff remains constant in the community; therefore, they should be the ones implementing programs.

The hegemony that could potentially occur between SDP interns and the local community in the attempt to establish sustainability pertains to which ideologies are being reproduced when teaching sustainability. If the end goal of SDP is for local communities to implement programs without the assistance of organizations, it is important to note how and which programs are taught to the local communities. Analysis of the interviews indicates hegemonic tendencies on sustainability. Ian conveyed the realization he had when it came to teaching the local staff how to run programs.

The ones that are going to be staying are this - the local staff, so they're the ones who really need to build their skill set because they're the ones who will know the kids from before. They're going to have another years coaching under their belt, so they may not be as naturally comfortable as a teacher, but more experience they get, the more they grow in that role and 
it's more the future of the program because the interns won't be there regardless of who the interns are they won't be there forever. (Ian)

The fact of the matter is that, in SDP work, the interns are there to help facilitate the program implementation and are not the ones directly serving the community. The people who are actually leading programs and educating the community need to be people from the community. The SDP interns eventually must return home, leaving the local community to continue the programs. Involvement of the community and building a local staff allows for programming to continue when interns leave and when new interns arrive.

The participants spoke about how having local staff allows for not only consistent programming, but also effective programming. The local coaches are the ones who effectively reproduce hegemonic ideologies, as initially those ideas are placed onto them. Since the interns come in and are seen as foreigners by the local community, having local staff help in program implementation created a sense of approval. People of the community seeing their friends and family involved with the work of an SDP organization enabled others to see value in the program. The involvement of people from the local community allows for effective programming because they are familiar with the ongoing issues and how the issues really affect the community. Their insight on the issues affecting the community gives way for intimate and personal relationships.

For Daniel, having the local community buy into the program was very important to the sustainability of his work. When Daniel was an SDP intern, he was one of the first to implement a program for a relatively new organization in an African country. Due to 
this relative newness of concept, the local community had a hard time buying into the programs that were introduced. It was only when local coaches and staff were brought in that the community started to believe in the program, resulting in community involvement. In order for Daniel to get his SDP program started, he had to convince a few locals to buy into his program, so that they could reach out to the rest of the community. Without the help of the local community, Daniel had trouble attracting people to the program. Daniel expresses his experience of having local staff and coaches involved in programming by saying:

Oh yea for sure, I mean, if you don't...it's...you cant have long term, you can't support having just foreign volunteers coming and doing all the work because, like I said, if you don't get any help from the outside and if you get the people that can try to convince the locals. Like, I can try and tell the locals whatever I want. They're not going to believe me though unless a (Local person) or another (Country Person) was saying, 'No he's right, this will work, try this, this is why he's doing it, your kids will help out or this will help your kids out this way.' (Daniel)

Daniel incorporating locals into his program represents the hegemonic theory because he was able to influence a group of locals that in turned influenced others from the community.

When discussing sustainability as an important goal, one must be aware of how hegemonic ideas can potentially spread due to sustainability. As discussed by the participants, the interns are only there to help implement the program, while the staff and coaches from the local community are the ones truly teaching the community; however, the ones teaching the local staff are the American SDP interns. As a result, the local coaches are in turn teaching the local communities the ideas of the American SDP 
interns. Looking back on Americanization and the hegemonic theory, both are apparent in community sustainability by the SDP interns reproducing and disseminating American teachings throughout the local community.

Aaron was another participant that spoke at great lengths about the importance of sustainability that was created when there was high involvement of the local community in the programming process. As Aaron was detailing his view on the importance of sustainability or, in his words "Capacity building," he acknowledged that eventually it would be beneficial for local staff or volunteers to climb organizational ranks and become the leaders of their local SDP organization. The ability to have local people eventually become leaders of SDP organizations in their community provides an end goal where local communities are the ones providing programs and there is no need for intern support. Aaron expressed his displeasure of seeing international interns get hired on full time as officials in the community. If SDP organizations want sustainability, it seems contradictory to hire internationals rather than locals. By hiring internationals as SDP officials, organizations are not giving power to the local community to ultimately become self-sustaining. Instead, what could be seen is hegemonic stability where SDP organizations continue to have their own people in leadership positions in local communities. An SDP organization hiring international workers to run programs in local communities keeps the power within the organization and not with the community.

Elizabeth was another participant who spoke of the need to have programs eventually become self-sustaining. Her experience centered on how her program moved from one community to another because the potential for sustainability was greater. 
Elizabeth shared that when she first settled into her internship, there was much pushback on programming by leaders of the community, to the point where sustainability was an unlikely outcome. In comparison to Daniel, who shared how SDP programs need local support in order to have sustainability, Elizabeth spoke of how her program moved from a rural setting to a more urban setting because the community in the urban setting believed in what the SDP program was providing. Elizabeth's outlook on sustainability and movement of the program is shared below:

The goal is to sustain these sort of programs and to make it sustainable for the community to eventually have the community be the ones in charge and there was so much more possibility for that in this other location closer to (Name of city) where, like I said, where we had that local support, where we had these fantastic people who wanted to coach these kids, who wanted to be involved. (Elizabeth)

In a perfect situation, the local community will eventually be implementing programs related to SDP. Elizabeth realized during her internship the importance of having the local communities support the SDP organization, as well as the programs that were being implemented. Since the first community Elizabeth was implementing programs in did not support her program, it was hard for Elizabeth to establish an atmosphere of sustainability. The local community did not cooperate with Elizabeth and eventually, the program had to move to different community. The experience shared by Elizabeth shows how, when SDP interns are unable to influence the local community, it is difficult for the interns to implement their programs. Therefore, for SDP interns to actually get their program started, ideological hegemonic influence might need to be forced in order to get the local community to recognize value in the programming. When teaching the local community to become sustainable, SDP organizations must first have 
the local community's support. The process entails the reproduction of ideologies across the community for a substantial amount of time. It is important to note that the ideologies that are taught to achieve sustainability will perpetuate; therefore, it is important to know from where these ideologies derive.

In terms of program sustainability, Natalie spoke about hiring her replacement when her time as an intern was coming to an end. Natalie decided to hire a person who was native to the country and understood the complex dynamics of ongoing issues in the local community. Natalie explained her thoughts on incorporating people who grew up in the community, stating that it was important because they will be influential. During the interview, Natalie was open about the importance of hiring her replacement from the host country and its benefits to the continuation of the program she was working in, saying, "And so yeah, definitely tried to hire people that were very local, if not in the town. My replacement was actually in one town over. I had hired her from one town over, so she knew the dynamic and things like that." The ability to hire her replacement gave Natalie the power and responsibility to make a decision that would benefit her program's sustainability. Natalie's decision to hire someone from the next town was purposeful because she felt comfortable that the program she had implemented would continue after she returned to the United States. The hegemonic implication of Natalie hiring her replacement was that her influence and ideologies ingrained in the program would still be carried out despite her absence.

In Ian's interview, he spoke at great lengths about the importance of sustainability and how the future of SDP programs lie completely within the people of the local 
community. Ian explained his reasoning of involving the local community in establishing sustainability in two clear ways:

Then as we were there longer, we realized that it's more important for the future of the program if the local staff were the ones that are leading the trainings everyday and picking up these skills of different skills to use and how to engage with the kids, give the kids positive reinforcement...I think this goes back to what we were saying when we were talking about the training of local coaches. I think however much you do that and work with local people that are, you're not just the youth participants, but local partners that are going to carry on your program; however much you do that and successfully you train and work with these people is going to determine the success of the program. (Ian)

Ian expressed that during his experience, he came to realize the significant role local staff played in programming.

If sustainability is eventually achieved, but achieved through a reproduction of American ideas, then what actually occurred is cultural imperialism by way of Americanization (Donnelly, 1996). Sustainability was a topic that presented itself in many of the interviews. The participants felt it was critical that a result of their program implementation should be the local community being able to sufficiently sustain the program by themselves despite the annual revolution of interns. In this case, teaching the local community to sustain long enough until new cohorts of interns arrived implies that the control and power lies with the American SDP interns. There continues to be an ongoing cycle of American SDP interns coming in and out of the local communities, while the only constant that remains is the people of the local community. The American SDP interns, evidenced by how they give back to the community, leave a lasting impact on the local community. This lasting impact can potentially influence the local community by way of American teachings and ideas. 
The major theme of doing something greater consists of two minor themes, giving to the community and teaching them to sustain. I found this theme as an essential concept of the SDP internship experience because the interns were aware that the work they were doing was not for them, but they were still displaying hegemonic tendencies. As the interns expressed through many of the interviews, they were there to help the children, to assist the local staff, and to be involved in what was best for the community. The notion of being there to give to the community may ring true, but there were still depictions of hegemonic ideologies. The participants acknowledged that while they were there to help the local community, their own personal feelings still interfered. Giving to the community prompted the participants to identify that sustainability was something they were attempting to achieve. Critical to this theme is the need to recognize the manner in which sustainability is achieved. If sustainability is achieved through the SDP program then it could possibly be a reproduction of the interns' ideologies. These are two important concepts because international development work ought to be primarily focused on the populations that are affected by a dire situation. SDP is a field that is using sport to create an atmosphere that addresses an issue, and it is vital for SDP organizations to educate their interns that they are there to help the community, and that you can have some personal gain from the overall experience, but the main reason you are there is to help the community.

\section{Summary}

The current research-based thesis was conducted with an emphasis on the overall experience of American SDP interns. Analysis of the interview transcripts showed that 
all eleven participants had commonalities that arose from their SDP internship experience. These common themes provided detailed insight into the SDP internship experience. Evidenced by the interviews, cultural expectations were a powerful element that affected the internship experience. Whether it was encountering cultural challenges, negotiating cultural tensions, or attempting to bring American ideas into the local culture, the expectations of culture were pivotal in how the participants approached their internship. The participants had difficulty navigating through cultural expectations. For the most part, they wanted to consider the local culture, but would easily become frustrated when the local culture did not allow them to implement their own ideas. The theme of reflective privilege provided insight regarding the privilege of an SDP, where only those who are financially able can be SDP interns. It also allowed for the participants to express how the SDP experience changed their views upon their return to the US. Some of the participants described how they expanded on the American internship role by promoting organizational goals, creating social relationships, and by understanding the purpose of their respected SDP organization. The last theme that emerged from analysis of the interviews was doing something greater which incorporated giving back to the community and teaching them sustainability. 


\section{Chapter 5}

\section{Discussion and Conclusion}

The current thesis qualitatively examined the program experiences of former American SDP interns. SDP is a field in international development that aims to use sport as a tool to address humanitarian issues around the world (Kidd, 2008). SDP organizations commonly come from Western, developed nations that send workers abroad to implement programs. SDP organizations that come from Western or developed nations provide resources and training that are not available in the less-developed country in which they are working. One of those scarce resources is people to manage and implement programs that focus on alleviating problematic situations such as HIV/AIDS education, gender inequality, or providing a safe place for youth development. In answering this need for assistance, SDP organizations send a group of young interns to work for a predetermined time period. The interns act as educators, coaches, helpers, and members of the local community. Therefore, the purpose of this study was to examine American SDP interns' program experiences.

\section{Discussion}

This thesis was both similar and different to other research conducted on SDP interns' experiences. In relation to previous research involving SDP interns or volunteers, this researcher specifically chose to focus on Americans who interned for an American based SDP organization. Other researchers looked at Canadian interns and volunteers (Darnell, 2007, 2009, 2010a, 2010b, 2011, 2012b) and Swedish SDP officials (Hayhurst \& Frisby, 2012). There has been little research emphasizing the role of 
American interns in the field of SDP or American SDP in general; therefore, the current research provides insight on another group of people involved in SDP. I also attempted to apply the hegemonic theory (Bates, 1975) similar to SDP research conducted by Darnell (2007, 2010a, 2012b) to help explain and understand the experiences of the participants. As a result of the similarities and differences in methodology and focus, this study is important because there is currently no in-depth qualitative discourse involving American SDP interns.

In examining the program experiences of former American SDP interns, I attempted to apply the hegemonic theory to help understand power relationships or ideological influence created by the participants. I was influenced by previous qualitative researchers who have also examined SDP (Darnell, 2007, 2010a, 2010b, 2011, 2012; Hayhurst \& Frisby, 2010). The previous researchers also looked at the experiences of people who work directly in the field of SDP. The major difference in this thesis was that its focus was American SDP interns. I saw American SDP as an area where value could be added to the scholarly literature. My hope is that the findings from this thesis will provide further conversation on the field of SDP. Results from analysis indicate that there were ideas and actions related to the theory of hegemony portrayed by the participants when they were implementing programs in the local communities in which they were stationed. Hegemony and processes of Americanization became apparent from the interviews as the participants spoke about what they did during their internship, how they did them, and why they felt they needed to do such things. 
Semi-structured interviews were conducted with eleven former American SDP interns to gather insight on their SDP internship experience. From analysis of the interviews, four general categories of themes emerged: (1) cultural expectations, (2) reflexive privilege, (3) expansion of the American SDP internship role, and (4) doing something greater. Reflexive privilege and doing something greater were the only themes that had any relation to previous research (Darnell, 2010a; Darnell, 2011) while the other themes were specific to this research. I found that cultural expectations were an important topic of discussion among the participants because many of the dealings they experienced with culture shaped their internship experience. For instance, the participants were faced with many challenges due to cultural differences. In an attempt to implement their own pre-conceived cultural ideas, the participants had a troublesome time navigating through the differences in the local culture. Through analysis of the interviews, the effort of trying to change the local culture through reproduction of ideologies allowed for explanation using the hegemonic theory.

From the stories of the participants, one participant spoke about their culture, one discussed pushback from the community who did not approve of an idea of a youth center, one spoke about how her American idea of hard work in sport did not resonate when she was holding soccer programs for young girls, and, lastly, other participants spoke about how their American ideas on certain issues like HIV/AIDS and domestic violence did not echo during their internship. Many of the participants also spoke of the difficulty they had in negotiating challenges presented by culture. On one hand the 
participants wanted to respect the local culture and did not want to impede, but on the other hand, they saw cultural differences as a hindrance to their program implementation. Reflexive privilege was another theme that emerged from the interviews. I found this theme relevant when it came to the theory of hegemony because only those groups with financial power can be SDP interns. The participants' having to financially support themselves while they were abroad indicates that only people who come from well off socio-economic backgrounds can be SDP interns. This is important for SDP organizations to acknowledge because there may be suitable applicants from other socioeconomic groups; however, they are prevented from becoming interns because of financial obligation. Some participants spoke of how their way of living changed when they got home their internship. If SDP is designed to serve underprivileged communities, change must be made in the field for the people of the local communities, and not to the SDP interns when they return home.

The theme of expansion of the American SDP internship role was formed by participants' discussion about the things they experienced during their internship which forced them to promote organizational goals, create social relationships, and recognize the importance of interns understanding their purpose as an SDP intern. In using the hegemonic theory to help provide an understanding of this theme, hegemony provided discussion of the participants' expansion of their internship role and the ways in which they created social relationships with the local community. In promoting organizational goals, there was a reproduction of ideologies throughout communities. It is imperative 
that interns understand the purpose of their SDP internship because programming can be affected if the interns are preoccupied with personal endeavors.

The last theme of doing something greater came out of the participants'

discussion of giving back to the local community and eventually teaching them to be selfsustaining. The participants were particularly expressive when it came to acknowledging that they were there for the community, and whatever selfish reasons they had for being there were suppressed when they were implementing programs. Sustainability was discussed as being the end goal by the participants because it would mean the communities would be able to eventually implement their own programs and address any humanitarian issues. For these former American SDP interns, it was important to involve the local community and do everything they could to improve the conditions for the people they were there to help. Yet, the manner in which the participants gave to the community and ideas that were taught in achieving sustainability provide discussion to the theoretical framework of hegemony.

\section{Limitations}

There were few limitations in this overall research thesis. The first limitation is that only eleven participants were gathered for interviews where Darnell (2010a, 2010b) had twenty-seven total participants in his studies which credited more generalization of his theoretical findings. Another limitation was the length of interviews. I tried to be considerate of the time of the participants, so I made it a priority to keep interviews within one hour. Most of the participants lived in different time zones, so I did not want to appear bothersome to them in anyway. The last weakness that became apparent as I 
was conducting interviews was that personal bias started to emerge. In order to make sure personal bias did not impede in the research process, I started keeping a personal reflective notebook and kept notes after each interview was conducted.

\section{Future Research Suggestions}

Since SDP is still an emerging field of study, there are limitless possibilities on how to conduct scholarly research on the field. As different nations send volunteers or interns abroad to less-developed nations, there will continue to be a need to evaluate the different experiences. The importance in examining the experiences of SDP workers is to conceptualize the actual effects of their roles. In the case of this thesis, I suggest that further research be conducted on American SDP interns' program experiences. I was only able to capture the experiences of eleven participants who were all self-identified White-Americans, so it would be beneficial to the field of SDP for research to be done with other ethnic groups of Americans such as Black-Americans, Asian-Americans, and Latin-Americans. By continuing to examine other groups of actors in SDP, more analysis can be developed on the relationship dynamics within SDP. American SDP organizations have interns that are not White-Americans and research can be done focusing on these other populations.

Another area of research that can be investigated is the experiences of female interns. The female participants of this study brought to light interesting discussions about how their gender affected their SDP internship. I did not expand on the female SDP experience during data analysis because I wanted to incorporate the overall SDP experience as detailed by the participants of this study. Therefore although, it was not 
the focus of this study, I found that female SDP interns faced a lot of obstacles during their time abroad, and if investigated further, possible important findings could arise. In regards to methodology, it would be interesting and extremely relevant in adding to the literature for a study to be done directly in the field using an auto-ethnographic methodology (Tedlock, 2000). For someone to actually experience the SDP internship experience would be valuable to the field practically and theoretically. These are the suggestions I propose for future research on American SDP and the field of SDP in general.

\section{Implications}

This thesis presents an analysis on experiences of American SDP interns. The results from the interviews provide several potential implications for SDP organizations and people, in general, who are thinking about becoming SDP interns. Although, it should be noted that the analysis from this thesis cannot be applied across the SDP spectrum due to its focus on American SDP interns and the fact that the sample size was only 11 people. This thesis on American SDP interns' program experiences cannot be an outright source of generalizations on SDP; however, this thesis can be referenced for its findings and built upon by other studies conducted on the field of SDP. In an attempt to apply the hegemonic framework, this thesis elaborated on how power and ideologies were transferred by the participants. Throughout the data analysis and formation of the themes, the hegemonic theory helped explain the American SDP experience by critically analyzing the relationships and thought processes exhibited by the participants. 
The analysis of the data using the hegemonic theory was also conducted to see if any American ideologies would emerge in a demanding manner. Throughout some of the interviews, American ideas did appear as a force of ideological control that was woven into the SDP experience, but in relation to the hegemonic theory, those ideas did not truly rule over the ideas of the local community. What happened in the case of this thesis was that the participants did try to weave in American ideologies into their SDP internship experience because they thought it was appropriate in their SDP programs. It became clear from the interviews that the participants were unaware of their hegemonic attitudes, except for Amanda, who spoke about how and why people are selfish when they volunteer. Since hegemony is only a theory and not a tangible object, the participants did not know they were indirectly imposing ideas. The participants in this study truly felt that they were there to make a difference.

The experiences from the participants in this thesis indicate that the field is doing substantial work to try to reach the MDGs set in the early 2000's, but there are still some considerations to be taken when sending young people abroad to do international development work. The theme of reflexive privilege is more specific to this study and cannot be taken into consideration by all SDP organizations because of the American privilege that is established by being an SDP intern. The other themes could potentially be generalized to the realm of American SDP. From the interviews, it was found that almost all the participants had issues with culture in one way or another; therefore it may be appropriate for SDP organizations to immerse interns in the culture they are going to before they depart on their internship. 
The participants wanted to help and bring change, but the only way to do this was to try and change the culture. However, the participants struggled with wanting to respect the culture, but at the same time acknowledging that the culture was challenging their program implementation. It is really interesting to see how the participants internalized this negotiation of culture because, from the interviews, it appeared they did understand how crucial it is to let the local culture take precedence. The participants struggled regarding whose voice to listen to: their voice or the voice of the community. What became clear was that the ideas and the culture of the local community were taken into careful consideration when the participants implemented programs even when an attempt was made to tie in some American ideas.

Participants also expanded on their roles as American SDP interns. I found that interns who went above and beyond the duties of their internship role, whether trying to promote organizational goals across different communities or building social relationships, were unknowingly establishing power relationships. They also created and reproduced their own ideologies through the spread of their programs. SDP interns going into other communities and implementing programs gives them the power to potentially create meanings and ideologies that impose on local communities. The participants sharing their experiences on the sort of things they did outside their internship shows what being an SDP intern really entails, and it is not just simply implementing a sports program addressing HIV/AIDS or creating an atmosphere for youth development. But, once again, in an instance such as mentoring local coaches, SDP interns establish a 
relationship dynamic that is based on them having a knowledge for which local coaches are yearning.

The capacity to understand that the internship work is about helping the community and providing a platform for the community to eventually become selfsustaining in program implementation is another aspect of this study that SDP organizations can consider in their organizational structure. By SDP organizations selecting potential interns who truly want to help others, programs can possibly be more effective. An example of this is Ryan seeing one of his fellow interns who wanted to teach English, but teaching English was not the purpose of what they were trying to accomplish. An intern's role in the community is temporary. The longest time one of the participants interned in their host country was 14 months. With this in mind, interns have to understand that eventually they will return home leaving the community behind. It is the responsibility of SDP interns to do right by the community and implement programs that are beneficial for the community and to involve the community in every way possible, so, when all is said and done, members of the local community can run SDP programs when foreign interns leave.

Unless SDP interns are aware of the influential power they have on local communities through their programs, they will not fully understand the effect that SDP has. Therefore, it may be appropriate for American SDP organizations to train their interns about being thoughtful regarding what programs they implement and how they implement those programs. Teaching SDP interns to be reflective about their biases and 
culturally-ingrained ideas can allow for better conversation between all actors in the SDP context.

\section{Conclusions}

SDP is a field of international development that is gaining much momentum. It is recognized by national governments and international NGOs. There are many people that recognize the field as a worthy cause. Every year SDP NGOs send a group of young interns abroad to volunteer their services for a certain period of time. SDP interns help implement programs that aim to address pressing international humanitarian issues. The purpose behind the research of this thesis was to examine the experiences of American SDP interns' program experiences. An attempt was made to see if any American ideologies or dominance were conveyed by the participants. A total of 11 former American SDP interns participated in this research. Interviews with the former American SDP interns provided this thesis with four major themes. The four themes that emerged from the interviews were: cultural expectations, reflexive privilege, expanding the American SDP internship role, and doing something greater. The participants' experiences in relation to each of the derived themes gave a rich description about the SDP internship experience.

The interviews provided deep insight into the American SDP internship experience. The participants were very open about their SDP internship experience, even if some were negative in certain aspects. The hope is that findings from this thesis will help American SDP organizations better prepare the interns they send abroad before they leave, and also to better understand the mindset of interns while they are in the field. The 
end result of better-prepared and more culturally-competent interns will hopefully lead to having exceptional people in the field that can provide adequate education and programming to populations who need assistance.

In conclusion, this thesis brought forth discussion on the experiences of American SDP interns' program experiences. The American SDP interns who acted as participants of this thesis provided the themes of cultural expectations, reflexive privilege, expanding the American SDP internship role, and doing something greater. The themes are only relevant to this thesis, but give insight to the American SDP internship experience. SDP is seen as a special player in the field of international development. Many see the use of sport as a vehicle to address critical issues such as the MDGs. By studying not only the experiences of American SDP interns', but also all SDP interns in general, researchers can better understand the impact SDP has in addressing international humanitarian issues. In future research, SDP interns from different populations should be focused on and other methodologies should be applied. These suggestions will provide a broader range of interns and gain a more in-depth examination of the internship experience. In order to improve the field of SDP, it will be important to continue scholarly research with those who serve in an organizational manner. 


\section{References}

Arnold, J. P. (2001). Sport, moral development and the role of the teacher: Implications for research and moral education. Quest, 53, 135-150.

Bates, T. R. (1975). Gramsci and the theory of hegemony. Journal of the History of Ideas, 36, 351-366.

Beutler, I. (2008). Sport serving development and peace: Achieving the goals of the United Nations through sport. Sport in Society, 11, 359-369.

Berg, B. L. (2004). A dramaturgical look at interviewing. In B. L. Berg, Qualitative research methods for the social sciences (pp. 75-122). Boston: Pearson Education.

Black, R. D. (2010). The ambiguities of development: Implications for 'development through sport'. Sport in Society, 13, 121-129.

Browne, L. D \& Moore H. M. (2001). Accountability, strategy, and international nongovernmental organizations. Nonprofit and Voluntary Sector Quarterly, 30, 569-587.

Burnett, C. (2009). Sport for development approaches in the South African context: A case study analysis. South African Journal for Research in Sport, Physical Education and Recreation, 32, 29-42.

Clarke, G. (1998). Non-governmental organizations (NGOs) and politics in the developing world. Political Studies (1998), 36, 36-52.

Coalter, F. (2010). The politics of sport-for-development: Limited focus programmes and broad gauge problems? International Review for the Sociology of Sport, 45, 295314

Cote, J., Salmela, H.J., Baria, A., \& Russell J.S. (1993). Organizing and interpreting unstructured qualitative data. The Sport Psychologist, 7, 127-137.

Creswell, J. (2007). Philosophical, Paradigm, and Interpretive Frameworks. In J. C. Creswell, Qualitative Inquiry \& Research Design ( $2^{\text {nd }}$ Ed.) (pp. 15-34). Thousand Oaks: Sage.

Dale, G. A. (2000). Distractions and coping strategies of elite decathletes during their most memorable performances. The Sport Psychologist, 14, 17-41. 
Darnell, C. S. (2007). Playing with Race: Right to play and the production of whiteness in 'Development through sport'. Sport in Society, 10, 560-579.Thousand Oaks, CA. SAGE.

Darnell, C. S. (2010a). Sport, race, and bio-politics: Encounter with difference in "Sport for Development and Peace" internships. Journal of Sport and Social Issues, 34, 396-417.

Darnell, C. S. (2010b). Power, politics, and "Sport for development and peace": Investigating the Utility of Sport for International Development. Sociology of Sport Journal, 27, 54-75.

Darnell, C. S. (2011). Identity and learning in international volunteerism: 'Sport for development and peace' internships. Development in Practice, 21, 974-986.

Darnell, C. S. (2012a). Global citizenship and the ethical challenges of 'sport for development and peace'. Journal of Global Citizenship and Equity Education, 2, $2-17$.

Darnell, C. S. (2012b). Sport for Development and Peace: A Critical Sociology (1 $1^{\text {st }}$ ed.). Bloomsbury Academics.

Darnell, C. S. \& Black, R.D. (2011). Mainstreaming sport into international development studies. Third World Quarterly, 32, 367-378.

Darnell, C. S. \& Hayhurst M. C. L. (2011). Sport for decolonization: Exploring a new praxis of sport for development. Progress in Development Studies, 3, 183-196.

Darnell, C. S. \& Hayhurst, L. (2012). Hegemony, postcolonialism and sport-fordevelopment: a response to Lindsey and Grattan. International Journal of Sport Policy and Politics, 4, 111-124.

Donnelly, J. (2007). Development ethics and moral engagement: Some political and ethical dilemmas in development research. Studies in Qualitative Methodology, 8, 107-129.

Donnelly, P. (1996). The local and the global: Globalization in the sociology of sport. Journal of Sport and Social Issues, 20, 239-257.

Donnelly, P. (2008). Sport and human rights. Sport in Society. 11, 381-394.

Eichberg, H., \& Levinsen, A. (2009). Inter-ethnic football in the Balkans: Reconciliation and diversity. Sport, Ethics, and Philosophy, 3, 346-359. 
Fowler, A. (1991). The role of NGOs in changing state-society relations: Perspectives from eastern and southern Africa. Development Policy Review, 9, 53-84.

Frangonikolopoulos, A.C. (2005). Non-governmental organizations and humanitarian action: The need for a viable change praxis and ethos. Global Society, 19, 49-72.

Fusco, C. (2005). Cultural landscapes of purification: Sports spaces and discourses of whiteness. Sociology of Sport Journal, 22, 283-310.

Galily, Y. \& Sheard, K. (2002). Cultural imperialism and sport: The Americanization of Israeli basketball. Culture, Sport, Society, 5, 55-78.

Giulianotti, R. (2004). Human rights, globalization and sentimental education: The case of sport. Sport in Society, 7, 355-369.

Giulianotti, R. (2011a). Sport, peacemaking, and conflict resolution: A contextual analysis and modeling of the sport, development, and peace sector. Ethnic and Racial Studies, 34, 207-228.

Giulianotti, R. (2011b) Sport, transnational peacemaking, and global civil society: Exploring the reflective discourses of "sport for development and peace" project officials. Journal of Sport and Social Issues, 35, 50-71.

Giulianotti, R. \& Robertson, R. (2007). Recovering from the social: Globalization, football and transnationalism. Global Networks, 7, 144-186.

Gratton, C. \& Jones, I. (2004). Analyzing data II: Qualitative data analysis. In C. Gratton \& I. Jones, Research methods for sport studies (pp 217-227). New York: Routledge.

Hartman, D. \& Kwauk, C. (2011). Sport and development: An overview, critique, and reconstruction. Journal of Sport and Social Issues, 3, 284-305.

Harvey, J., Rail, G., \& Thibault L. (1996). Globalization and sport: Sketching a theoretical model of empirical analyses. Journal of Sport and Social Issues, 20, 258-277.

Hayhurst, MC. L (2009). The power to shape policy: charting sport for development and peace policy discourses. International Journal of Sport Policy, 1, 203-227.

Hayhurst, MC. L. \& Frisby, W. (2010). Inevitable tensions: Swiss and Canadian sport for development NGO perspectives with high performance sport. European Sport Management Quarterly, 10, 75-96. 
Hayhurst, MC. L., Wilson, B., \& Frisby, W. (2010). Navigating neoliberal networks: Transnational internet platform in sport for development and peace. International Review for the Sociology of Sport, 46, 315-329.

Hilhorst, D. (2002), Being good at doing good? Quality and accountability of humanitarian NGOS, Disasters, 26, 193-212.

Houlihan, B. (1994). Homogenization, Americanization, and creolization of sport: Varieties of globalization. Sociology of Sport Journal, 11, 356-375.

Humble, D. \& Smith, M. (2007). What counts as development research? In S. Hillyard (Series 8) M. Smith (Vol. 8), Negotiating boundaries and borders: Qualitative methodology and development research ( $1^{\text {st }} \mathrm{Ed}$.) (pp. 13-34). Oxford; Amsterdam; San Diego, CA: Emerald.

The International Platform for Sport for Development. Retrieved January $4^{\text {th }}, 2013$ from http://www.sportanddev.org

Jackson, J. S. \& Haigh, S. (2008). Between and beyond the politics: Sport and foreign policy in a globalizing world. Sport in Society, 11, 349-358.

Jarvie, G. (2011). Sport, development and aid: Can sport make a difference? Sport in Society, 14, 241-252.

Kay, T. (2009). Developing through sport: evidencing sport impacts on young people. Sport in Society, 12, 1177-1191.

Kidd, B. (1991). How do we find our own voices in the "new world order"? A commentary on Americanization. Sociology of Sport Journal, 8, 178-184.

Kidd, B. (2008). A new social movement: Sport for development and peace. Sport in Society, 11, 370-380.

Klein, M. A. (1991). Sport and culture as contested terrain: Americanization in the Caribbean. Sociology of Sport Journal, 8, 79-85.

Kroes, R. (1999). American empire and cultural imperialism: A view from the receiving end. Diplomatic History, 23, 463-478.

Leahy, T. (2010). Sexual abuse in sport: Implication for the sport psychology profession. In Ryba, V.T., Schinke J.R., \& Tenenbaum G. (Eds.), The cultural turn in sport psychology. (pp. 315-334). Morgantown, WV: Fitness Information Technology. 
Levermore, R. (2008a). Sport in international development: Time to treat it seriously? Brown Journal of World Affairs, 14, 55-66.

Levermore, R. (2008b). Sport: A new engine of development? Progress in Development Studies, 8, 183-190.

Levermore, R. (2011). Evaluating sport-for-development: approaches and critical issues. Progress in Development Studies, 11, 339-353.

Levermore, R. \& Beacom, A. (2012). Reassessing sport-for-development: moving beyond 'mapping the territory. International Journal of Sport Policy and Politics, $4,125-127$.

Lewis, D. (1998). Development NGOs and the challenge of partnership: Changing relations between the north and south. Social Policy \& Administration, 32, 501-512.

Lewis, D. \& Sobhan, B. (1999). Routes of funding, roots of trust? Northern NGOs, Southern NGOs donors, and the rise of direct funding. Development in Practice, 9, 117-129.

Lincoln, Y.S. \& Guba, E.G. (1985). Naturalistic Inquiry. Newbury Park, CA: Sage Publications.

Lyras, A. \& Hums, A.M. (2009). Sport and social change: The case for gender equality. Journal of Physical Education, Recreation \& Dance, 80, 7-9.

Maguire, J. (1994). Sport, identity politics, and globalization: Diminishing contrasts and increasing varieties. Sociology of Sport Journal, 11, 398-427.

Maro, N. C., Roberts, C. G., \& Sorensen, M. (2009). Using sport to promote HIV/AIDS education for at-risk youths: An intervention using peer coaches in football. Scandinavian Journal of Medicine and Science in Sports, 19, 129-141.

Manji, F. \& O'Coill, C. (2002). The missionary position: NGOs and development in Africa. International Affairs, 78, 567-583.

Martens, K. (2002). Mission impossible? Defining Nongovernmental organizations. International Journal of Voluntary and Nonprofit Organizations, 12, 271-285.

Maxwell, J. A. (2005). Validity: How might you be wrong? In J. A. Maxwell, Designing Qualitative research: An interactive approach ( $2^{\text {nd }}$ Ed.) (pp. 105-116). Thousand Oaks: Sage. 
Mchombo, S., (2006). Sports and Development in Malawi. Soccer in Society 7, 318-338.

Meier, M. \& Saveedra, M. (2009). Esther Piri and the moutawakel effect in Zambia: An analysis of the use of female role-models in sport-for-development. Sport in Society, 12, 1158-1176.

Mellor, M. (2007). Researching for change. In S. Hillyard (Series 8) \& M. Smith (Vol. 8), Negotiating boundaries and borders: Qualitative methodology and development research ( $1^{\text {st }}$ Ed.) (pp. 177-195). Oxford; Amsterdam; San Diego, CA: Emerald.

Mohan, G. (2002). The disappointments of civil society: The politics of NGO intervention in northern Ghana. Political Geography, 21, 125-154.

Nicholls, S., Giles, R.A., \& Sethna, C. (2010). Perpetuating the 'lack of evidence' discourse in sport for development: Privileged voices, unheard stories and subjugated knowledge. International Review for the Sociology of Sport, 46, 249-264.

Nixon, L. H. (2008). Sport in a changing world. ( $1^{\text {st }}$ Ed.) Boulder, CO. Paradigm Publishers.

Obiyan, S. A. (2005). A critical examination of the state versus non-governmental organizations (NGOs) in the policy sphere in the global south: Will the state die as the NGOs thrive in sub-Saharan Africa and Asia? African and Asian Studies, 4, 301-325.

Okolie, C. A. (2002). Development hegemony and the development crisis in Africa: The importance of the indigenous knowledges and the practices in the making of food policy. Journal of African American History, 4, 256-275.

Koss, J. \& Alexandrova, A. (2005). HIV/AIDS prevention and peace through sport. Lancet, 366, 3-4.

Osswewaarde, R., Nijhof, A., \& Heyse, L. (2008). Dynamics of ngo legitimacy: How organizing betrays core missions of INGOs. Public Administration Development, $28,42-53$.

Pease, S. K. (2012). International Organizations ( $5^{\text {th }}$ Ed.). Boston, MA. Pearson Education.

Peacock-Villada, P., DeCelles, J., \& Banda, S.P. (2007). Grassroot soccer resiliency pilot program: Building resiliency through sport-based education in Zambia and South Africa. New Directions for Youth Development, 116, 141-154. 
Petras, J. (1997). Imperialism and NGOs in Latin America, Monthly Review, 49, 10-27.

Rookwood, J. (2008). Soccer for peace and social development. Peace Review: A Journal of Social Justice, 20, 471-479.

Sage, H. G. (1990). Power and Ideology in American Sport ( $1^{\text {st }}$ Ed.). Human Kinetics.

Spaaij, R. (2009). The social impact of sport: Diversities, complexities, and contexts. Sport in Society, 12, 1103-1117.

Sugden, J. (2006). Teaching and playing sport for conflict resolution and co-existence in Israel. International Review for the Sociology of Sport, 41, 221-240.

Sugden, J. (2008). Community and the instrumental use of football. Anyone for football for peace? The challenges of using sport in the service of co-existence in Israel. Soccer in Society, 9, 405-115.

Tedlock, B. (2000). Ethnography and ethnographic representation. In Denzin, N.K. \&

Thibault, L. (2009). Globalization of sport: An inconvenient truth. Journal of Sport Management, 23, 1-20.

Tilley, Q. V. (2002). New Help or new hegemony? The transnational indigenous people's movement and being Indian' in El Salvador, Journal of Latin American Studies, $34,525-554$.

Tuohey, B. \& Cognato, B. (2011). Peaceplayers international: A case study on the use of sport as a tool for conflict transformation. SAIS Review, 31, 51-63.

UNICEF - Sport for Development - Overview. Retrieved December 1 ${ }^{\text {st }}, 202$ from http://www.unicef.org/sports/index_23624.html

United Nations Millennium Development Goals. Retrieved December 1 ${ }^{\text {st }}, 2012$ from http://www.un.org/wcm/content/site/sport/home/sport/sportandmdgs

Warleigh, A. (2001). 'Europeanizing' civil society: NGOs as agents of political socialization. Journal of Common Market Studies, 39, 619-639.

Willets, P. (2006). What is a non-governmental organization? City University London.

Wilson, B. \& Hayhurst, L. (2009). Digital activism: Neoliberalism, the internet, and sport for youth development. Sociology of Sport Journal, 26, 155-181. 
Wolf, E. \& Hums, M. (2006). Sport and human rights. Chronicle of Kinesiology \& Physical Education in Higher Education, 17, 3-4.

Wolff, A. (2011, September 26). Sport saves the world. Sports Illustrated. Retrieved from http://sportsillustrated.cnn.com/vault/article/magazine/MAG1190627/1/index.htm

Wright, G. (2012). NGOs and western hegemony: causes for concern and ideas for change. Development in Practice, 22, 124-134. 


\section{APPENDIX A - PERSONAL EPISTEMOLOGY}

Having been born to immigrant parents that fled a war-torn country filled with violence and poverty, I know that my life could have been completely different.

Realizing that we still live in a world where others have to deal with struggles like HIV/AIDS, poverty, and gender inequality made me think about what I can do to make a difference. Being a part of academia has afforded me the avenues to make this happen. This thesis came about as a result my interests in international relations, social issues, and sport. Combining these three aspects I stumbled upon the work of Sport for Development and Peace (SDP). After hours of online searching for personal interest, I found many organizations believed in the concept of using sport to make this world a better place. Sport for Development and Peace shows that sport is more than just a physical activity; instead, sport has an aura of faith, meaning, and hope. The fact that a simple game of soccer holds the ability to educate a child how to be safe with HIV/AIDS (i.e., Right to Play) or that a violent sport like boxing can teach conflict resolution in dangerous environments (i.e., Fight 4 Peace) is amazing because, in essence, sport is so simple. I became curious about SDP interns' experiences, as they relate to power relationships after reading previous research on the topic, and came to the conclusion that interns must be educated about being aware of their ideologies and mindset when working in SDP because this awareness will benefit everyone involved in the SDP process. At the end of the day I hope to be a person who can contribute to this world in any way that I can. That is the rationale for embarking upon this research adventure: to promote critical discussion in order to improve the practices and outcomes of SDP. 


\section{APPENDIX B - SAN JOSÉ STATE UNIVERSITY IRB APPROVAL}

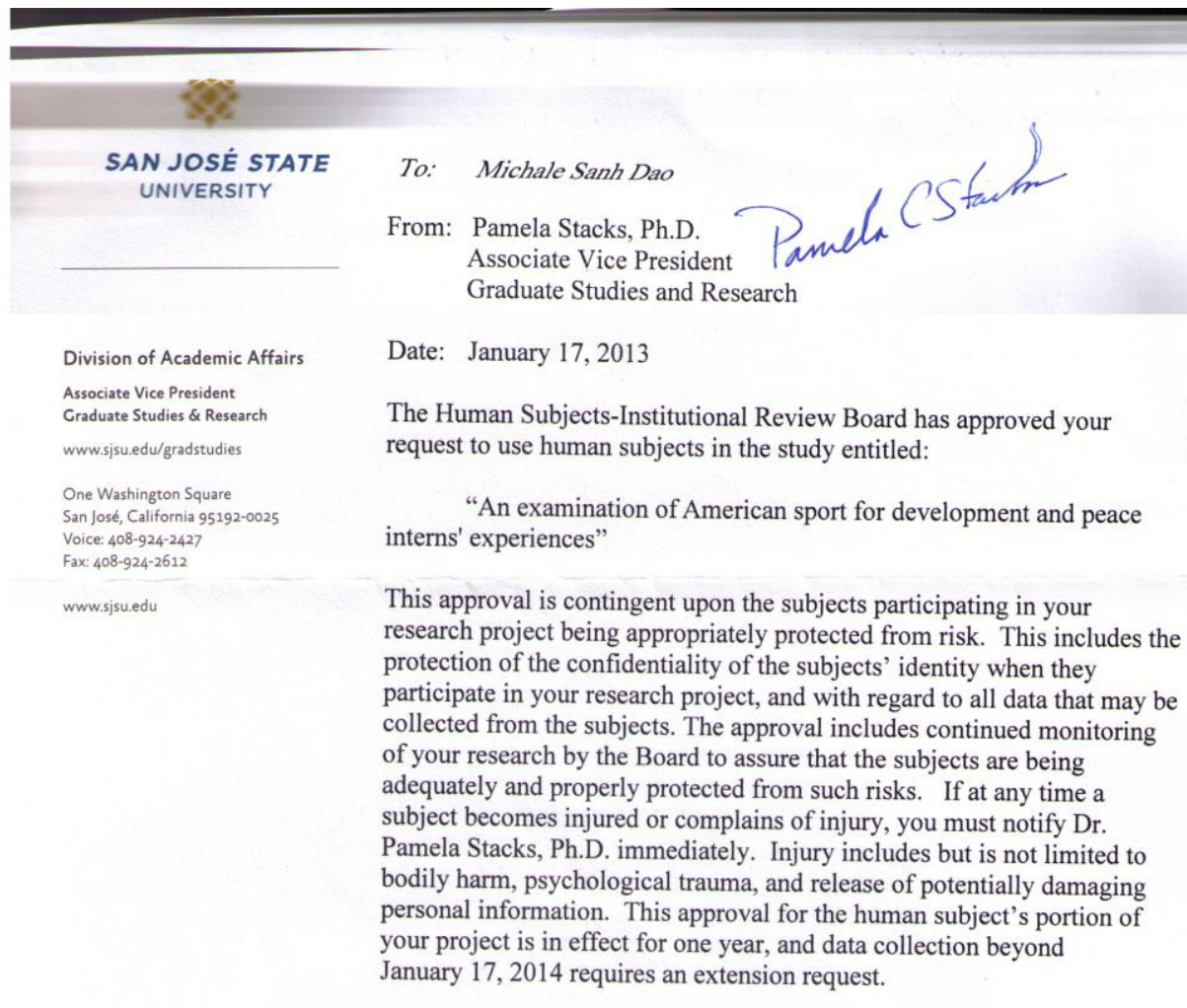

Please also be advised that all subjects need to be fully informed and aware that their participation in your research project is voluntary, and that he or she may withdraw from the project at any time. Further, a subject's participation, refusal to participate, or withdrawal will not affect any services that the subject is receiving or will receive at the institution in which the research is being conducted.

If you have any questions, please contact me at (408) 924-2427.

Protocol \# S1204139

cc. Jessica Chin

0054

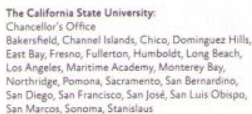




\section{APPENDIX C - RECRUITMENT LETTER}

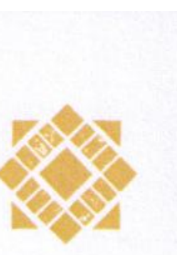

San José State

UNIVERSITY

College of Applied

Department of Kinesiology

One Washington Square

San Jose, CA 95192-0054

Voice: 408-924-3010
The California State University Chancellor's Office Domingere

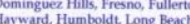
os Angeles, Maritime Academy. Montrerey bay, Northridge. Pomona San Francisco, San Jose, San Luis Obispo San Marcos, Sonoma, Stanisto

(insert date here)

Dear (insert name of participant),

My name is Michael Dao and I am currently a Master's student at San Jose State University. I am writing this letter to ask for your assistance with the research based thesis I am currently working on in order to complete my Master's degree. The proposed focus of my thesis is to examine the experiences of American Sport for Development and Peace interns.

The thought of this thesis originated due to my particular interest in the field of Sport for Development and Peace. Throughout the last couple of years I have been fixated on the impact sport has in addressing international humanitarian issues. From academic and popular literature I am enthusiastic about the endless possibilities that sport creates in helping others around the world. After reading much scholarly work on Sport for Development and Peace I found that even though the concept of using sport to address humanitarian issues is greatly commended, there are still some doubts in the overall implementation of Sport for Development and Peace programs. A doubt of concern is the personal experiences of interns as it relates to personal attitudes, beliefs and knowledge. Therefore, the primary purpose of this thesis is to theoretically explore the experiences of interns who have directly worked in the field. The hope is to use the findings to better prepare future Sport for Development and Peace interns.

The assistance I am asking you for is to allow me to interview you about your internship experience. The research for this thesis will be conducted using semi-structured interviews. Based on time and location, interviews will be done in person, over the phone or via Skype. Duration of each interview will be under the discretion of each participant; although, the hope is that all interviews last roughly one hour, so that substantial and in depth information can be retrieved. Questions for the interviews will be predetermined and will focus exclusively on aspects of the Sport for Development and Peace internship experience. Your participation is important in examining the experience of American Sport for Development and Peace interns.

Human Subjects approval from the University's Institutional Review Board (IRB) has already been approved for this study. The approval of this study by the IRB is important because it will ensure the anonymity of all participants and protect them from any harm. I will not use any real names nor will I use the real names of the Sport for Development and Peace organizations. All names will be changed or be given a generic identifier. No information will be used that could potentially lead back to any participant or organization.

Following the written completion of the thesis, I will be happy to provide each participant and the respected organization that each worked for a copy of the thesis. I believe that Sport for Development and Peace is a great endeavor in making this world better and safer. This thesis will provide feedback on how to improve the field as a whole. It is my hope that this thesis will help Sport for Development and Peace organizations provide a better understanding of the internship process. I am asking for your help in making this happen. Together we can make Sport for Development and Peace even that much better.

Please confirm your willingness to participate in this research by emailing me at michael.s.dao@gmail.com. If you have any questions please feel free to ask and I will happily answer them the best I can. I look forward to hearing back from you soon. Thank you for your time and your help with my thesis.

Sincerely,

Michael S. Dao

M.A. Candidate

Department of Kinesiolgy,

San Jose State University 


\section{APPENDIX D- CONSENT FORM}

\section{Agreement to Participate in Research}

Responsible Researcher: Michael S. Dao, Department of Kinesiology, San Jose State University

Title of Protocol: An examination of American sport for development and peace interns' experiences.

San José State

UNIVERSITY

College of Applied
Sciences and Arts

Department of Kinesiology

One Washington Square Voice: $408-924-3010$
Fax: $408-924-3053$
1. You have been asked to take part in a research orientated thesis investigating Sport for Development and Peace program experiences of American interns.

2. This research thesis is being supported by the Office of Graduate Studies and Research, and by the Department of Kinesiology at San Jose State University. A primary goal of this thesis is to better understand the ideologies and experiences of American Sport for Development and Peace interns during their tenure in the field.

3. You will be asked to participate in an interview lasting approximately 60 minutes. The interview will be audio taped and arranged at your convenience.

4. There are no anticipated risks associated with participation in this study.

5. While there are no expected benefits associated by participating in this study, it is hoped that you will gain a better understanding of your thoughts and experiences regarding your time working in the field of a Sport for Development and Peace organization.

6. Although the results of this study may be published, no information that could identify you or the organization you interned for will be included. Human Subjects approval from San Jose State University's Institutional Review Board (IRB) has already been approved for this study. An important part of the approval is to ensure the protection and the anonymity of all participants. No real names will be used in the study. All names including those of participants and names of Sport for Development and Peace organizations will be changed in order to maintain confidentiality of interns and organizations. No information will be used or published that could potentially lead back to interns and organizations. You will only be referred to by a code name.

7. There will be no compensation for participation in this study.

8. Questions about the thesis may be addressed to the graduate student and secondary researcher, Michael S. Dao at michael.s.dao@gmail.com. Complaints about the thesis may be presented to Shirley Reekie, Ph.D, Chair of the Kinesiology Department at San Jose State University, at shirley.reekie@sjsu.edu. Questions about research subjects' rights or research-related injury may be presented to Pamela Stacks, Ph.D, Associate Vice President of Graduate Studies and Research, at Pamela.stacks@sjsu.edu.

9. No service of any kind, to which you are otherwise entitled, will be lost or jeopardized if you choose not to participate in the study.

10. Your consent is being given voluntarily. You may refuse to participate in the entire study or in any part of the study. You have the right to not answer a question you do not feel comfortable answering. If you decide to participate in the study, you are free to withdraw at anytime without any consequence or negative effect on your relations with the thesis or San Jose State University.

11. After you receive and sign two consent forms, you will receive one for your records signed and dated by the researcher, and the other to return to the researcher.

Participant's Initial

Researcher's Initia 


\section{APPENDIX E - SEMI-STRUCTURED INTERVIEW GUIDE}

1. How did you become interested in working for a sport for development and peace organization?

2. What are the primary causes supported by the organization you work for?

3. Can you tell me a little about your position?

a. How long did you work for the organization?

b. How long has it been since you've left your internship?

c. What does your job description entail?

4. How would you describe your experience working for (name of organization)?

- What duties were you assigned during your placement?

- What kind of program did you implement?

5. What knowledge or ideas did you have about (name of country) before you went on your internship?

- How did any of those ideas change during your stay?

- How did they change when you got back home to the US?

6. What impact do you feel SDPs interns make for the host country?

7. How do you feel about your experience as an SDP intern?

a. What preparations did you make prior to leaving for (country)?

b. What would you have done differently if you could do it over again?

8. Were there any surprising experiences as you worked to implement the SDP program?

9. What were some positive experiences you had working as an SDP intern?

10. Could you describe a time that was challenging for you as an SDP intern?

11. What advice would you give to anyone who is thinking about interning for an SDP organization?

12. Finally, is there anything else you'd like to talk about from your intern experience that you feel was important to you? 